UNIVERSIDADE DE SÃO PAULO

ESCOLA DE ENGENHARIA DE LORENA

DAVISON RAMOS DE ALMEIDA JUNIOR

CRESCIMENTO ANORMAL DE GRÃO EM FIOS FINOS DE FERRO

COMERCIALMENTE PURO

LORENA - SP

2019 

DAVISON RAMOS DE ALMEIDA JUNIOR

\section{CRESCIMENTO ANORMAL DE GRÃO EM FIOS FINOS DE FERRO COMERCIALMENTE PURO}

Tese apresentada à Escola de Engenharia de Lorena da Universidade de São Paulo para a obtenção do título de Doutor em Ciências do Programa de Pós-Graduação em Engenharia de Materiais na área de Materiais Convencionais e Avançados

Orientador: Prof. Dr. Hugo Ricardo Zschommler Sandim

Versão original

LORENA - SP

2019 
AUTORIZO A REPRODUÇÃO E DIVULGAÇÃO TOTAL OU PARCIAL DESTE TRABALHO, POR QUALQUER MEIO CONVENCIONAL OU ELETRÔNICO, PARA FINS DE ESTUDO E PESQUISA, DESDE QUE CITADA A FONTE

Ficha catalográfica elaborada pelo Sistema Automatizado da Escola de Engenharia de Lorena, com os dados fornecidos pelo(a) autor(a)

Almeida Junior, Davison Ramos de

Crescimento anormal de grão em fios finos de

ferro comercialmente puro / Davison Ramos de Almeida

Junior; orientador Hugo Ricardo Zschommler Sandim -

Versão Original. - Lorena, 2019.

$105 \mathrm{p}$.

Tese (Doutorado em Ciências - Programa de Pós Graduação em Engenharia de Materiais na Área de Materiais Convencionais e Avançados) - Escola de Engenharia de Lorena da Universidade de São Paulo. 2019

1. Crescimento anormal de grão. 2. Ebsd. 3. Ferro de pureza comercial. 4. Fios. 5. Trefilação a frio. I. Título. II. Sandim, Hugo Ricardo Zschommler, orient. 
Aos meus sobrinhos,

Luiz Antônio Ramos Teruel

e

Ana Beatriz Ramos Sarante 



\section{AGRADECIMENTOS}

Agradeço primeiramente e, sobretudo, à minha família. Aos meus pais pelo exemplo e amor, que sobrepõe as distâncias e dificuldades impostas pela vida. Às minhas irmãs que sempre estiveram ao meu lado.

Agradeço ao Prof. Dr. Hugo Ricardo Zschommler Sandim por seu suporte e orientação durante o desenvolvimento deste trabalho. Agradeço a paciência e dedicação presentes desde o início de nosso trabalho em conjunto.

Agradeço ao Prof. Dr. Angelo Fernando Padilha pela gentileza em ceder o material utilizado neste trabalho.

Agradeço ao Prof. Dr. Paulo Rangel Rios pelas ricas discussões e raciocínios tão criativos que resultaram em algumas publicações.

Ao Prof. Dr. Hélcio Izário Filho (DEQUI-EEL-USP) pelas análises químicas via ICP em nossas amostras.

Agradeço à CNPq pela concessão de bolsa durante um período de doutorado e à CAPES pela bolsa concedida no Programa Doutorado Sanduíche no Exterior (PDSE), no qual pude desenvolver parte da minha pesquisa no renomado Max-Planck Institut für Eisenforschung (MPIE), em Düsseldorf, Alemanha.

Agradeço à Monika Nellessen e Katja Angenendt pela paciência, hospitalidade e dedicação despendida durante meu estágio no MPIE. Agradeço ao Dr. Aleksander Kostka pela ajuda nas análises de microscopia de transmissão e pelos conselhos. Agradeço ao Dr. Alisson Kwiatkowski da Silva pela ajuda na preparação das amostras e análises de tomografia de sonda atômica. Também agradeço ao Prof. Dr.-Ing. Dierk Raabe por sua cordialidade e pela atenção prestada durante meu estágio no MPIE.

Agradeço também aos amigos que estiveram presentes no período de composição deste trabalho, assim como os presentes em outras etapas da minha vida. 



\title{
RESUMO
}

\author{
ALMEIDA JUNIOR, D.R. Crescimento anormal de grão em fios finos de ferro \\ comercialmente puro. 105 p. Tese (Doutorado em Ciências) - Escola de \\ Engenharia de Lorena, Universidade de São Paulo, Lorena, 2019.
}

O crescimento anormal de grão em fio de metais com estrutura ccc foi bastante estudado no início do século XX devido ao desenvolvimento da indústria de filamentos para lâmpadas incandescentes. A presente Tese de Doutorado estuda o crescimento anormal de grão num fio de ferro de pureza comercial. A revisão bibliográfica apresenta os aspectos físicos mais relevantes do fenômeno, bem como características para o caso de fios trefilados de metais com estrutura cúbica de corpo centrado. A análise experimental baseia-se nos resultados obtidos por microscopia ótica, eletrônica de varredura, eletrônica de transmissão, difração de elétrons retroespalhados e tomografia de sonda atômica. Os resultados do material na condição "como recebido" mostram a existência de heterogeneidades microestruturais importantes ao longo da direção radial do fio no estado deformado e que explicam as características heterogêneas na recristalização primária e no crescimento de grão. A recristalização primária resulta em heterogeneidades de tamanho de grão. O posterior recozimento em $850^{\circ} \mathrm{C}$ mostra um ligeiro crescimento normal de grão para tempos de recozimento inferiores a $4 \mathrm{~h}$ que ocorre de forma mais intensa na região central do fio. Os grãos anormais das amostras recozidas por mais de $4 \mathrm{~h}$ aparecem no centro e possuem orientação preferencial da fibra $<110>$ // WD (onde WD é a direção de trefilação). A distribuição dos precipitados é heterogênea devido à interação entre amostra e atmosfera, o que garante baixa mobilidade para os contornos próximos à superfície livre mesmo após prolongado recozimento. Os resultados mostram que a ocorrência de crescimento normal é um fator necessário para o surgimento de grãos anormais. Esta interpretação possui fundamentos topológicos e apresenta maior aderência aos resultados experimentais do que outros modelos teóricos reportados na literatura.

Palavras chave: Crescimento anormal de grão. EBSD. Ferro de pureza comercial. Fios. Trefilação a frio. 



\title{
ABSTRACT
}

\begin{abstract}
ALMEIDA JUNIOR, D.R. Abnormal grain growth in thin wires of commercially-pure iron. $105 \mathrm{p}$. Thesis (Doctor of Science) - Escola de Engenharia de Lorena, Universidade de São Paulo, Lorena, 2019.
\end{abstract}

Abnormal grain growth in wires of bcc metals has been studied extensively since the beginning of the $X X^{\text {th }}$ Century due to the development of tungsten filaments for bulb lamps. The present thesis aims to study the abnormal grain growth in commercially-pure iron wires. The revision of literature presents the physical aspects most relevant for the phenomenon, as well as the main features occurring in wires of bcc metals during their annealing. The experimental analysis was performed by using light optical microscopy, scanning and transmission electron microscopy, electron backscatter diffraction and atom probe tomography. The results of the sample in the as-received condition show the occurrence of inhomogeneities of the deformation microstructure along the radial direction, which explains the inhomogeneous features noticed in primary recrystallization as well as in grain growth. The recrystallized samples show an inhomogeneous grain size distribution along the radial direction. Isothermal annealing at $850^{\circ} \mathrm{C}$ shows the occurrence of moderate normal grain growth up to $4 \mathrm{~h}$. For longer times, abnormal grain growth is noticed. Normal grain growth is more effective at the center. Abnormal grains appear at the center and present preferential orientation $<110>/ / W D$, where WD is the wiredrawing direction. The particle size distribution is heterogeneously distributed along the radial direction and it is strongly dependent on the interaction between the wire and the annealing atmosphere. This feature is effective to hinder the boundary movement close to the surface. Prior normal grain growth is a key factor to trigger abnormal grain growth. This interpretation is based on topological features and presents better adherence to experimental results when compared with other theoretical models reported in the literature.

Keywords: Abnormal Grain Growth. EBSD. Commercially-pure iron. Wires. Colddrawing. 



\section{LISTA DE FIGURAS}

Figura 1 - Distribuição esquemática dos dez tipos de pontos triplos. Eles são distribuídos no gráfico considerando suas energias integrais e suas anisotropias energéticas. Os pontos triplos mais relacionados aos modelos de crescimento anormal são apresentados.

Figura 2 - Imagens de microscopia ótica da seção longitudinal de um fio na condição "como recebido".

Figura 3 - Imagem de microscopia ótica da seção transversal de um fio na condição "como recebido" mostrando o encaracolamento das lamelas deformadas. 43

Figura 4 - Valores médios de microdureza Vickers na condição "como recebido". Os dados foram agrupados em relação à distância do eixo central, onde 0 é o centro.

Figura 5 - Mapa de orientações da seção longitudinal do fio na condição "como recebido". A imagem é colorida seguindo a escala da figura de polo inversa com relação a WD. 44

Figura 6 - Distribuição de volume das principais fibras de textura em relação a posição radial para o fio na condição "como recebido". 44

Figura 7 - Desorientação média de núcleos ao longo da direção radial, medido na amostra na condição "como recebido". Foram considerados núcleos dos primeiros até os sétimos vizinhos.

Figura 8 - Mapa da KAM do fio na condição "como recebido" mostrando a região próxima à superfície até o centro.

Figura 9 - Distribuição do gradiente de orientação em uma região próxima à superfície e no centro, para a amostra na condição "como recebido". Método de Ørsund et al. (131).

Figura 10 - Desorientação média de núcleos (KAM) em função da distância. Os valores da linearização para os pontos da superfície e do centro acompanham o gráfico. A inclinação da curva representa o gradiente de orientação. Método de Kamaya (132). 48

Figura 11 - Mapa de gradiente de orientação do fio na condição "como recebido" mostrando as diferenças de gradientes encontrados entre a superfície e o centro. 
Figura 12 - Imagens de microscopia ótica das amostras recozidas em $550^{\circ} \mathrm{C}$ por (a) 5; (b) 15 e (c) 30 min.

Figura 13 - Mapa de orientações do fio recozido em $650^{\circ} \mathrm{C}$ por $10 \mathrm{~min}$. Escala da figura de polo inversa em relação a WD 52

Figura 14 - Área média dos grãos ao longo da direção radial para o fio recozido em $650^{\circ} \mathrm{C}$ por $10 \mathrm{~min}$. 53

Figura 15 - Volume das principais fibras ao longo da direção radial. Fio recozido em $650^{\circ} \mathrm{C}$ por $10 \mathrm{~min}$. 53

Figura 16 - Mapas da amostra recozida em $650^{\circ} \mathrm{C}$ por 10 min mostrando (a) os contornos de alto ângulo em preto e os de baixo ângulo em vermelho e (b) os grãos são coloridos conforme os valores de dispersão intragranular de orientações (GOS). 54

Figura 17 - Perfis de desorientação ponto à origem e ponto a ponto, calculados dentro de um dos grãos que apresenta GOS $>2$. Fio recozido em $650^{\circ} \mathrm{C}$ por $10 \mathrm{~min}$ 54

Figura 18 - Distribuição da desorientação entre as orientações médias dos grãos com GOS $>2^{\circ}$ e a fibra $<110>/ / W D$, medida em um fio recozido em $650^{\circ} \mathrm{C}$ por $10 \mathrm{~min}$ 55

Figura 19 - Frequência de contornos que apresentam relação CSL assumindo o critério de Brandon. Fio recozido em $650^{\circ} \mathrm{C}$ por $10 \mathrm{~min}$. 56

Figura 20 - Mapas de orientação para os fios recozidos em $850^{\circ} \mathrm{C}$ em diferentes tempos mostrando o crescimento normal de grão. A coloração segue a escala da figura de polo inversa em relação a WD. 59

Figura 21 - Área média dos grãos em função da posição radial no fio recozido em $850^{\circ} \mathrm{C}$ por diferentes tempos. As barras de erro são os intervalos de confiança de $95 \%$. 60

Figura 22 - Mapas de orientação do maior grão encontrado na amostra recozida por 4 h. O grão é colorido com relação a direção de trefilação (WD) e da direção radial $(R D)$. As figuras de polo apresentam as orientações discretas dentro do grão. 60

Figura 23 - Distribuições normalizadas para diversas amostras do fio de ferro. Os gráficos apresentam as distribuições dos grãos com orientação pertencente a fibra $<110>$ // WD e também dos grãos com outras orientações. 
Figura 24 - Distribuições de número de vizinhos para diversas amostras do fio de ferro. Os gráficos apresentam as distribuições dos grãos com orientação pertencente a fibra $<110>/ /$ WD e também dos grãos com outras orientações. 62

Figura 25 - Frequência de grãos com (a, c, e) mais de 12 vizinhos e com (b, d, f) tamanho normalizado maior que 1 para grãos ao longo da direção radial. Os dados são das amostras recozidas em $850^{\circ} \mathrm{C}$ por diversos tempos e os gráficos são referentes a $(a, b)$ todos os grãos; $(c, d)$ grãos com orientações pertencentes a fibra $<110>$ // WD e (e, f) grãos com outras orientações.

Figura 26 - Contiguidade dos grãos com orientação pertencente à fibra $<110>/ /$ WD para as amostras recozidas em $850^{\circ} \mathrm{C}$ por diferentes tempos. 64

Figura 27 - Distribuição espacial de pontos triplos ao longo da direção radial para as amostras recozidas em $850^{\circ} \mathrm{C}$ antes do crescimento anormal de grão. 66

Figura 28 - Frequência dos tipos de pontos triplos da amostra recozida em $850^{\circ} \mathrm{C}$ por $3 \mathrm{~min}$ e $4 \mathrm{~h}$. As distribuições são relativas apenas aos grãos encontrados no centro. 66

Figura 29 - Imagens das lamelas retiradas na (a) superfície e no (b) centro da amostra recozida em $850^{\circ} \mathrm{C}$ por $3 \mathrm{~min}$. MET, campo escuro. 67

Figura 30 - Tomografia de força atômica (APT) mostrando duas partículas de AIN encontradas na amostra recozida em $850^{\circ} \mathrm{C}$ por $3 \mathrm{~min}$. A intensidade da cor dos voxels representa a densidade local dos respectivos íons.

Figura 31 - Distribuições de tamanho de partículas, medidas no centro e na superfície. Amostra recozida em $850^{\circ} \mathrm{C}$ por $3 \mathrm{~min}$.

Figura 32 - Seção longitudinal dos fios recozidos em $850^{\circ} \mathrm{C}$ por diversos tempos. O tamanho dos grãos anormais é atemporal. Microscopia ótica..... 70

Figura 33 - Comprimento de contornos por unidade de área $\left(L_{A}\right)$ e volume da fibra $<110>/ / W D$ para a amostra recozida em $850^{\circ} \mathrm{C}$. O primeiro ponto representa a amostra após a recristalização primária............ 71

Figura 34 - Figura de polo invertida mostrando as orientações médias dos 363 grãos anormais verificados nos fios recozidos em $850^{\circ} \mathrm{C}$ para

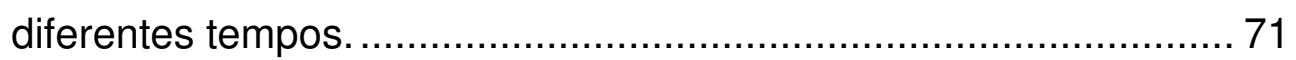


Figura 35 - Desorientação em relação à fibra <110> // WD para (a) os 363 grãos anormais e (b) todos os grãos encontrados no fio recozido em $850^{\circ} \mathrm{C}$ por $4 \mathrm{~h}$. 72

Figura 36 - Distribuição de tamanho de todos os grãos anormais e daqueles que apresentam grãos-ilha. A frequência de grãos anormais com grãosilha é calculada em relação ao total de grãos anormais dentro de cada grupo. 75

Figura 37 - Imagens de STEM das lamelas retiradas da (a) superfície e do (b) centro na amostra recozida em $850^{\circ} \mathrm{C}$ por $72 \mathrm{~h}$. Detecção do campo escuro. 75

Figura 38 - Distribuição de tamanho de partículas medidas no centro e na superfície da amostra recozida em $850^{\circ} \mathrm{C}$ por 3 min e $72 \mathrm{~h}$. As distribuições do menor tempo foram adicionadas para propósitos comparativos. 76

Figura 39 - Imagem de microscopia eletrônica de varredura (FEG-SEM) mostrando uma colônia perlítica na amostra recozida em $850^{\circ} \mathrm{C}$ por $48 \mathrm{~h}$. Detecção de elétrons retroespalhados. 76

Figura 40 - Imagens de microscopia ótica de fios com diferentes diâmetros após recozimento em $850^{\circ} \mathrm{C}$ por $24 \mathrm{~h}$.

Figura 41 - Imagens da seção longitudinal de um fio recozido em $850^{\circ} \mathrm{C}$ por $6 \mathrm{~h}$ em alto vácuo dinâmico. 80

Figura 42 - Imagem de SEM de um fio recozido em $850^{\circ} \mathrm{C}$ por $24 \mathrm{~h}$ apresentando um grão anormal que cresceu em toda a seção radial. 80

Figura 43 - Microscopia ótica da seção longitudinal de um fio recozido em $850^{\circ} \mathrm{C}$ por $24 \mathrm{~h}$ ao ar e sob pressão atmosférica. 80

Figura 44 - Imagens de microscopia ótica da seção longitudinal de um fio recozido em $850^{\circ} \mathrm{C}$ por $24 \mathrm{~h}$ em atmosfera rica em gás nitrogênio. 81

Figura 45 - Microscopia ótica na seção longitudinal de um fio recozido em $850^{\circ} \mathrm{C}$ por $24 \mathrm{~h}$ após ser tingido com solução rica em enxofre. 82

Figura 46 - Parâmetro estimador em função da razão de aspecto. O eixo da direita traz a variação percentual na superfície de um esferóide prolato, em comparação a superfície de uma esfera com o mesmo volume. 84 
Figura 47 - Seccionamento seriado de uma região que apresentou indícios de molhamento no estado sólido. (a) e (c) são imagens de microscopia ótica e (b) é um mapa de orientações. A sequência de profundidade vai de "a" até "c".

Figura 48 - Distribuição de tamanho dos grãos anormais, juntamente com a distribuição daqueles que apresentam vizinhos com orientação similar. A frequência de grãos anormais com vizinhos de orientação similar é calculada em relação ao total de grãos de cada grupo..... 88 


\section{LISTA DE TABELAS}

Tabela 1 - Composição química experimental do fio de ferro. Porcentagem em massa.

29

Tabela 2 - Comprimentos da interface partícula-matriz por unidade de área, medidos sobre imagens obtidas por microscopia eletrônica de varredura. 74

Tabela 3 - Área de contornos por unidade de volume $\left(\mathrm{Sv}^{\mathrm{GB}}\right)$; área de interface matriz/partícula por unidade de volume $\left(\mathrm{Sv}^{\mathrm{z}}\right)$ e parâmetro de correlação (ß) dado pela razão entre os dois últimos parâmetros... 85 


\section{SUMÁRIO}

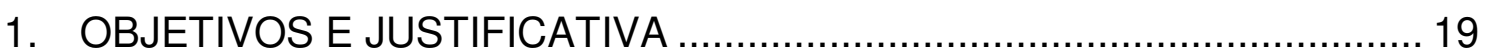

2. INTRODUÇÃO

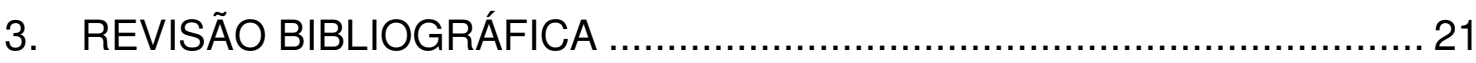

3.1. Aspectos físicos do crescimento anormal de grão ................................. 21

3.2. Deformação, recristalização e crescimento de grão em fios metálicos com

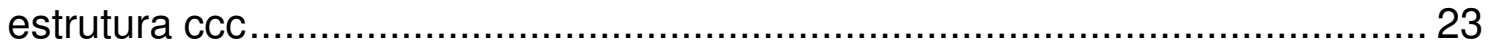

3.3. Modelos de seleção de orientação durante o crescimento anormal .......... 25

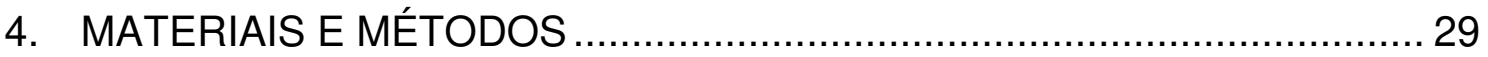

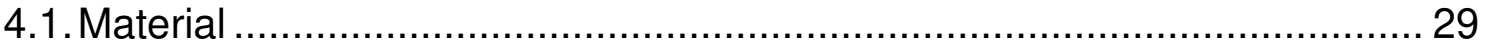

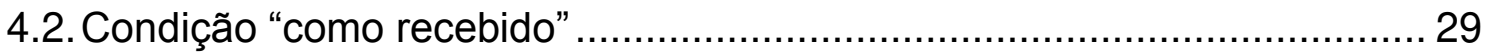

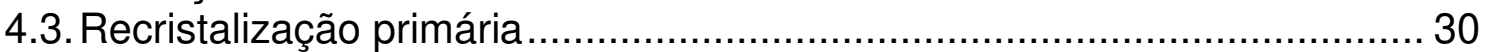

4.4. Fio recozido em $850^{\circ} \mathrm{C}$ por diversos tempos ....................................... 32

4.5. Amostras afinadas por polimento eletrolítico ….................................... 36

4.6. Amostras recozidas em diferentes atmosferas ........................................ 36

4.7. Equilíbrio de pressões no crescimento normal de grão ............................. 37

4.8. Análise de molhamento no estado sólido ............................................... 39

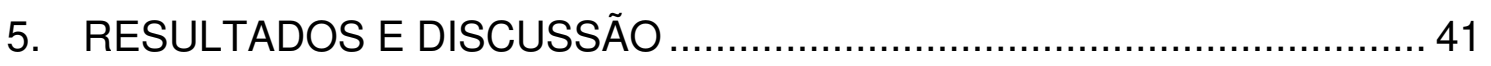

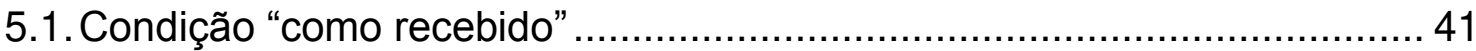

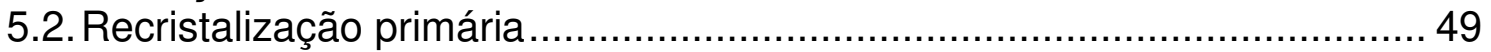

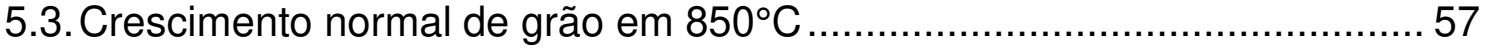

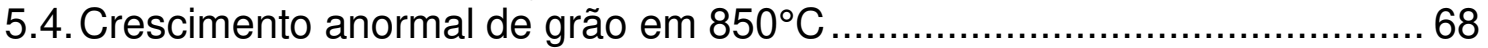

5.5. Efeito da dimensão da amostra no crescimento anormal de grão ............. 77

5.6. Efeito da atmosfera de recozimento no crescimento anormal de grão ...... 78

5.7. Equilíbrio de pressões no crescimento normal de grão ............................. 83

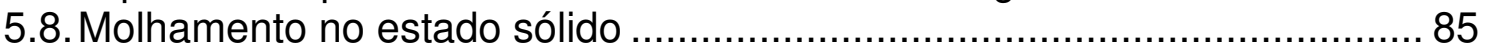

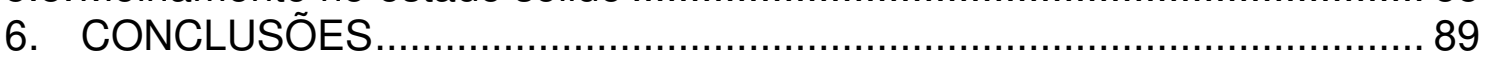

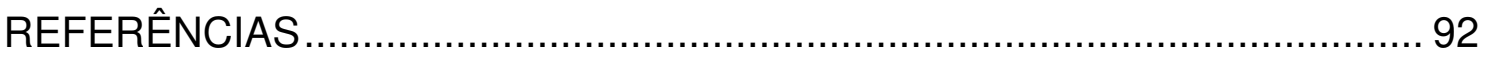





\section{OBJETIVOS E JUSTIFICATIVA}

Esta Tese de Doutorado teve como objetivo investigar de forma sistemática as diversas características das mudanças microestruturais e da orientação cristalográfica que ocorrem quando um fio fino de ferro de pureza comercial é recozido em condições favoráveis à ocorrência de crescimento anormal de grão. É preciso ressaltar que a maioria dos trabalhos envolvendo o crescimento de grão em fios aborda metais e ligas com estrutura cúbica de faces centradas (cfc).

No caso de metais e ligas com estrutura cúbica de corpo centrado (ccc), a maioria dos trabalhos da literatura reporta o crescimento anormal de grão em chapas finas e laminadas dos chamados aços elétricos, dada à sua relevância tecnológica na fabricação de transformadores e núcleos de motores elétricos.

A presente Tese pretende contribuir para o entendimento dos mecanismos que regem o crescimento anormal de grão no material em estudo. Embora se trate de um material bastante simples (ferro de pureza comercial), esse sistema possui como característica principal o caráter quase-unidimensional do crescimento anormal de grão e a elevada área interfacial da amostra com a atmosfera.

Os aspectos originais desta Tese dizem respeito à investigação do crescimento anormal de grãos num fio fino de ferro (material e geometria), os efeitos geométricos e da atmosfera de recozimento e à análise comparativa e criteriosa dos diferentes mecanismos apontados na literatura como responsáveis pelo crescimento anormal de grão, aplicados ao presente caso. 


\section{INTRODUÇÃO}

O crescimento anormal de grão é um importante fenômeno que ocorre no estado sólido. O primeiro registro do fenômeno data de 1916 (1). Desde lá, foram apresentadas diversas aplicações práticas como a melhoria das propriedades elétricas e magnéticas dos aços elétricos por crescimento seletivo dos grãos com orientação Goss (2,3); a produção de monocristais de metais refratários (4-6), semicondutores $(7,8)$; ligas com memória de forma (9); o controle do crescimento de grão em filamentos de tungstênio usados nas lâmpadas incandescentes $(10,11)$; o recozimento direcional de chapas de superligas à base de níquel para aplicações aeronáuticas e aeroespacial $(12,13)$ e a melhoria das propriedades magnetoestrictivas de materiais para atuadores como sensores elétricos $(14,15)$.

O estudo do crescimento de grão em fios trefilados de metais que apresentam estrutura cúbica de corpo centrado (ccc) foi intenso na primeira metade do século 20 para o desenvolvimento do mercado de filamentos para lâmpadas incandescentes. Porém, há poucos trabalhos na literatura com resultados que explicam de forma clara as diversas características da reação.

Esta tese apresenta detalhes dos fenômenos que ocorrem no recozimento de fios de ferro de pureza comercial, particularmente o crescimento anormal de grão. O detalhamento se torna necessário principalmente na descrição da microestrutura da condição "como recebido", uma vez que não há informações detalhadas sobre o processamento termomecânico prévio do fio. Além disso, foram caracterizadas a recristalização primária de amostras recozidas em temperaturas de recozimento mais baixas, onde não há indícios de crescimento normal de grão. O crescimento anormal de grão é interpretado por características probabilísticas (instabilidades locais) desenvolvidas na microestrutura. A caracterização dos precipitados foi realizada, pois as partículas de segunda fase exercem grande influência na migração dos contornos de alto ângulo. Rotinas computacionais foram desenvolvidas para o tratamento estatístico dos dados de orientação cristalográfica e outras características da mesotextura para embasar as conclusões desta Tese, os quais foram obtidos pela técnica de difração de elétrons retroespalhados (EBSD). 


\section{REVISÃO BIBLIOGRÁFICA}

\subsection{Aspectos físicos do crescimento anormal de grão}

O crescimento anormal de grão é um fenômeno caracterizado pelo crescimento seletivo de alguns grãos com relação aos outros (16). Do ponto de vista estatístico, o fenômeno é caracterizado pela dispersão na distribuição de tamanho de grão, inicialmente monomodal, até o surgimento de uma distribuição bimodal. Do ponto de vista topológico, a principal característica é o aumento no número de vizinhos do grão anormal com o tempo de recozimento (17).

O crescimento anormal de grão se caracteriza pelo desvio do comportamento "normal" que é condicionado ao movimento dos contornos devido à suas próprias curvaturas em busca do equilíbrio dos elementos estruturais, de forma que os grãos crescem de forma coletiva (18-20). Alguns fatores que influenciam o crescimento normal podem levar ao crescimento anormal de grão. Entre eles estão a presença de partículas de segunda fase $(3,17,21,22)$, a presença de forte textura cristalográfica (23); as interações entre os contornos de grão e a superfície livre do material $(24,25)$; leves deformações (26-28), presença de porosidade (29) e a limitação na mobilidade de pontos triplos em materiais nanométricos (30-32). Os elementos em solução sólida exercem efeitos na migração dos contornos (33-35) e podem favorecer o crescimento anormal de grão (36), entretanto ainda não há provas substanciais deste efeito $(35,37,38)$.

O estudo do início do crescimento anormal de grão é difícil devido à natureza aleatória do fenômeno (39). Entretanto, alguns indícios experimentais podem ajudar a explicar as microestruturas formadas se interpretados do ponto de vista probabilístico.

Muitos estudos sugerem que uma distribuição de tamanho de grão mais larga aumenta a probabilidade para o crescimento anormal de grão $(6,40-48)$. Tweed et al. (41) observaram experimentalmente esta característica em um sistema com partículas estáveis. A interpretação desta característica remonta ao célebre trabalho de Hillert (49) que também pode ser interpretado considerando os aspectos topológicos do agregado policristalino $(17,39)$.

A recristalização primária em metais deformados gera uma microestrutura de grãos livres de defeitos e a distribuição de tamanho dos grãos recristalizados 
torna-se mais estreita quanto maior for a deformação imposta ao material $(50,51)$. Partindo do princípio de que uma distribuição larga de tamanho de grão aumenta a probabilidade para o crescimento anormal de grão, é possível compreender porque o fenômeno é dificultado no caso de elevadas deformações (48). Para o caso de pequenas deformações, menores que 5\% (26), a probabilidade para crescimento anormal de grão aumenta ou pelo excesso de energia livre devido aos subgrãos $(9,27)$ ou por um possível espalhamento na distribuição do tamanho de grão devido à recristalização primária.

A presença de partículas parece ser essencial para o fenômeno em metais $(3,21,39,52,53)$. Para que o crescimento anormal ocorra, é necessária uma fração intermediária de partículas que inibam o crescimento normal de grão. As mudanças geométricas e dimensionais dos precipitados durante o recozimento, como as que ocorrem na dissolução ou no engrossamento (54), aumentam a probabilidade do crescimento anormal de grão (27,45,55-58). A transformação alotrópica de regiões isoladas na matriz também pode induzir o fenômeno $(9,27,59)$.

A textura cristalográfica eleva a frequência de contornos de baixo ângulo, sabidamente de baixa energia e mobilidade (60). A presença destes contornos leva à formação de estruturas fora do equilíbrio $(20,61)$, inibe o crescimento normal e influencia a cinética de crescimento anormal $(23,48,62,63)$. Uma outra possibilidade é que o crescimento normal dos grãos em uma matriz com textura acentuada possibilita que alguns grãos com orientações próximas ou com alguma relação de orientação especial (64) se toquem e formem aglomerados de grãos que, juntos, apresentem vantagens dimensionais e/ou topológicas. Este fenômeno força o desequilíbrio nas transições topológicas, que também é um fator que aumenta a probabilidade de crescimento anormal de grão $(65,66)$. Essa última interpretação tem raízes topológicas e poderia explicar a vantagem no crescimento dos grãos Goss encontrados nas bandas de cisalhamento de chapas de aço elétrico laminadas a frio $(40,67)$. Outra característica topológica importante é que os grãos maiores durante o crescimento normal de grão sofrem apenas duas das três possíveis transições topológicas, sendo predominante o desaparecimento de grãos em contato mútuo, seguido da troca com vizinhos, em menor frequência (68). A primeira transição faz os grãos maiores crescerem perdendo vizinhos, enquanto que na última eles crescem ganhando vizinhos. O mútuo contato de 
grãos com orientações semelhantes forma interfaces de baixo ângulo de desorientação e baixa energia, tidas como imóvel. Isso diminui a frequência da transição de desaparecimento de grãos menores em contato. Assim, o grão maior pode crescer ganhando vizinhos e tornar-se um grão anormal (17).

Outras características do crescimento anormal de grão são a orientação preferencial dos grãos anormais $(40,69)$ e a distribuição heterogênea deles no espaço $(6,40,42,43,46,67,69-71)$. A posição preferencial pode estar relacionada à prévia recuperação da matriz (70), à heterogeneidade espacial de textura $(40,67,69)$ ou à heterogeneidade da deformação $(43,71)$. A preferência cristalográfica para o crescimento anormal de grão é explicada por diversos modelos, que serão rapidamente descritos no Capítulo 3.3 desta Tese.

É comum encontrar algumas microestruturas peculiares junto ao grão anormal que não são esperadas em estruturas isotrópicas (72). Exemplos marcantes são os chamados grãos-ilha e grãos-península (73). Também são encontrados grãos com menos de 6 lados com curvaturas de contornos que sugerem expansão volumétrica, assim como pontos triplos com ângulos diedrais fora de equilíbrio $(74,75)$.

Muitos autores relacionam a formação dos grãos-ilha à baixa mobilidade dos seus contornos $(76,77)$. Contornos de baixo ângulo ou contornos de alta relação de coincidência (CSLs) são encontrados circundando os grãos-ilha em metais com estrutura cúbica de face centrada $(12,13,78,79)$. Isto não é reportado em metais ccc, que têm alta frequência de contornos de alto ângulo relacionada aos grãosilha (80). Uma outra interpretação seria a de que o crescimento normal dos grãos antes do crescimento anormal daria condições dimensionais para que alguns grãos pudessem persistir como grãos-ilha $(6,81,82)$. A presença de solutos e partículas também tem influência na formação destas microestruturas (15).

\subsection{Deformação, recristalização e crescimento de grão em fios metálicos com estrutura ccc}

Primeiramente serão apresentados os aspectos do processo de trefilação a frio de fios metálicos com estrutura ccc. Este tópico é importante, pois as características da trefilação são diferentes das encontradas na laminação a frio, que é o processo comumente empregado na produção de chapas de aços 
elétricos com grãos orientados. Também serão apresentadas as características experimentais da recristalização primária e do crescimento de grão.

O processo de trefilação a frio consiste em alongar um corpo, normalmente cilíndrico, pela passagem deste por uma matriz cônica vazada sob a ação de uma força. Embora a deformação ocorra pelas forças compressivas da reação metalmatriz, este processo caracteriza-se pela existência de tensão trativa exercida na saída que força a passagem do material pela matriz (83). Isso faz com que a deformação tenha caráter uniaxial (84), assim como a verificada na tração de corpos de prova e na extrusão de perfis (83).

Quando trefilados, os metais ccc apresentam encruamento contínuo em uma ampla faixa de deformação (em alguns casos, até $\varepsilon \approx 12$ (85)). Também ocorre o aumento na desorientação entre células de discordâncias e subgrãos com o aumento da deformação (86). Este fenômeno, juntamente com a constante subdivisão da microestrutura, provoca deformação redundante nos grãos durante a trefilação (84). A deformação redundante ocorre pela necessidade em compatibilizar a deformação dos grãos e ela é verificada visualmente pelo encaracolamento dos grãos na seção transversal (wavy or curled grains $(85,86)$, ou Van-Gogh sky microstructure $(84,87))$.

Devido às tensões atuantes na trefilação, é possível que a deformação seja heterogênea ao longo da direção radial. A distribuição da deformação é influenciada pelos diâmetros de entrada e saída e pelo semiângulo da matriz (83). Tensões cisalhantes ocorrem na interação metal-matriz (88). Outros fenômenos de restauração como a recuperação dinâmica podem ser acelerados pelo aquecimento localizado $(70,89)$, principalmente no processo industrial que emprega uma sequência de reduções (90). A simetria do fio faz com que esta geometria apresente um eixo de referência (direção de trefilação, WD) e que as texturas desenvolvidas durante a trefilação sejam do tipo fibra (91).

As orientações com a direção <110> paralela à direção de trefilação são comuns em metais ccc deformados sob tração (92) e se intensificam com a deformação (86). A literatura reporta heterogeneidades na textura cristalográfica ao longo da direção radial $(43,93,94)$ tanto quanto às componentes quanto às intensidades. 
Quando o fio trefilado é recozido para promover a recristalização primária, ocorrem mudanças microestruturais motivadas pela redução da energia armazenada na forma de defeitos. A recristalização primaria cria grãos livres de deformação que geralmente são alongados na direção de trefilação $(43,95)$. Também se observa uma variação significativa no tamanho de grão ao longo da direção radial, com grãos maiores encontrados próximos à superfície (43). Nos metais ccc, a textura de deformação tende a ser mantida após a recristalização primária $(10,95,96)$ que variam ao longo da direção radial $(43)$. Kurzydlowski et al. (97) mostram que a recristalização primária da ferrita é complexa, com os grãos sofrendo diversas mudanças morfológicas. Os núcleos de recristalização de uma mesma orientação formam-se em aglomerados e os fenômenos de recristalização e crescimento de grão podem ocorrer concomitantemente. O crescimento normal de grão em ferro e aços elétricos é inibido por partículas como óxidos (98), MnS $(3,67,99)$, AIN (100-102) e outros compostos como TiC ou TiS, $\mathrm{Si}_{3} \mathrm{~N}_{4}$ ou $\mathrm{SiO}_{2}(92)$.

O crescimento anormal de grão em fios ccc é reportado em molibdênio puro (43) e também dopado (56,57), tântalo puro (103), tungstênio puro (104) e dopado $(10,44,55,96,104-106)$, em ferro de pureza comercial (74) e em aços baixocarbono com partículas de AIN $(42,107)$. Os grãos anormais em fios de Mo puro (43) surgem na superfície, enquanto que em fios dopados com potássio e silício eles aparecem na região central (57). Grãos anormais em fios de ferro (74) são encontrados na região central e são alongados na direção de trefilação, possivelmente devido à distribuição heterogênea das partículas $(10,104,105)$.

Quanto à orientação dos grãos anormais, as primeiras análises apresentam grãos anormais com elevados índices de Miller $(43,96)$. Outros autores verificaram que a os grãos anormais possuem orientação de fibra com a direção <110> paralela à direção de trefilação $(57,104)$, sendo esta textura também reportada em fios de aço baixo-carbono (42).

\subsection{Modelos de seleção de orientação durante o crescimento anormal}

A primeira explicação sugerida para a seleção de orientação no crescimento anormal é baseada na dispersão de tamanhos de grão encontrada na microestrutura (49) e pode ser estendida para uma teoria topológica (17). Os grãos maiores teriam maior velocidade de crescimento, sofreriam menor ancoramento de partículas e seriam os candidatos naturais ao crescimento anormal $(108,109)$. 
Esta teoria não possui aceitação geral, pois, como no exemplo dos aços elétricos, os grãos com orientação Goss não têm vantagem dimensional e/ou topológica após a recristalização primária (110). Nota-se que o trabalho anterior desqualifica o modelo topológico para o crescimento anormal de grão, entretanto, o autor desconsidera os fenômenos ocorrentes durante o recozimento que poderiam criar as condições para que alguns grãos com orientação Goss apresentem vantagem dimensional/topológica para o crescimento anormal de grão $(111,112)$.

Com o desenvolvimento de técnicas de determinação da microtextura como a difração de elétrons retroespalhados (EBSD), tanto em microscopia de transmissão como de varredura, assim como a microdifração de raios $X$ (113), iniciou-se uma série de trabalhos que tentam explicar o fenômeno baseado nas características anisotrópicas dos elementos estruturais. Estes modelos são conhecidos por apresentarem uma natureza determinística e são apoiados por resultados de simulação microestruturais sob diferentes condições $(19,61,114,115)$. Nota-se que a teoria estatística de Hillert também apresenta um caráter determinístico, uma vez que os grãos com vantagem dimensional/topológica serão os eleitos para o crescimento anormal (116).

A capacidade de classificação dos elementos estruturais é limitada à capacidade analítica existente. Assim, muitas das explicações sugeridas nos primórdios dos mapeamentos de EBSD eram sustentadas no modelo de contornos especiais de alta coincidência $(52,117,118)$. Este modelo só considera a desorientação relativa entre as redes, ou seja, apenas três dos pelo menos cinco graus de liberdade de um contorno de grão (119). A baixa frequência destes contornos em metais ccc sugere que esta hipótese não consegue explicar, de forma inequívoca, o crescimento anormal de grão $(48,74,117,120)$.

Outro modelo sugere que a grande frequência de contornos com desorientação relativa entre 25 e $45^{\circ}$ circundando os candidatos ao crescimento anormal é o motivo pelo qual o grão desenvolve crescimento anormal (73). Os grãos Goss têm maior frequência destes contornos $(48,80)$. Esta interpretação é baseada na distribuições de desorientação dos contornos antes do crescimento anormal e é um tanto equivocada, pois a baixa frequência de grãos com orientação Goss (120) após a recristalização primária garante a estes grãos baixa contiguidade. Isso resulta em uma distribuição de desorientação acumulada em graus intermediários de desorientação, parecida com a distribuição aleatória de 
Mackenzie (121). Com o crescimento de grão, o grão selecionado ganha mais vizinhos e pode aumentar sua contiguidade com grãos que apresentam a mesma orientação. Este fenômeno resultaria no aumento da frequência de contornos com baixo $\left(<15^{\circ}\right)$ e elevado $\left(>45^{\circ}\right)$ ângulos e a diminuição daqueles com desorientações intermediárias $(80,120)$.

Os três modelos comentados consideram que a seleção para o crescimento anormal ocorre pela vantagem em crescimento apresentada pela orientação Goss. Isso não é suficiente para explicar o porquê apenas alguns dos grãos com esta orientação desenvolvem-se como grãos anormais. Esta e outras críticas a estes modelos foram listadas por Morawiec (121).

Outro modelo que ganha aceitação é o de que o crescimento anormal é controlado pelo molhamento no estado sólido de contornos e pontos triplos (122). Nesta hipótese, o mecanismo que levaria ao crescimento anormal seria a troca de contornos que compõem os pontos triplos por elementos de menor energia, em um processo similar ao verificado no crescimento anormal de subgrãos na nucleação da recristalização primária $(109,123)$. Este modelo tem sido sustentado por observações metalográficas $(13,74,124-126)$ e há tentativas de atrelar comprovações experimentais de desorientação $(75,126,127)$ a este mecanismo $(13,122)$, porém estas evidências ainda carecem de relevância estatística. Muitos destes indícios experimentais foram encontrados na presente Tese, porém não há como relacionar estas observações com os modelos sugeridos para descrever 0 crescimento anormal de grão.

Uma outra interpretação sugerida é de que o crescimento seletivo ocorre pela redução de defeitos após a recristalização primária $(71,121,128)$. Morawiec (121) apresenta esta hipótese como alternativa para explicar o surgimento dos grãos anormais, porém o próprio autor a desqualifica devido às poucas evidências apresentadas até aquele momento. Poucos estudos recentes apresentam indícios que poderiam sustentar esta hipótese. Oliveira et al. (48) verificaram uma menor desorientação média nos grãos anormais. Grãos anormais apresentam menor gradiente de orientação em chapas de tântalo (129). Embora recentes, estes indícios não são conclusivos pois o crescimento anormal muda a distribuição de defeitos no volume varrido $(101,113)$, uma vez que as discordâncias e defeitos pontuais são aniquilados pelo contorno em movimento. 
A visão clássica do crescimento de grão motivado pela redução da área de contornos e do engrossamento da microestrutura via transições topológicas (130) apresenta maior consistência com as características apresentadas pelo fenômeno de crescimento anormal de grão e; portanto, poderia ser estendida para os diversos casos apresentados na literatura. 


\section{MATERIAIS E MÉTODOS}

\subsection{Material}

O material estudado foi um fio de ferro com pureza comercial, trefilado a frio e com diâmetro nominal de $0,3 \mathrm{~mm}$, adquirido junto à empresa Carlo Erba. $\mathrm{O}$ material foi gentilmente cedido pelo Prof. Dr. Angelo Fernando Padilha da Escola Politécnica da Universidade de São Paulo (EPUSP). O histórico termomecânico do fio na condição inicial é desconhecido. A composição química experimental é mostrada na Tabela 1 (74).

\subsection{Condição "como recebido"}

O fio foi montado em resina condutora e lixado até obter seções longitudinais planas. As amostras foram polidas seguindo o procedimento metalográfico usual (74). As microestruturas foram reveladas com Nital $4 \%$ (solução $4 \% \mathrm{HNO}_{3}$ em etanol) e as imagens adquiridas em um microscópio marca Leica® modelo DM4000M. Os ensaios de dureza Vickers foram realizados em um microdurômetro da marca Buhler®, modelo Micromet 2004 com carga de $25 \mathrm{~g}$ durante $15 \mathrm{~s}$. As medidas foram feitas na seção longitudinal. Os dados foram agrupados relativos à distância em relação ao eixo central do fio. Para o mapeamento de orientações por meio de difração de elétrons retroespalhados, a amostra polida foi mapeada com um detector EDAX TSL acoplado a um microscópio eletrônico de varredura marca JEOL 6500F com step size de $50 \mathrm{~nm}$. Os dados foram analisados com o MTEX 4.5.3 beta, uma toolbox gratuita para Matlab® desenvolvida para análise de orientações cristalográficas. Foram realizadas limpezas nos dados excluindo os pixels com índice de confiança menor que 0,1 .

Tabela 1 - Composição química experimental do fio de ferro. Porcentagem em massa.

Composição química $(\% \mathrm{~m})$

\begin{tabular}{ccccccccc}
\hline $\mathbf{M n}$ & $\mathbf{C r}$ & $\mathbf{N i}$ & $\mathbf{C}$ & $\mathbf{O}$ & $\mathbf{N}$ & $\mathbf{S}$ & $\mathbf{A l}$ & $\mathbf{F e}$ \\
0,031 & 0,023 & 0,0204 & 0,018 & 0,036 & 0,028 & 0,004 & $<0,001$ & Bal.
\end{tabular}

Fonte: Elaborada pelo autor. 
Devido à simetria triclínica da amostra, as texturas foram representadas em figuras de polo inversa em relação à WD. Os mapas de orientação também foram coloridos com relação a esta direção. Os volumes das fibras foram calculados com uma tolerância de $10^{\circ}$ em relação à orientação ideal. O valor de desorientação média dos núcleos (Kernel Average Misorientation, KAM) foi encontrado considerando apenas os primeiros vizinhos e assumindo a tolerância máxima de $4^{\circ}$ para evitar que os contornos de grão influenciem os resultados.

Para o cálculo do gradiente de orientação, foram utilizados os métodos de Ørsund et al. (131) e de Kamaya (132). Para o primeiro, foram analisadas a desorientação de todas as linhas de pixels perpendiculares à WD dentro de cada lamela. As lamelas foram reconstruídas pelo software assumindo tolerância de $10^{\circ}$ e excluindo lamelas com menos de 4 pixels. As desorientações e distâncias foram calculadas em relação ao primeiro pixel de cada linha. Estes valores foram linearizados por regressão utilizando a função y = a.x, sendo a inclinação da linha igual ao gradiente de orientação. Quando o $R^{2}$ foi maior ou igual a 0,95 , o valor foi armazenado, formando um grupo amostral para cada região do fio. Já o cálculo de gradiente de orientação pelo método de Kamaya (132) é realizado calculando o valor de KAM para diferentes tamanhos de núcleos. Cada tamanho de núcleo representa uma distância física, assim, os valores de KAM foram plotados em função da distância referente ao tamanho de núcleo e os dados foram linearizados utilizando uma função do tipo $y=a \cdot x+b$. A interseção da linha com o eixo y é considerada como o erro de medida e a inclinação da curva é o gradiente de orientação. Este método possui a vantagem de não ser necessária a prévia identificação dos grãos (lamelas) para ser implementado, além disso, é possível gerar imagens de gradiente de orientação se este procedimento for realizado para cada pixel do mapeamento.

\subsection{Recristalização primária}

Foi realizada uma série de recozimentos variando a temperatura e o tempo (74) para estudar as características microestruturais da recristalização primária. Para o acompanhamento da dinâmica do fenômeno, foram obtidas imagens de microscopia ótica de fios recozidos em $550^{\circ} \mathrm{C}$ por 5,15 e 30 min. Para a caracterização microestrutural, foi selecionada a condição de menor temperatura com o menor tempo onde a reação é completa. A condição escolhida foi de recozer 
o fio sobre vácuo mecânico em $650^{\circ} \mathrm{C}$ por 10 min, seguido de têmpera em água. Este recozimento possibilitou completa recristalização primária sem indícios de crescimento normal de grão. Estas amostras foram montadas e polidas para revelar a seção longitudinal.

Para o mapeamento de orientações por EBSD, a amostra polida foi mapeada com um detector EDAX TSL acoplado a um microscópio eletrônico de varredura marca Cambridge, modelo Camscan 4 com step size de $2 \mu \mathrm{m}$. A razão de aspecto foi calculada usando a razão entre os diâmetros de Feret. Para análise da área média dos grãos em relação à posição radial, as coordenadas relativas ao baricentro dos grãos foram agrupadas em 30 grupos que vão de 0 até 1 e então calculada a média da área dos grãos para cada grupo, juntamente com o intervalo de confiança de $95 \%$.

$O$ volume das fibras ao longo da direção radial foi calculado dividindo $O$ mapeamento inicial em 30 posições ao longo da direção radial. A área de cada posição foi dividida em 15 áreas menores. Os valores apresentados são os volumes médios de cada posição. As barras de erro representam o desvio padrão das medidas. Para o cálculo de volume de fibra foi considerado tolerância de $10^{\circ}$.

Os contornos foram classificados conforme o ângulo de desorientação entre os grãos que os compõem. Contornos com desorientação entre 2 e $10^{\circ}$ foram classificados como de baixo ângulo. Aqueles com desorientação maior que $10^{\circ}$ são classificados como contornos de alto ângulo. Os contornos com alta relação de coincidência foram classificados de $\sum 1$ até $\sum 21 \mathrm{~b}$ seguindo o critério de Brandon (118).

A dispersão intragranular de orientações (Grain Orientation Spread, GOS) é calculada pelo ângulo de desorientação determinado entre a orientação média do grão e a orientação individual de cada pixel que o compõe (133). A orientação dos grãos com GOS maior que $2^{\circ}$ é representada pelo ângulo de desorientação entre a orientação média dos grãos e a orientação ideal da fibra. Para estudar a desorientação intragranular, foi utilizada a análise do perfil de desorientação em relação à origem e também ponto a ponto. $O$ eixo de desorientação foi desconsiderado nas análises, embora ele possa influenciar a interpretação dos resultados (134). 


\subsection{Fio recozido em $850^{\circ} \mathrm{C}$ por diversos tempos}

As microestruturas das amostras recozidas em $850^{\circ} \mathrm{C}$ por até $4 \mathrm{~h}$ antes do crescimento anormal de grão são apresentadas como mapa de orientações utilizando a figura de polo inversa com a direção de trefilação. Para análise da área média dos grãos em relação à posição radial, as coordenadas relativas ao baricentro dos grãos foram agrupadas em 30 grupos que vão de 0 até 1 e então calculada a área média dentro de cada grupo, juntamente com o intervalo de confiança de $95 \%$. As distribuições normalizadas de tamanho de grão foram calculadas utilizando os tamanhos normalizados, dados por:

$$
r=\ln \frac{R}{\bar{R}}
$$

onde $\mathrm{R}$ é o raio equivalente do grão em questão e $\bar{R}$ é o raio médio equivalente da amostragem. Foram definidos grupos com tamanho de 0,1 para agrupar os dados. As distribuições de número de vizinhos foram levantadas diretamente com os dados da reconstrução de grãos. Em ambos os casos, a amostragem foi dividida em dois grupos: grãos orientados próximos à fibra $<110>/$ WD e grãos com outras orientações. As amostras analisadas foram a recozida em $650^{\circ} \mathrm{C}$ por 10 min para recristalização primária e também as recozidas em $850^{\circ} \mathrm{C}$ por até $4 \mathrm{~h}$. Para identificar onde ocorre o aumento no número de grãos grandes e com muitos vizinhos, foram somadas as frequências de grãos que apresentam tamanho normalizado maior que 1 e o somatório da frequência de grãos que apresentam mais de 12 vizinhos. Este processo foi realizado nos grãos encontrados em 15 posições diferentes ao longo da direção radial.

A contiguidade é uma variável microestrutural que pode ser medida pela razão entre os valores parciais de área dos contornos por unidade de volume (135). A área de contornos por unidade de volume (Sv) é proporcional ao comprimento de contornos por unidade de área $\left(L_{A}\right)$. Tomado os devidos cuidados para realizar os mapeamentos sempre na mesma seção do fio, é possível supor a mesma constante de proporcionalidade para todas as amostras $(136,137)$. Assim, a contiguidade pode ser calculada com dados medidos em uma seção bidimensional pela equação: 


$$
C=\frac{2 * L_{A(f-f)}}{2 * L_{A(f-f)}+L_{A(f-o)}}
$$

onde $L_{A}(f-f)$ é o comprimento de contorno por unidade de área entre grãos orientados na fibra e $L_{A}\left(f_{-o}\right)$ é o comprimento de contorno por unidade de área entre grãos orientados na fibra e grãos com outras orientações. A contiguidade varia entre zero, para grãos totalmente separados até um, que representa uma microestrutura totalmente preenchida com grãos orientados na fibra $<110>$ // WD (97). Os valores de contiguidade foram calculados para a amostra após a recristalização primária e para as amostras recozidas em $850^{\circ} \mathrm{C}$ antes do crescimento anormal de grão.

Os pontos triplos foram classificados de acordo com o ângulo de desorientação dos contornos que os compõem, sendo estes classificados dentro de três classes: baixos ângulos $\left(<15^{\circ}\right)$; altos ângulos $\left(\geq 15^{\circ}\right)$ e contornos especiais do tipo CSL. Os contornos do tipo CSL foram agrupados juntos de $\Sigma 3$ até $\Sigma 21$, utilizando o critério de Brandon. Esta classificação possibilita dividir os pontos triplos em dez grupos, que são apresentados na Figura 1. Eles foram qualitativamente distribuídos no gráfico considerando suas energias integrais e também suas anisotropias energéticas $(75,138)$. Os pontos triplos mais relacionados à cada um dos modelos propostos para o crescimento anormal de grão também foram identificados no gráfico.

O volume das principais fibras foi calculado assumindo uma tolerância de $10^{\circ}$ em relação à orientação ideal. Os contornos especiais tipo CSL foram identificados usando o critério de Brandon. As medidas de comprimento dos contornos por unidade de área $\left(L_{A}\right)$ foram calculadas recortando dos mapeamentos de EBSD áreas com $200 \times 200 \mu \mathrm{m}^{2}$. Este procedimento foi repetido até que a precisão relativa das medidas foi menor que $10 \%$. Os valores apresentados são as médias de cada amostra e as barras de erro são os intervalos de confiança de $95 \%$. Estes recortes também foram utilizados para calcular o volume médio da fibra $<110>$ // WD. 
Figura 1 - Distribuição esquemática dos dez tipos de pontos triplos. Eles são distribuídos no gráfico considerando suas energias integrais e suas anisotropias energéticas. Os pontos triplos mais relacionados aos modelos de crescimento anormal são apresentados.

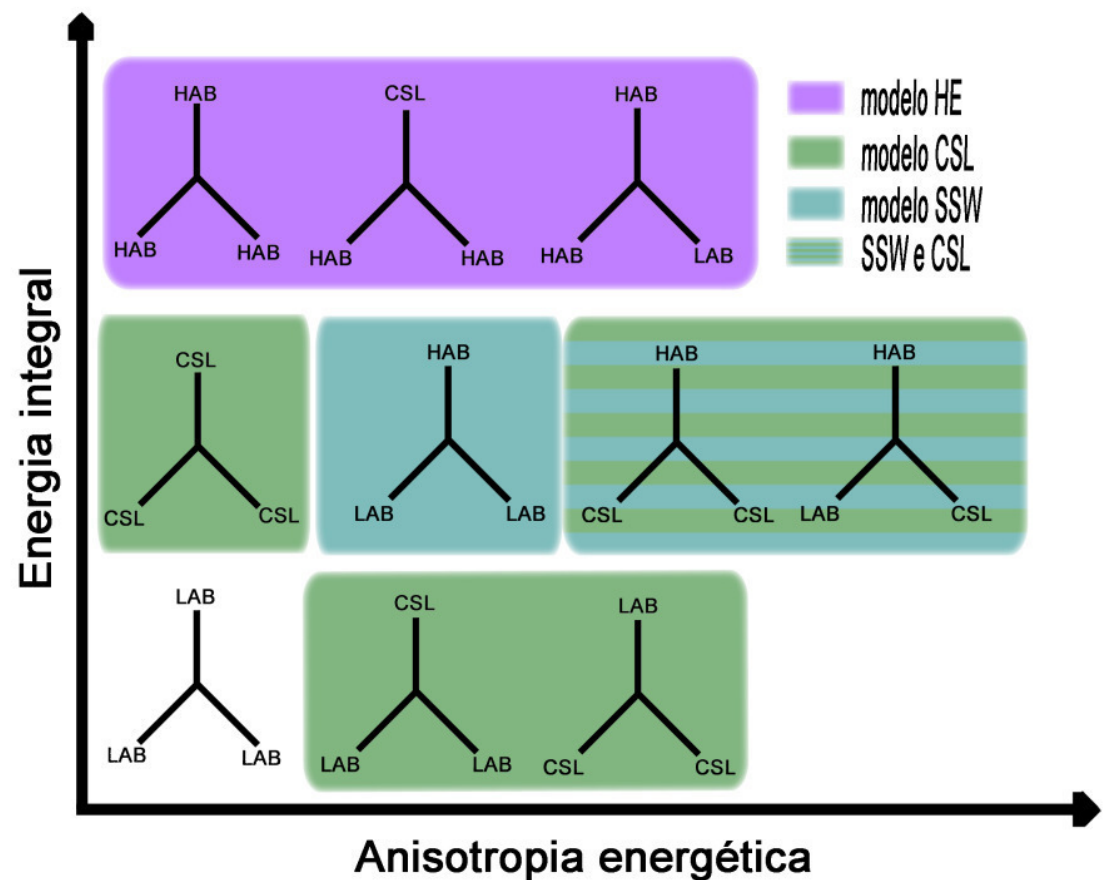

Fonte: Elaborada pelo autor.

Para uma interpretação quantitativa sobre a orientação dos grãos anormais, foi analisada a frequência das desorientações entre a orientação média dos grãos anormais e a fibra <110> // WD. Os grãos anormais foram identificados de forma arbitrária como aqueles com área de seção maior que 7 vezes a área média dos grãos. Suas áreas aparentes foram agrupadas em escala logarítmica de base 10. Os grãos-ilha foram identificados pelo software pelo número de vizinhos que eles possuem (1 vizinho).

As partículas presentes nas amostras recozidas em $850^{\circ} \mathrm{C}$ por 3 min e $72 \mathrm{~h}$ foram caracterizadas em relação à composição química e ao tamanho. Devido às pequenas dimensões das partículas (dezenas de nanômetros), fez-se necessário o uso de técnicas de alta resolução para a caracterização, como a microscopia eletrônica de transmissão. Para tal, foram preparadas duas lamelas de cada região do fio (centro e superfície) pelo método lift-out (139). As lamelas foram afinadas até transparência aos elétrons $(<100 \mathrm{~nm})$. Para o preparo das lamelas, foi utilizado um microscópio de varredura com feixe secundário de íons de gálio, marca Helios FEG-SEM G4 CX. As imagens das partículas foram obtidas no 
campo escuro. A composição química das partículas foi determinada por espectroscopia da dispersão de energia de raios $X$ (EDX).

A composição química das partículas da amostra recozida em $850^{\circ} \mathrm{C}$ por 3 min também foi analisada utilizando a técnica de tomografia de sonda atômica (Atom Probe Tomography, APT). Nesta técnica, é possível analisar a composição química de compostos em escala atômica pela aceleração direta dos íons da amostra contra um detector bidimensional (140). As amostras para APT apresentam formato de agulhas com o diâmetro da ponta na ordem de dezenas de nanômetros. Pelo tempo de viagem de cada íon, é possível identificar sua natureza química (140). Pela posição de colisão no detector é possível estimar a posição espacial dos íons na amostra (141). As amostras foram preparadas em um microscópio eletrônico de varredura que possui um feixe secundário de íons de gálio (FIB). A análise das agulhas foi feita em um equipamento Cameca LEAP 3000X. A identificação dos íons é realizada conflitando a distribuição da razão massa/carga dos íons com os valores tabelados para diversos íons monoatômicos, encontrados no apêndice do livro de Gault et al. (142). O espaço amostrado foi dividido em voxels de $1 \mathrm{~nm}^{3}$, seguido de contagem número de íons dentro de cada voxel. As imagens apresentadas são coloridas conforme o íon considerado e a intensidade da cor dos voxels é proporcional à densidade de íons. Os dados foram analisados com auxílio do software Matlab.

As distribuições de tamanho de partículas foram levantadas medindo as características dimensionais das partículas em imagens da seção longitudinal para duas áreas distintas, o centro e a superfície. Para tal, foi utilizado um microscópio de varredura Zeiss FEG-SEM Merlin operando à distância de trabalho de $5.7 \mathrm{~mm}$ e aceleração de $10 \mathrm{kV}$. As imagens foram tiradas em alta resolução (4096 x 3072 pixels²). Esta configuração garante a máxima resolução espacial do equipamento (0.8 nm/pixel, segundo o site do fabricante). O uso de imagens de microscopia eletrônica de varredura diminui os erros sistêmicos presentes em outras técnicas de análise de partícula como a extração de réplicas em filmes de carbono (143). As partículas foram selecionadas nas imagens baseado nos gradientes de contraste e cor, as quais foram acentuados utilizando modulação gama e a equalização dos histogramas de intensidade (144). A binarização e as medidas dimensionais das partículas foram realizadas com o auxílio do freeware 
ImageJ. Os resultados são mostrados pelo agrupando dos raios equivalentes das partículas em grupos de $5 \mathrm{~nm}$.

\subsection{Amostras afinadas por polimento eletrolítico}

Alguns fios passaram por polimento eletrolítico antes de serem recozidos para promover o crescimento anormal de grão com a intenção de remover a camada mais próxima à superfície do fio sem promover deformação plástica. Para tal, utilizou-se a solução $60 \% \mathrm{H}_{2} \mathrm{SO}_{4}$ como meio eletrolítico, um tubo com $5 \mathrm{~mm}$ de diâmetro feito de aço inoxidável AISI 304 como ânodo e a própria amostra como cátodo. O fio foi colocado dentro do tubo de forma a manter a distância entre amostra e catodo constante. O polimento foi realizado com a ajuda de uma fonte de corrente simples, operando com diferença de potencial de $5 \mathrm{~V}$ por $600 \mathrm{~s} \mathrm{e}$ limitada para correntes até 1,2 A para evitar aquecimento.

\subsection{Amostras recozidas em diferentes atmosferas}

Alguns fios foram tratados em diferentes atmosferas para compreender a relação existente entre a precipitação de partículas e a dinâmica do crescimento de grão. Até então, todas as amostras haviam sido encapsuladas em tubo de quartzo sobre vácuo mecânico ( 10-2 mbar), que não é suficiente para retirar todos os gases do interior das ampolas. Uma das amostras foi recozida em vácuo dinâmico feito por uma bomba turbomolecular e recozida em $850^{\circ} \mathrm{C}$ por 6 e $24 \mathrm{~h}$. Outra amostra foi recozida ao ar e pressão atmosférica, outra encapsulada com o tubo de quartzo preenchido de gás nitrogênio à pressão atmosférica e outra tingida com solução Klemm I por 5 min $(50 \mathrm{~mL}$ de solução concentrada de tiossulfato de sódio, $\mathrm{Na}_{2} \mathrm{~S}_{2} \mathrm{O}_{3} .5 \mathrm{H}_{2} \mathrm{O}+1 \mathrm{~g}$ de metabissulfito de potássio, $\mathrm{K}_{2} \mathrm{~S}_{2} \mathrm{O}_{5}$ ). Esta solução forma um filme rico em enxofre na superfície metálica. As três últimas amostras foram tratadas em $850^{\circ} \mathrm{C}$ por $24 \mathrm{~h}$. Para efeito comparativo, foram calculados os comprimentos de interceptos lineares para estas amostras, medidos na direção de trefilação para as regiões do centro e da superfície. As medidas da amostra recozida em $850^{\circ} \mathrm{C}$ por $3 \mathrm{~min}$ em ar atmosférico e pressão de vácuo mecânico também é apresentada para efeito comparativo. 


\subsection{Equilíbrio de pressões no crescimento normal de grão}

A força motriz para o crescimento de grão $(\Delta \mathrm{P})$ num sistema contendo partículas finamente dispersas pode ser descrita como sendo a diferença entre 0 potencial termodinâmico associado à presença dos contornos de alto ângulo ( $\mathrm{PGG}$ ) e a pressão de arraste exercida pelas partículas sobre os contornos (Pz), dado pela Equação (4):

$$
\Delta P=P^{G G}-P^{Z}=\gamma\left(S_{V}^{G G}-\beta S_{V}^{Z}\right)
$$

onde " $\gamma$ " é a energia interfacial dos contornos de grão por unidade de área; $S_{V}{ }^{G G}$ é a área de contornos por unidade de volume; $S^{z}{ }^{z}$ é a área de interfaces matriz/partículas por unidade de volume e $B$ é um parâmetro encontrado analiticamente por Rios como igual a 3 (145). As medidas de área de superfície por unidade de volume não são simples de serem calculadas em seções de sólidos opacos por duas razões: a anisotropia de forma presente em grãos/partículas e suas diversas heterogeneidades na amostra. As relações estereológicas, entretanto, trazem algumas ferramentas para que essas limitações sejam superadas.

A área de contorno por unidade de volume foi calculada cortando áreas circulares com diâmetro de $50 \mu \mathrm{m}$ da superfície e do centro dos mapas de EBSD. O software calcula automaticamente o comprimento de contornos dentro de cada área, o que torna possível o cálculo do comprimento de contornos por unidade de área $\left(L_{A}\right)$. Quando os grãos são isomórficos, a relação entre a propriedade tridimensional e as medidas bidimensionais é bem estabelecida, entretanto, para grãos com anisotropia morfológica, certas considerações devem ser compreendidas. No caso do ferro ccc laminados à frio, os grãos são anisotrópicos após a recristalização primária (97) ou o crescimento de grão (95), com os eixos mais longos alinhados paralelos à direção de laminação. Nos fios, os grãos lembram esferóides prolatos que apresentam o diâmetro maior alinhado com a direção de trefilação. Os grãos aparecem isomórficos quando vistos na seção radial ao passo que quando vistos na seção longitudinal, eles possuem a forma de elipses. O parâmetro de forma da elipse $(\eta)$ pode ser descrito pela média geométrica entre os dois principais diâmetros, contidos na seção longitudinal. Este é dado pela Equação (5): 


$$
\eta_{L}=\sqrt[3]{\frac{d_{W D}^{2}}{d_{R D}^{2}}}=\sqrt[3]{A R^{2}}
$$

onde dwD e dRD são os diâmetros dos grãos na direção de trefilação e radial, respectivamente. Por definição, o parâmetro de forma é relacionado a razão de aspecto dos grãos (AR). A área de superfície por unidade de volume de qualquer corpo tridimensional é dado por (137):

$$
S_{V\left(L_{A(R D)}, \eta_{L}, \eta_{T}\right)}=\left[\frac{2}{\eta_{T} \pi} \frac{S\left(\eta_{L}, \eta_{T}\right)}{L\left(\eta_{L}\right)}\right] * L_{A(R D)}^{\text {longitudinal }}
$$

onde o termo entre colchetes no lado direito da equação (6) é a relação entre a superfície de um esferóide prolato e o perímetro da elipse que surge quando o esferóide é visto na seção longitudinal. Aplicando as considerações geométricas, é possível verificar que $S v^{G G}$ na seção longitudinal será dado por:

$$
S_{V\left(L_{A}(R D), \eta_{L}, \eta_{T}\right)}=\frac{8}{\pi} \eta_{L}\left(\frac{\frac{\eta_{T}}{\eta_{L}}+\frac{\eta_{L}}{\sqrt{\left(\eta_{L}\right)^{2}-\left(\eta_{T}\right)^{2}}} \arccos \left(\frac{\eta_{T}}{n_{L}}\right)}{\left.\eta_{L}+\eta_{T}+\sqrt{2\left(\eta_{L}{ }^{2}+\eta_{T}{ }^{2}\right.}\right)}\right) * L_{A(R D)}^{\text {longitudinal }}
$$

A Equação (7) também depende da forma dos grãos quando vistos na seção transversal $\left(\eta_{T}\right)$. Entretanto, esta variável pode ser simplificada se o esferóide prolato for racionalizado como o produto do alongamento de uma esfera na direção de trefilação, de forma que o volume é mantido constante e, portanto, $\eta_{L} * \eta_{T}^{2}=1$. Ao adicionar esta consideração na Equação (7), temos:

$$
S_{V\left(L_{A(R D)}, \eta_{L}\right)}=\frac{8}{\pi} \eta_{L}\left(\frac{\eta_{L}^{-\frac{3}{2}}+\frac{\eta_{L}}{\sqrt{n_{L}{ }^{2}-\eta_{L}^{-1}}} \arccos \left(\eta_{L}^{-\frac{3}{2}}\right)}{\eta_{L}+\eta_{L}^{-\frac{1}{2}+} \sqrt{2\left(n_{L}^{2}+n_{L}^{-1}\right)}}\right) * L_{A(R D)}^{\text {longitudinal }}
$$

A Equação (8) mostra que a área de contornos por unidade de volume em fios pode ser descrita somente por medidas realizadas na seção longitudinal, se os grãos puderem ser considerados esferoides prolatos com o maior diâmetro alinhado na direção de trefilação. O fator de forma é encontrado considerando a média da razão de aspecto dos grãos presentes em cada uma das áreas recordadas, o que significa que mudanças locais de forma serão consideradas na 
análise. É importante apontar que o comprimento de contornos por unidade de área também depende da seção analisada, que neste caso deve ser a seção longitudinal no meio do diâmetro do fio. Todas as amostras foram preparadas cuidadosamente de modo a revelar exatamente esta seção e minimizar esta variável analítica.

As considerações geométricas das partículas são mais simples de serem aplicadas. As partículas aparecem nas imagens com formato redondo, de modo que elas podem ser simplificadas como esferas e $\eta\llcorner=1$. A Equação (8) então é simplificada para a relação de Saltikov:

$$
S_{V}^{Z}=\frac{4}{\pi} L_{A}
$$

O perímetro calculado diretamente pela análise de partículas do software ImageJ não representa precisamente o perímetro das partículas porque a rotina linear de varredura do microscópio eletrônico cria um excesso de ruído nas interfaces. Para evitar este efeito, foi decidido calcular o comprimento de interface por unidade de área $\left(L_{A}\right)$ considerando as partículas como esferas, de modo que ele pode calculado dado por:

$$
L_{A}=\frac{\sum_{1}^{n} 2 \pi r_{n}}{A_{p}}
$$

onde Ap é a área recortada. O somatório é feito sobre o perímetro equivalente de todas as partículas encontradas na área teste, que é calculado utilizando o raio equivalente dado por $r_{n}=\left(A_{n} / \pi\right)^{1 / 2}$, onde $A_{n}$ é a área aparente da partícula na imagem. Os resultados são representados pela média aritmética de todas as áreas recortadas, juntamente com o intervalo de confiança de 95\% mostrado como barras de erro. O intervalo de confiança do parâmetro B é encontrado considerando a lei de propagação de erros.

\subsection{Análise de molhamento no estado sólido}

Foram verificados indícios de molhamento no estado sólido utilizando o seccionamento seriado de poucas camadas em regiões previamente identificadas, seguindo os critérios estabelecidos em literatura $(126,146)$. Como há uma amostragem significativa de grãos anormais, foi possível criar um algoritmo que 
busca na vizinhança do grão anormal por grãos com orientação similares (menos de $2^{\circ}$ de diferença) (122). Espera-se com este algoritmo identificar de forma mais generalista indícios de molhamento no estado sólido.

Os grãos anormais foram identificados de forma arbitrária como sendo aqueles com área maior que 7 vezes a média da amostragem. Eles foram agrupados pelo logaritmo de base 10 da área aparente nas seções mapeadas, 0 que gerou uma distribuição discreta da área dos grãos anormais. Em seguida, calculou-se a frequência de grãos anormais com indícios de molhamento no estado sólido referente à cada grupo de tamanho de grão anormal. 


\section{RESULTADOS E DISCUSSÃO}

\subsection{Condição "como recebido"}

O fio de ferro na condição "como recebido" encontra-se encruado. A Figura 2 mostra a seção longitudinal do fio. O material apresenta uma microestrutura de deformação composta por lamelas alongadas na direção de trefilação. Quando se analisa a seção radial, nota-se uma microestrutura de grãos encaracolados mostrados na Figura 3. Por possuir esta morfologia, é possível prever que o fio sofreu elevada deformação a frio (85). As imagens de microscopia ótica não permitem evidenciar, a priori, a presença de heterogeneidade microestrutural.

Foram realizados ensaios de dureza na seção longitudinal ao longo da direção radial. A Figura 4 mostra que a dureza média na região periférica é significativamente menor que na região central. Este perfil de dureza é esperado na trefilação de metais com matrizes com pequenos semiângulos de abertura (88). Em reduções severas, o acúmulo de defeitos (maior dureza) ocorre na região próxima à superfície $(88,147)$. Wright $(70)$ também cita a presença de heterogeneidade na dureza ao longo da seção radial em fios de cobre (OFHC). Ele atribuiu o fenômeno à recuperação dinâmica iniciada pelo aquecimento localizado no processo de trefilação. Espera-se que este efeito seja mais aparente em metais com estrutura ccc, pois eles apresentam sensível variação da taxa de encruamento com a temperatura de deformação (148).

A Figura 5 mostra o mapa de figura de polo inversa em relação à WD. Notase a existência de pixels pretos que predominam na região central do fio. Estes pixels foram desconsiderados da análise, pois a indexação da orientação apresentou baixo índice de confiança (149). A presença destes pixels na região central implica em acúmulo localizado de deformação (133). O fio na condição "como recebido" apresenta textura de fibra com grande quantidade de cristais orientados com a direção $<110>$ paralela à WD, que são caracterizados pela coloração verde na Figura 5. O fio apresenta forte textura após a trefilação (91), sendo que o volume global desta componente de fibra é de aproximadamente $53 \%$. Embora a coloração verde predomine na Figura 5 , há lamelas próximas à superfície que apresentam colorações que se espalham pelas arestas do triangulo, com grande presença de orientações do tipo <100> // WD. 
Foram determinados os volumes das fibras referentes aos três eixos principais: $<100>/ / W D,<110>/ / W D$ e $<111>/ / W D$, que são mostrados na Figura 6. Há heterogeneidade na distribuição da fibra $<110>/ / W D$ ao longo da direção radial, algo anteriormente reportado em fios de ferro (93) e molibdênio (43). O centro apresenta o maior volume de orientações próximas a fibra $<110>/ / W D$, atingindo volume de $74,8 \pm 6,8 \%$. A região periférica possui menor volume, sendo encontrado $21,4 \pm 10 \%$ em uma das extremidades. Nesta mesma extremidade há uma fração de orientações próxima à fibra $<100>/ /$ WD. Embora a intensidade da fibra <110> // WD seja proporcional à deformação real (86), outros parâmetros podem influenciar a textura cristalográfica de trefilados como matriz com elevado semiângulo, alta redução por passe ou a trefilação com deficiência de lubrificação. Estas condições levam ao enfraquecimento da fibra $<110>/ /$ WD e o fortalecimento da $<100>/ /$ WD (150).

Figura 2 - Imagens de microscopia ótica da seção longitudinal de um fio na condição "como recebido".

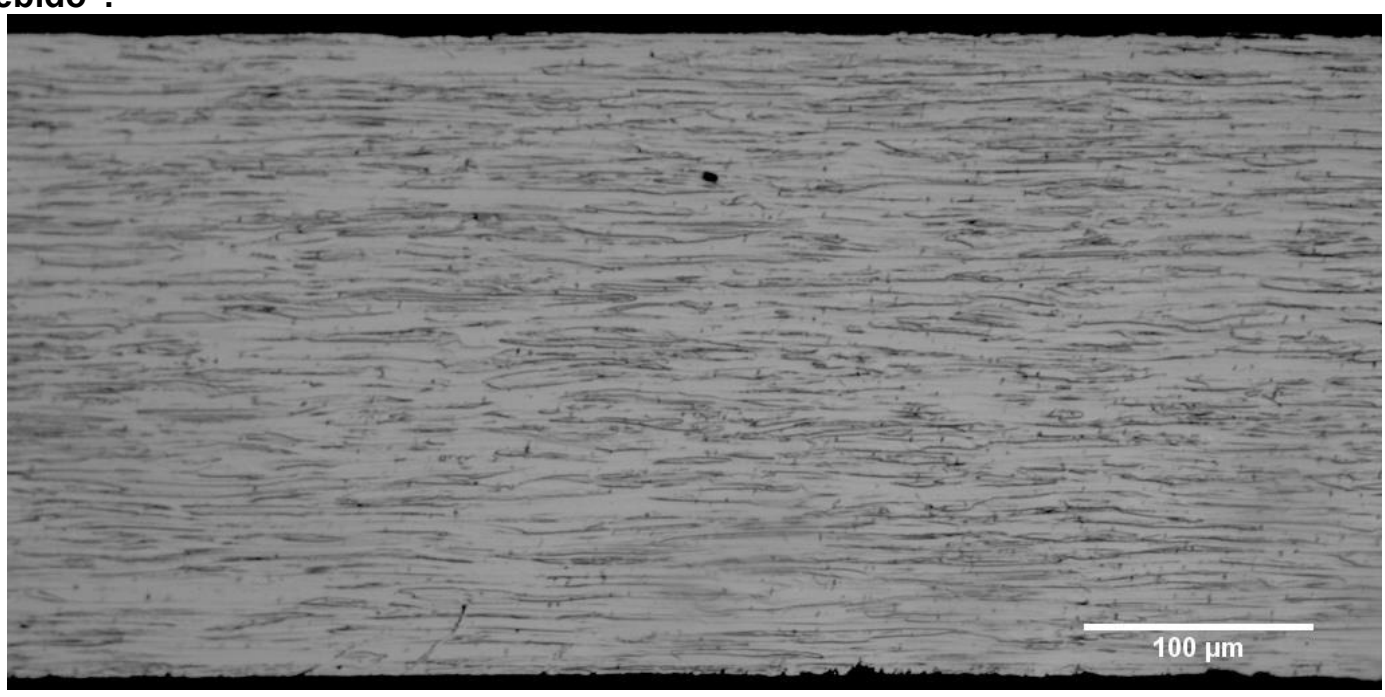

Fonte: Elaborada pelo autor. 
Figura 3 - Imagem de microscopia ótica da seção transversal de um fio na condição "como recebido" mostrando o encaracolamento das lamelas deformadas.

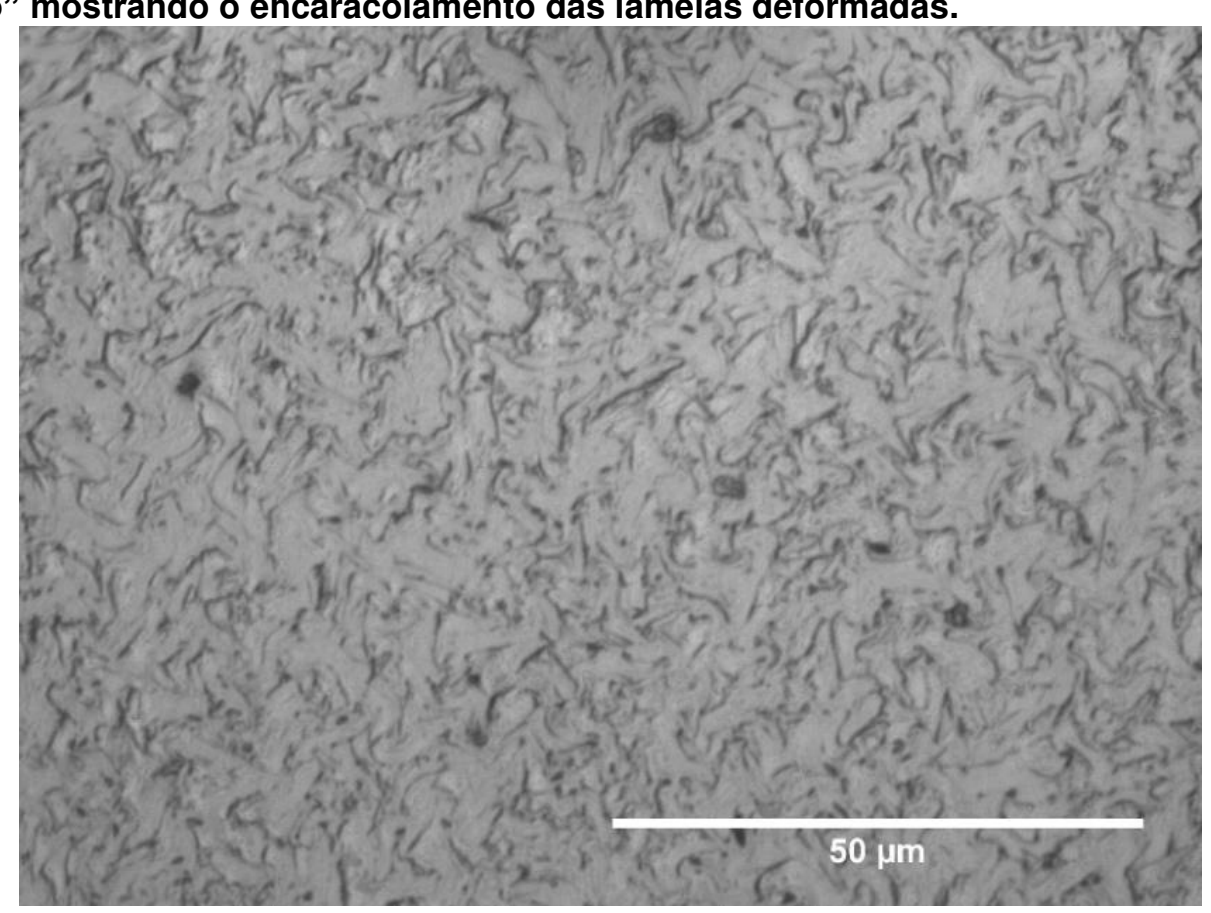

Fonte: Elaborada pelo autor.

Figura 4 - Valores médios de microdureza Vickers na condição "como recebido". Os dados foram agrupados em relação à distância do eixo central, onde 0 é o centro.

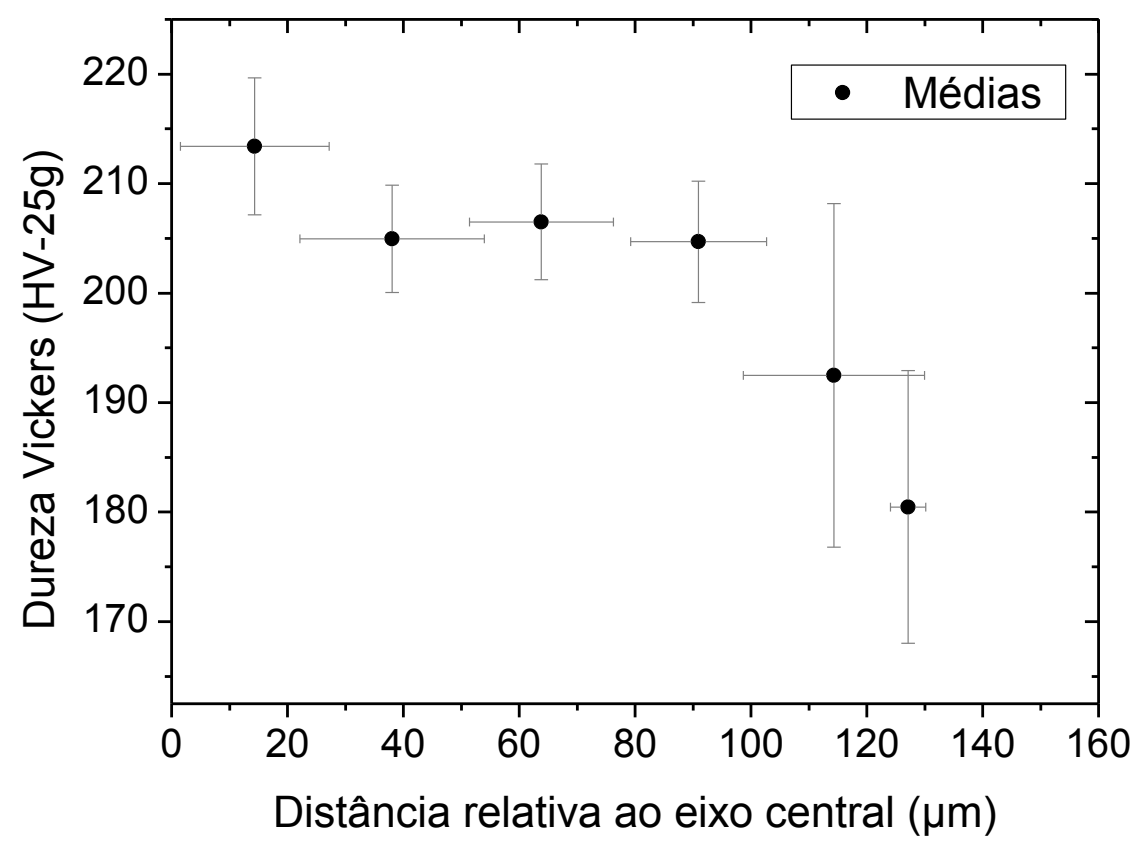

Fonte: Elaborada pelo autor. 
Figura 5 - Mapa de orientações da seção longitudinal do fio na condição "como recebido". A imagem é colorida seguindo a escala da figura de polo inversa com relação a WD.

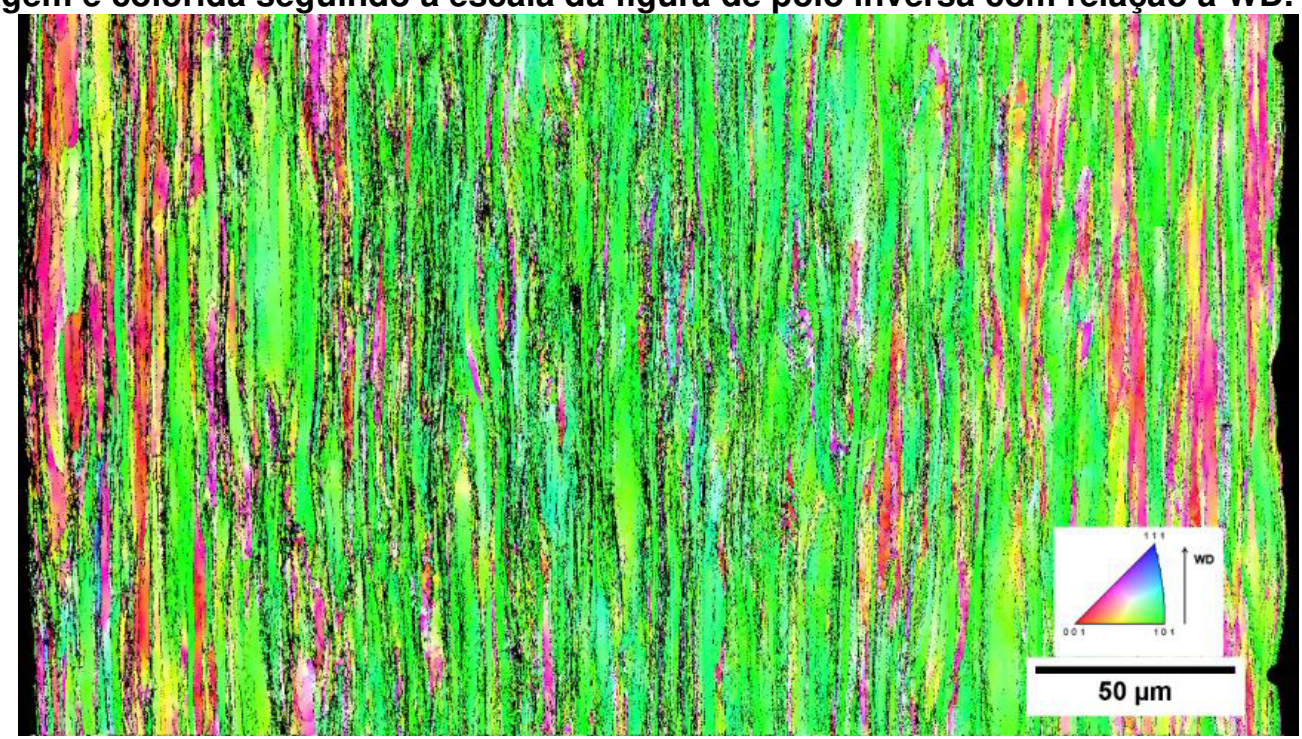

Fonte: Elaborada pelo autor.

Figura 6 - Distribuição de volume das principais fibras de textura em relação a posição radial para o fio na condição "como recebido".

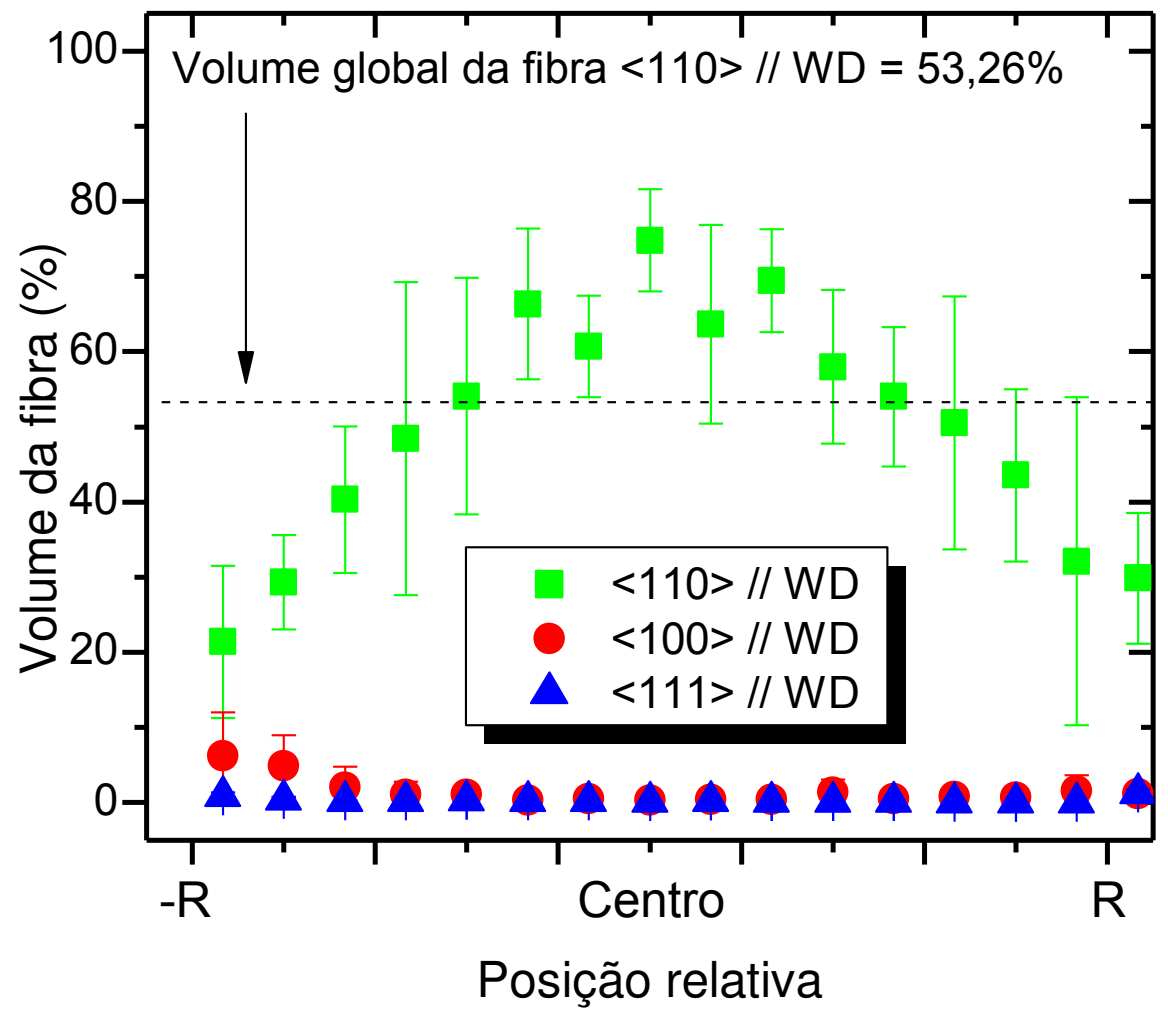

Fonte: Elaborada pelo autor. 
A Figura 7 mostra as desorientações médias de núcleos (KAM) ao longo da direção radial, considerando diferentes tamanhos de núcleos. A região central possui valor médio de KAM significativamente maior que a superfície para todos os tamanhos de núcleos. Como o valor médio de KAM é proporcional à deformação $(133,151)$, é possível concluir que a região central encontra-se mais deformada que a região periférica.

Foram criados mapas dos valores de KAM para cada pixel, considerando apenas os primeiros vizinhos. Esta escala facilita a visualização das desorientações locais (152). A Figura 8 mostra parte da seção longitudinal contendo a região próxima à superfície (lado esquerdo) e o centro do fio (lado direito). É possível observar que algumas lamelas próximas à superfície não são subdivididas em células enquanto que outras apresentam células equiaxiais limitadas por contornos de baixo ou de alto ângulo. A deformação é heterogeneamente distribuída entre as lamelas próximas à superfície e mais homogênea no centro.

Segundo Schwartz et al. (133), a análise de KAM representa apenas mudanças locais de desorientação, sendo a medida do gradiente de orientação mais adequada para a avaliação quantitativa da deformação plástica. Além disso, regiões com maior gradiente de orientação apresentam maior probabilidade para a nucleação de grãos durante a recristalização primária $(109,153)$.

O método proposto por Ørsund et al. (131) pode ser empregado nos dados de EBSD; entretanto, esta técnica apresenta algumas limitações pois ela "força" a condição em que o gradiente de orientação tende a zero quando a distância tendendo a zero. Ele também desconsidera outros tipos de variáveis experimentais encontradas nas medidas de desorientação utilizando EBSD $(132,133)$. Além disso, os resultados desta técnica são anisotrópicos. Os gradientes de orientação são mostrados na Figura 9 na forma de histogramas. Os resultados são dispersos, com grande frequência de gradientes menores que 10 $\% / \mu \mathrm{m}$ na região superficial e alta frequência de gradientes maiores que $10 \% \mathrm{~m}$ no centro. $O$ gradiente de orientação médio na superfície é de $10,1 \pm 1,6 \% / \mu \mathrm{m}$ ao passo que, na região central, ele é 13,5 $\pm 1,9 \% / \mu \mathrm{m}$. Estes valores são uma ordem de grandeza maiores que os encontrados em alumínio (131) e aço (152), ambos recuperados. 
O método de Kamaya (132) apresenta diversas vantagens no cálculo do gradiente de orientação, quando comparado ao método anterior. Os gradientes de orientação foram recalculados sobre a mesma área da Figura 8 e são mostrados na Figura 10. A desorientação média varia linearmente com a distância (132), sendo que os ajustes lineares apresentaram coeficiente de correlação $\left(R^{2}\right)$ próximos a 1. Os interceptos das retas com o eixo y representam o ruído de fundo da medida de orientação (132), sendo encontrado valor de $0,33 \pm 0,03^{\circ}$ para a superfície e $0,35 \pm 0,07^{\circ}$ para o centro. A inclinação da reta representa o gradiente de orientação em curta escala (centenas de nanômetros), sendo encontrado 4,07 $\pm 0,34 \%$ m na superfície e $6,30 \pm 0,83 \% / \mu \mathrm{m}$ no centro. Este resultado mostra que o gradiente de orientação no centro é maior do que na superfície. Os gradientes de orientação reportados para um aço austenítico laminado a frio com $\sim 10 \% \mathrm{em}$ redução são inferiores a $0.5 \%$ m (132). Esta diferença pode ser atribuída à elevada deformação imposta na trefilação, porém, deve-se também considerar os diferentes mecanismos de deformação destes metais. A diferença no gradiente de orientação implica em maior probabilidade de núcleos de recristalização primária se desenvolverem no centro (153).

O método de Kamaya também possibilita a criação de imagens do gradiente de orientação se o cálculo for empregado para cada pixel do mapa (132). A Figura 11 apresenta o mapa do gradiente de orientação da mesma seção apresentada na Figura 8. É possível visualizar a diferença no gradiente de orientação entre a superfície e o centro, muito embora algumas regiões próximas à superfície apresentam características similares às do centro. Para que ocorra a recuperação dinâmica sem o surgimento de núcleos de recristalização, é necessário que haja pequeno gradiente de orientação dentro das lamelas $(109,153)$. Taheri et al. (89) concluíram que a energia de ativação para recuperação dinâmica dos aços é alta e que as temperaturas desenvolvidas durante a trefilação a frio não seriam suficientes para iniciar o fenômeno. Entretanto, Kemp et al. (90) mostram que uma sequência de passes permitiria elevar a temperatura até níveis onde os mecanismos de recuperação seriam ativados. O gradiente de orientação no centro é maior que o da periferia, sendo que ambas regiões apresentam elevados gradientes. Isto indica que a recuperação dinâmica não foi o mecanismo causador das diferenças microestruturais e mecânicas verificadas entre o centro e a superfície. Entretanto, a Figura 11 evidencia algumas lamelas que apresentam 
gradiente de orientação menor que $1 \% / \mu \mathrm{m}$, o que mostra que algumas regiões seriam passíveis de recuperação dinâmica.

O aumento na deformação de policristais resulta no aumento da desorientação intragranular e do gradiente de orientação $(109,133,153)$, portanto, o centro apresenta maior dureza e maior densidade da fibra $<110>$ // WD devido às características heterogêneas da trefilação que conferiram ao material maior acúmulo de deformação nesta região.

Figura 7 - Desorientação média de núcleos ao longo da direção radial, medido na amostra na condição "como recebido". Foram considerados núcleos dos primeiros até os sétimos vizinhos.

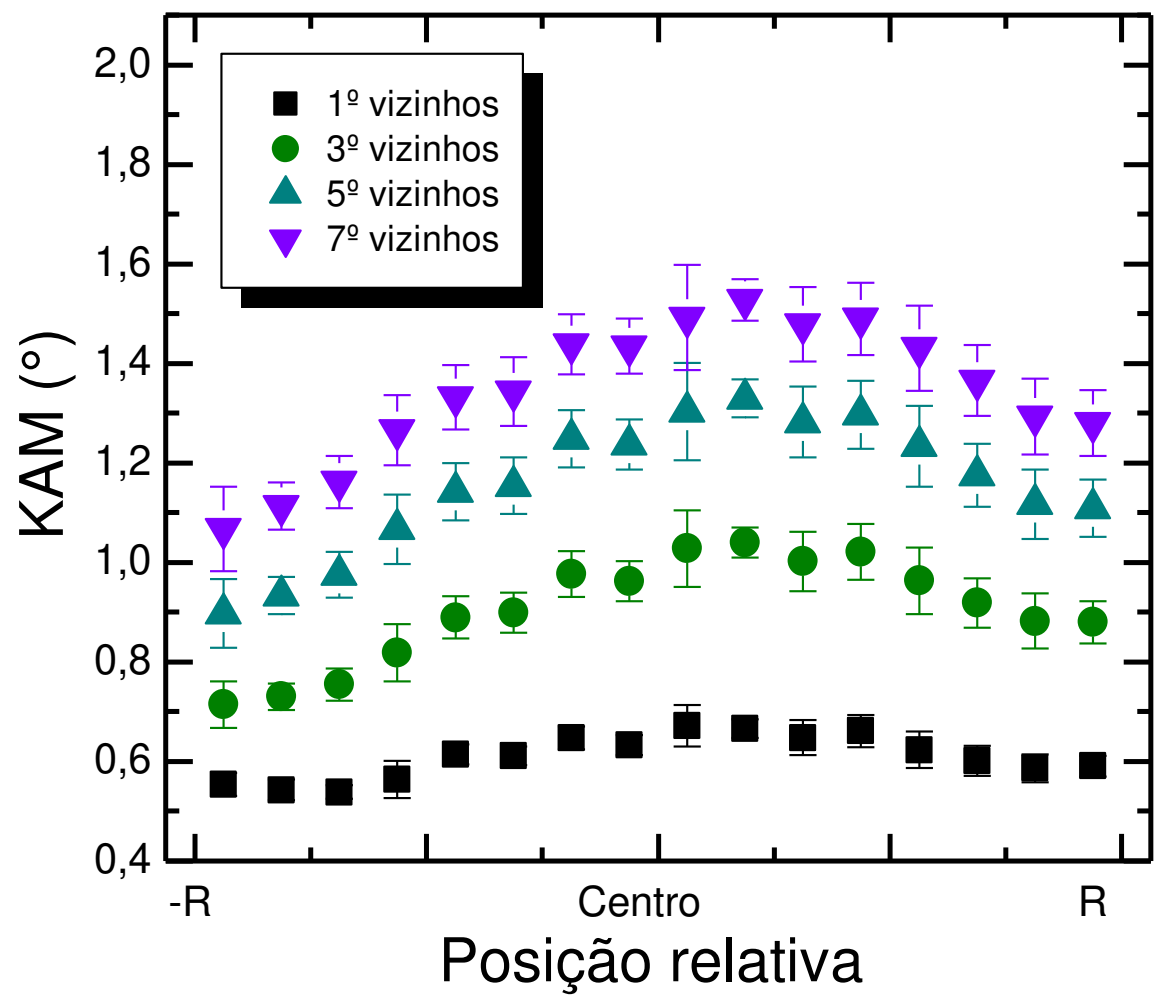

Fonte: Elaborada pelo autor.

Figura 8 - Mapa da KAM do fio na condição "como recebido" mostrando a região próxima à superfície até o centro.

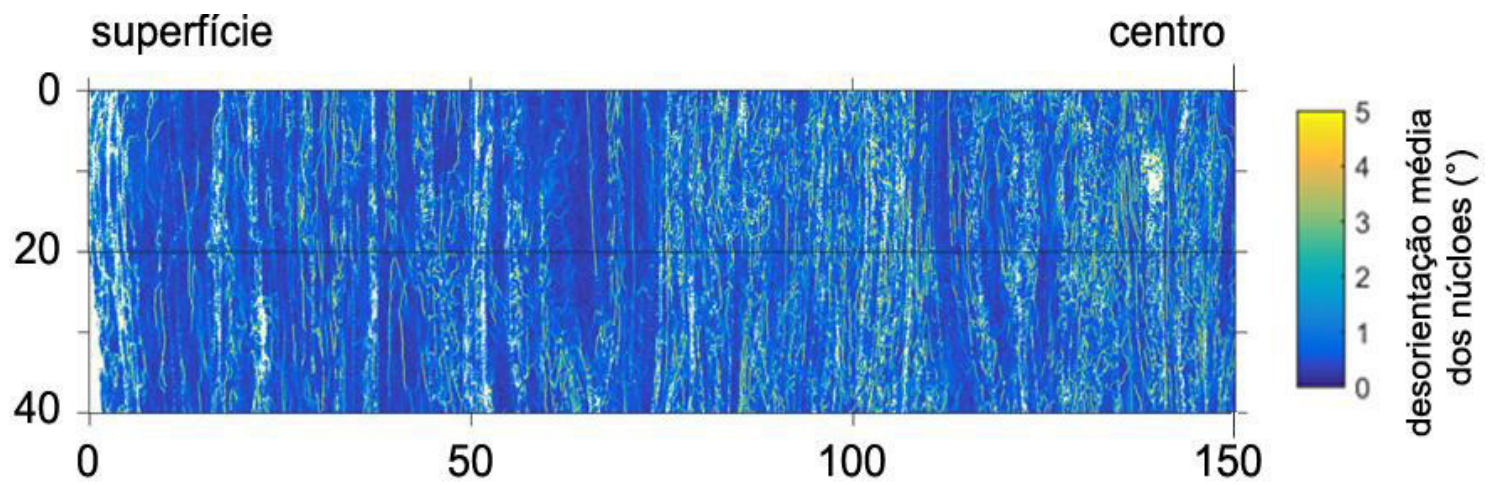

Fonte: Elaborada pelo autor. 
Figura 9 - Distribuição do gradiente de orientação em uma região próxima à superfície e no centro, para a amostra na condição "como recebido". Método de Ørsund et al. (131).

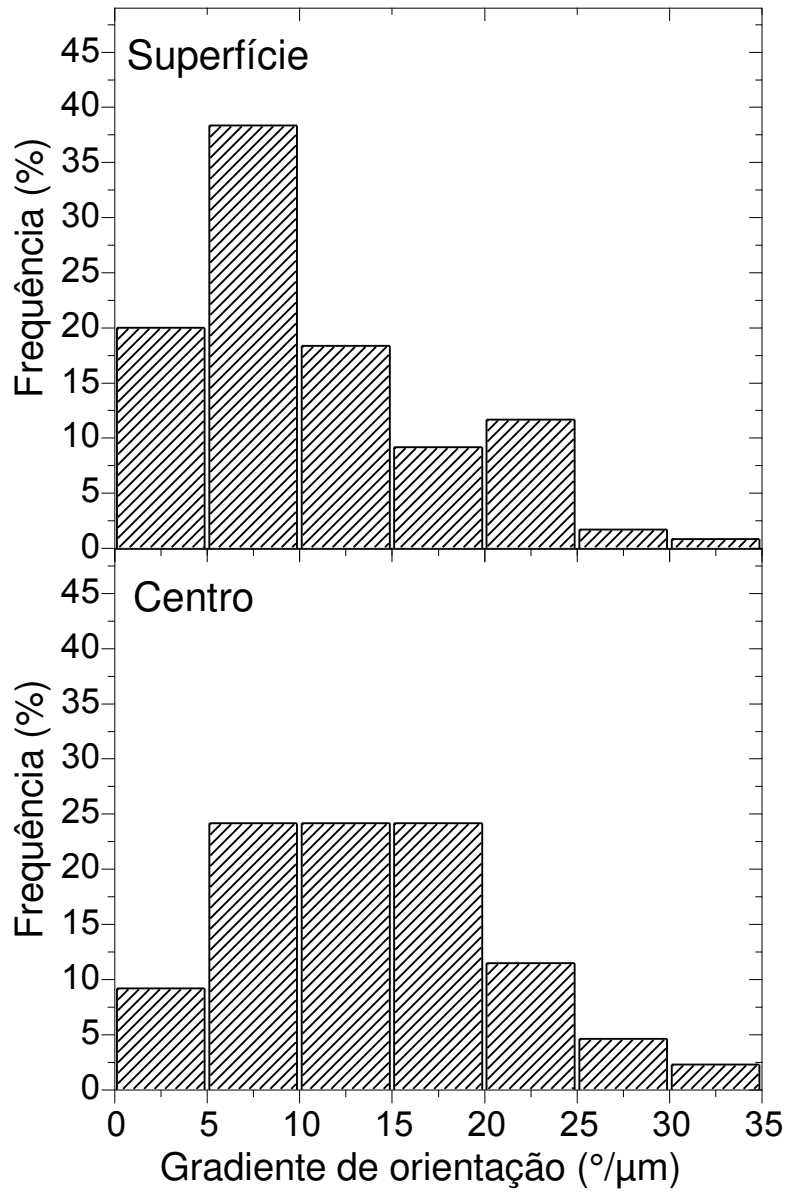

Fonte: Elaborada pelo autor.

Figura 10 - Desorientação média de núcleos (KAM) em função da distância. Os valores da linearização para os pontos da superfície e do centro acompanham o gráfico. A inclinação da curva representa o gradiente de orientação. Método de Kamaya (132).

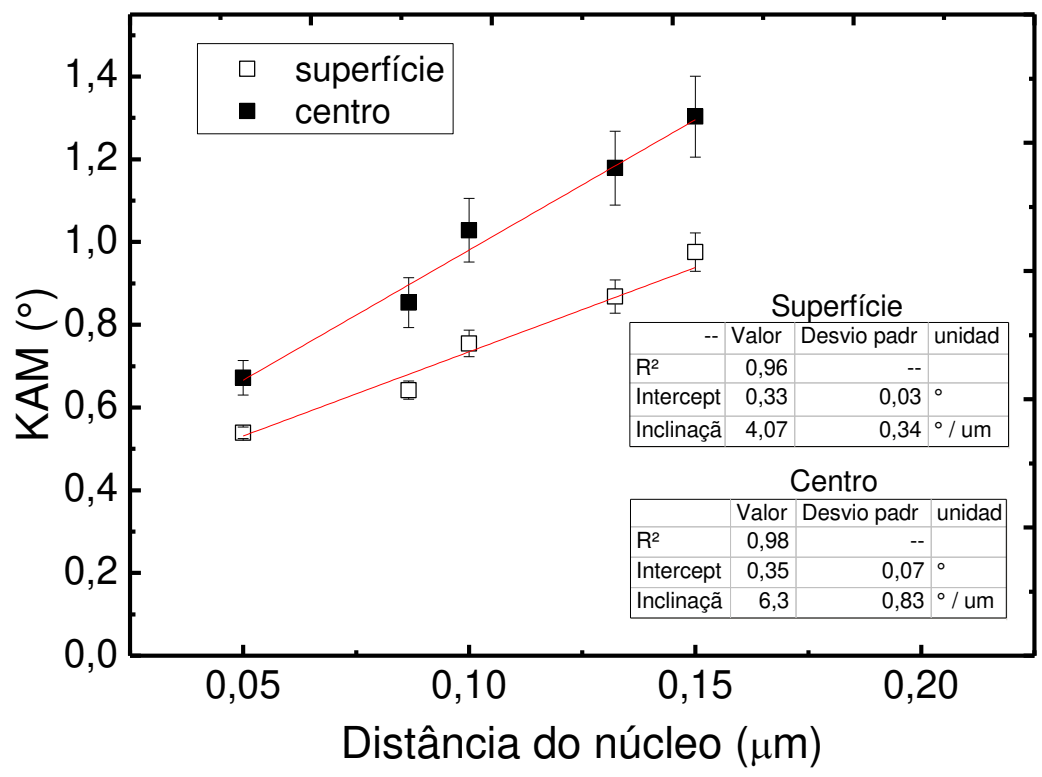

Fonte: Elaborada pelo autor. 
Figura 11 - Mapa de gradiente de orientação do fio na condição "como recebido" mostrando as diferenças de gradientes encontrados entre a superfície e o centro.

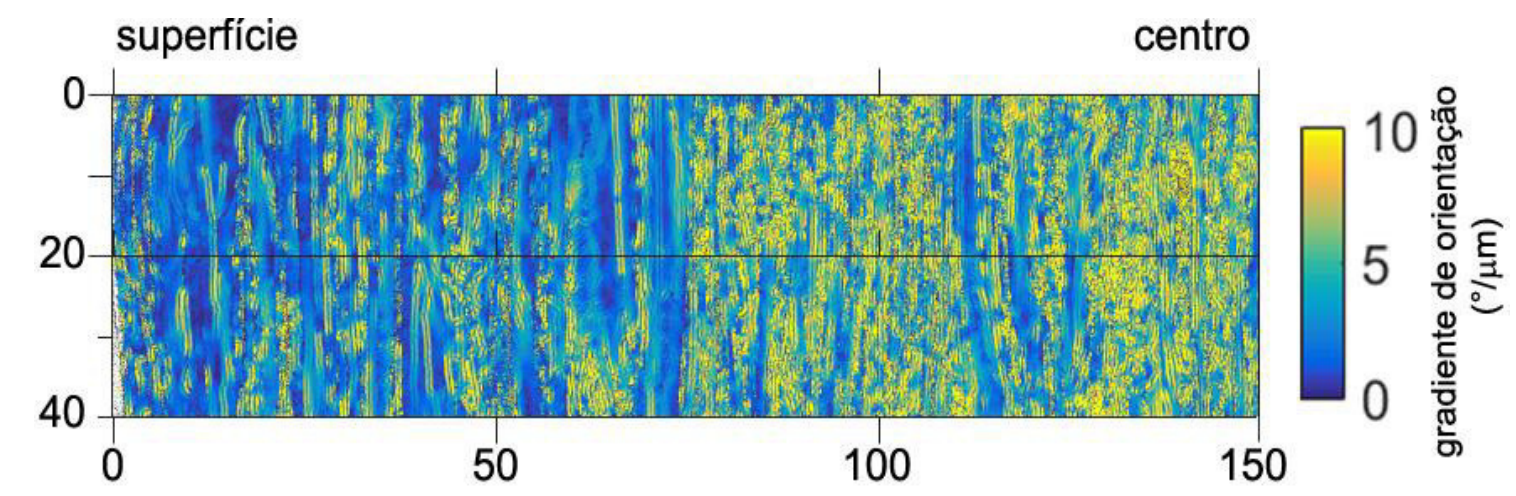

Fonte: Elaborada pelo autor.

\subsection{Recristalização primária}

A recristalização primária do fio ocorre de forma heterogênea, porém apenas em $550^{\circ} \mathrm{C}$ foi possível acompanhar esta característica com maiores detalhes (74). As imagens para diferentes tempos de recozimento em $550^{\circ} \mathrm{C}$ são mostradas na Figura 12. Após 5 min, é possível identificar alguns núcleos que se encontram dispersos na matriz, porém em maior quantidade no centro. Alguns destes núcleos são identificados por setas na Figura 12a. Após 15 min, os núcleos do centro estão em plena expansão enquanto que algumas regiões próximas à superfície apresentam menor frequência de núcleos. Após 30 min, a recristalização primária é quase completa no centro, enquanto que a superfície apresenta recristalização parcial com algumas regiões recuperadas. O encruamento heterogêneo da amostra na condição como recebida explica a heterogeneidade na recristalização primária, onde parte das lamelas da superfície não apresenta o encruamento mínimo para promover a recristalização, além de apresentar baixos gradientes de orientação que facilitam a recuperação.

O fio recozido em $650^{\circ} \mathrm{C}$ por 10 min representa a condição de recozimento de menor temperatura, no menor tempo, em que a recristalização primaria é completa. Nesta microestrutura, mostrada na Figura 2Figura 13, não há indícios de crescimento normal de grão (contornos levemente curvados e grãos poligonais). Foram analisadas 17587 seções de grãos, sendo encontrada área média de $102 \pm 1,2 \mu \mathrm{m}^{2}$ e uma distribuição de tamanhos que lembra uma curva 
log-normal. Além disso, os grãos são ligeiramente alongados em WD, com razão de aspecto de $1,54 \pm 0,38$.

Os grãos próximos à superfície são significativamente maiores que os do centro. Esta característica é evidente no gráfico da Figura 14. A mesma característica heterogênea foi encontrada na recristalização primária de fios de molibdênio puro (43), em chapas de um aço elétrico (40) e neste fio quando recozido em $850^{\circ} \mathrm{C}$ por 3 min (74). Os resultados mostrados na Figura 14 comprovam que a diferença entre o tamanho de grão da superfície e do centro provém de heterogeneidades na recristalização primária e não devido ao posterior crescimento (normal) de grão. A microestrutura desta amostra sugere maior potencial termodinâmico para crescimento de grão no centro, onde a área total de contornos por unidade de volume é maior.

A textura de recristalização é similar à encontrada na condição "como recebido", com presença predominante da fibra <1 $10>$ // WD. Entretanto, há um enfraquecimento na intensidade desta fibra, como mostra a Figura 15 que apresenta o volume das fibras ao longo da direção radial. $O$ enfraquecimento ocorre majoritariamente no centro. O mesmo comportamento é reportado em fios de molibdênio (43) e de ferro (95). Alguns grãos próximos à superfície estão orientados com $<100>$ aproximadamente paralelo à WD.

Os contornos identificados pelo software são majoritariamente de alto ângulo, sendo que apenas $3,8 \pm 0,3 \%$ do comprimento total de contornos apresentam desorientação menor ou igual a $10^{\circ}$. Estes contornos são mostrados em vermelho na Figura 16a. Os grãos com contornos de baixo ângulo apresentam elevada dispersão intragranular de orientações (GOS). Os grãos da Figura 16b são coloridos em relação a esta propriedade. Em busca de compreender a natureza destes grãos, foram analisados os perfis de desorientação intragranular. Nota-se pelo perfil ponto à origem que estes grãos acumulam até $15^{\circ}$ de desorientação de um lado ao outro do grão. Um exemplo é mostrado na Figura 17. Os picos no perfil ponto a ponto mostram desorientações maiores que $20^{\circ}$ entre pixels vizinhos. Isto demonstra que os diversos volumes que formam este grão são originários de diferentes núcleos de recristalização. A aglomeração de grãos de uma mesma orientação aumenta a frequência de contornos de baixo ângulo, o que pode influenciar a cinética de crescimento normal (23) e aumentar a probabilidade de crescimento anormal $(41,154)$. Os grãos orientados na fibra 
<110> // WD não possuem vantagem dimensional sobre os demais grãos (110), embora muitos deles já apresentem tamanhos consideráveis após a recristalização primária (Figura 17).

Nota-se que $54,4 \%$ dos grãos com contornos de baixo ângulo estão orientados a menos de $10^{\circ}$ da fibra $<110>/ /$ WD, como mostra a distribuição da Figura 18 que é calculada considerando apenas grãos com GOS maior que $2^{\circ}$. A frequência acumulada é maior que a global (34,9\%). Os grãos com GOS maior que $2^{\circ}$ representam $5,6 \pm 0,3 \%$ dos grãos amostrados. Isso sugere que os grãos com orientação <110> // WD estão distribuídos de forma heterogênea na microestrutura (97) e que eles apresentam certa contiguidade após a recristalização primária. 
Figura 12 - Imagens de microscopia ótica das amostras recozidas em $550^{\circ} \mathrm{C}$ por (a) 5 ; (b) 15 e (c) 30 min.
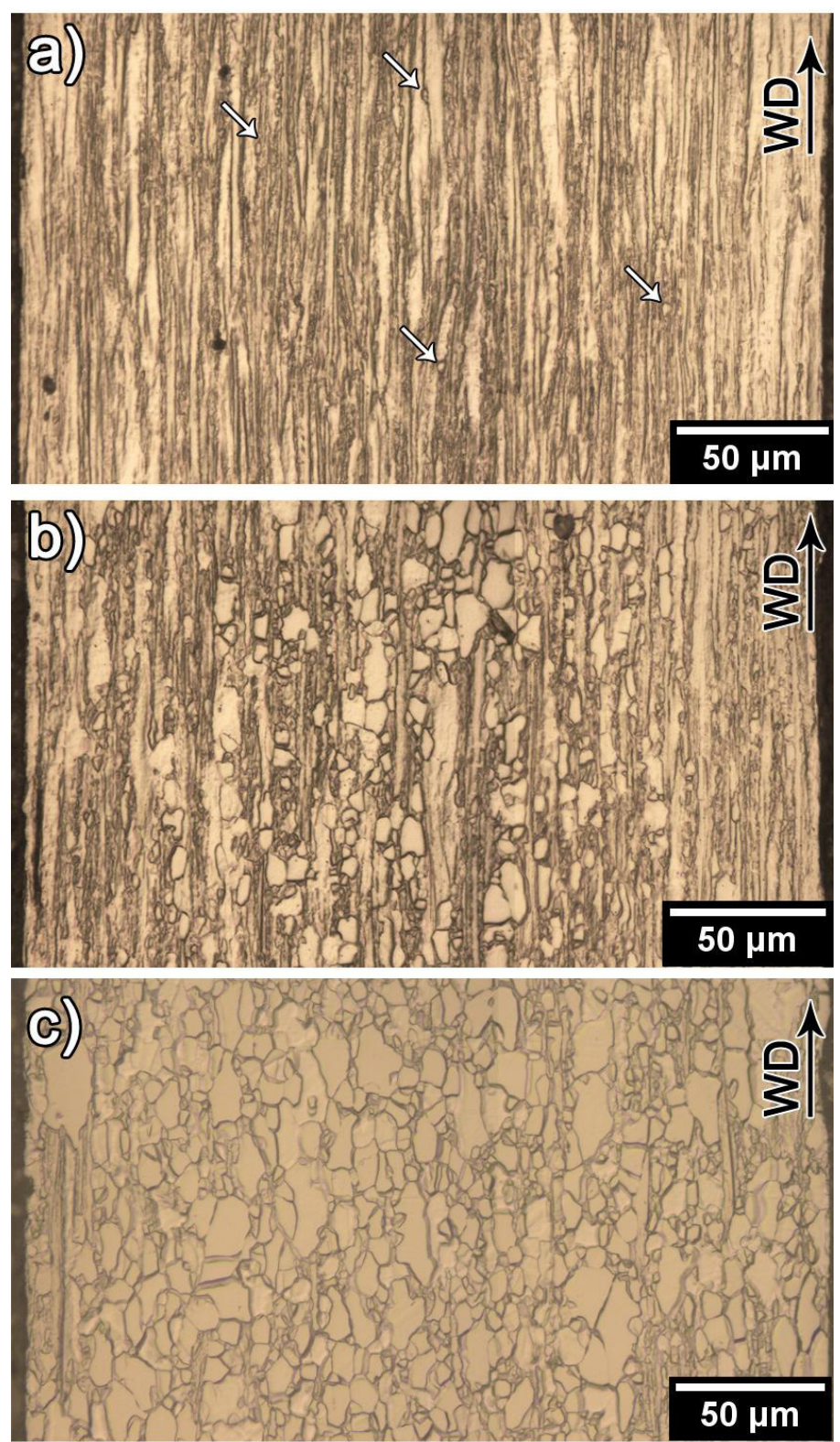

Fonte: Elaborada pelo autor.

Figura 13 - Mapa de orientações do fio recozido em $650^{\circ} \mathrm{C}$ por $10 \mathrm{~min}$. Escala da figura de polo inversa em relação a WD.

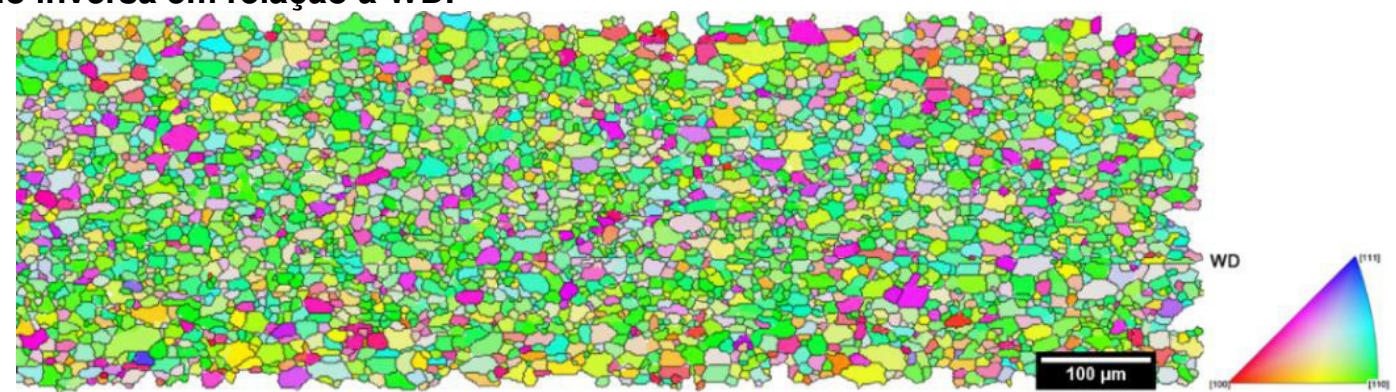

Fonte: Elaborada pelo autor. 
Figura 14 - Área média dos grãos ao longo da direção radial para o fio recozido em $650^{\circ} \mathrm{C}$ por $10 \mathrm{~min}$.

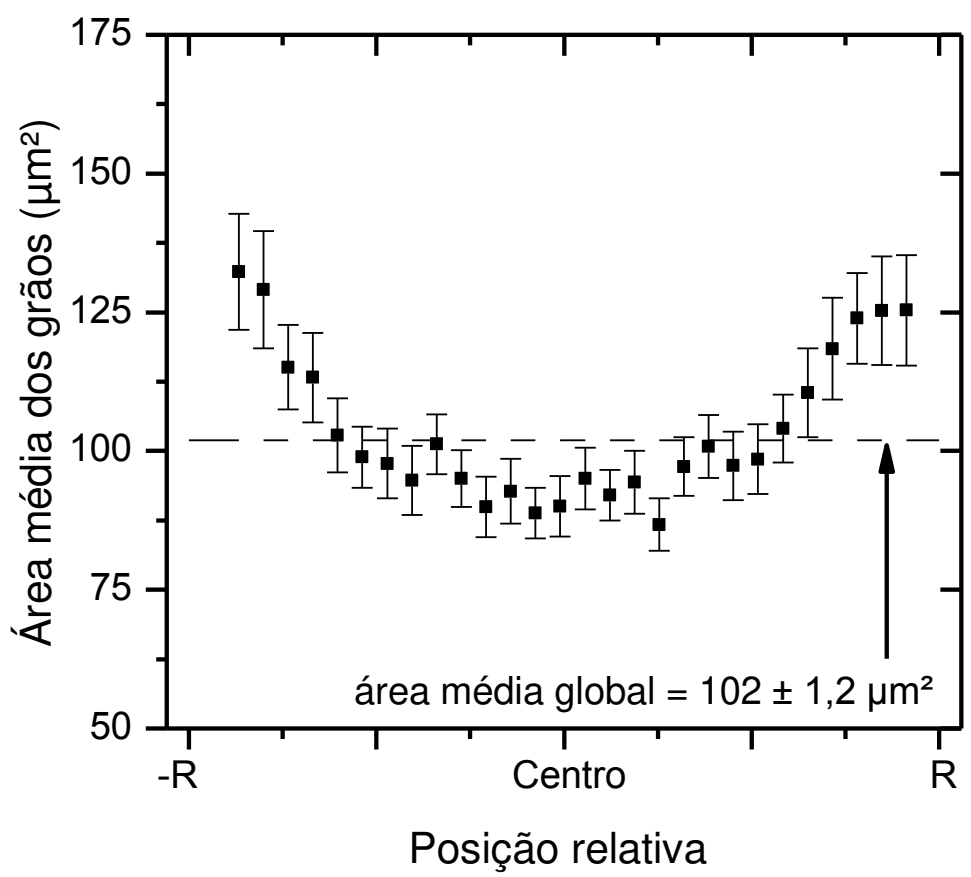

Fonte: Elaborada pelo autor.

Figura 15 - Volume das principais fibras ao longo da direção radial. Fio recozido em $650^{\circ} \mathrm{C}$ por $10 \mathrm{~min}$.

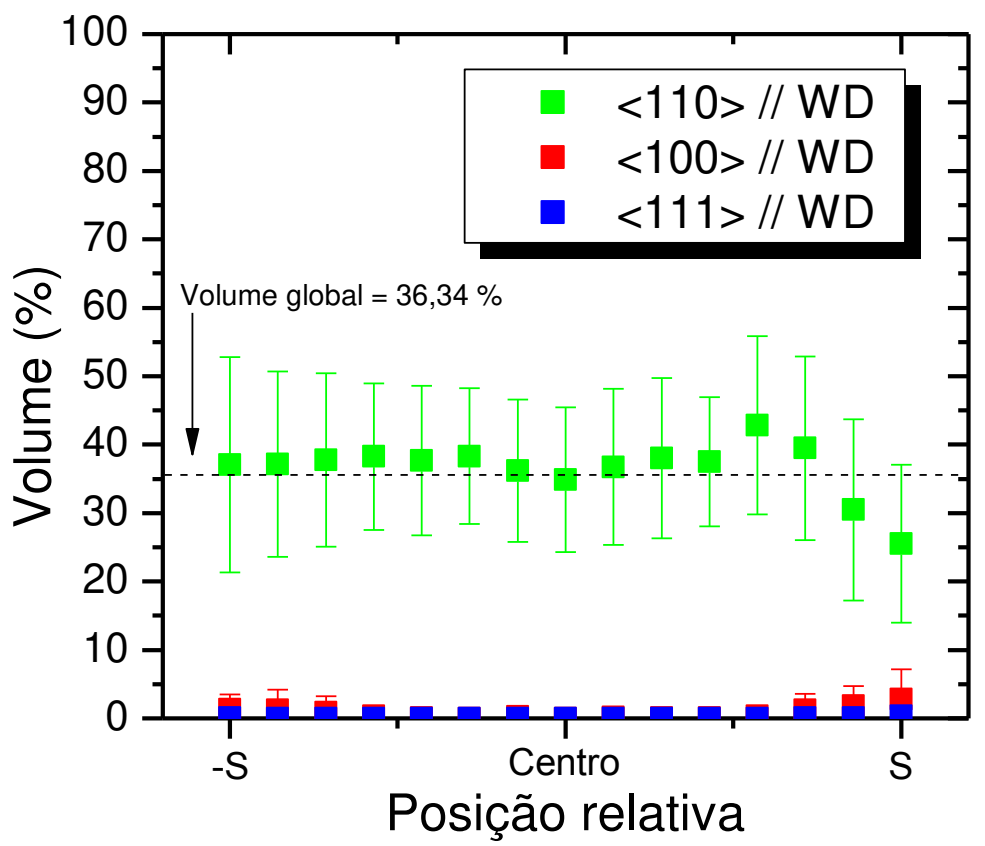

Fonte: Elaborada pelo autor. 
Figura 16 - Mapas da amostra recozida em $650^{\circ} \mathrm{C}$ por 10 min mostrando (a) os contornos de alto ângulo em preto e os de baixo ângulo em vermelho e (b) os grãos são coloridos conforme os valores de dispersão intragranular de orientações (GOS).

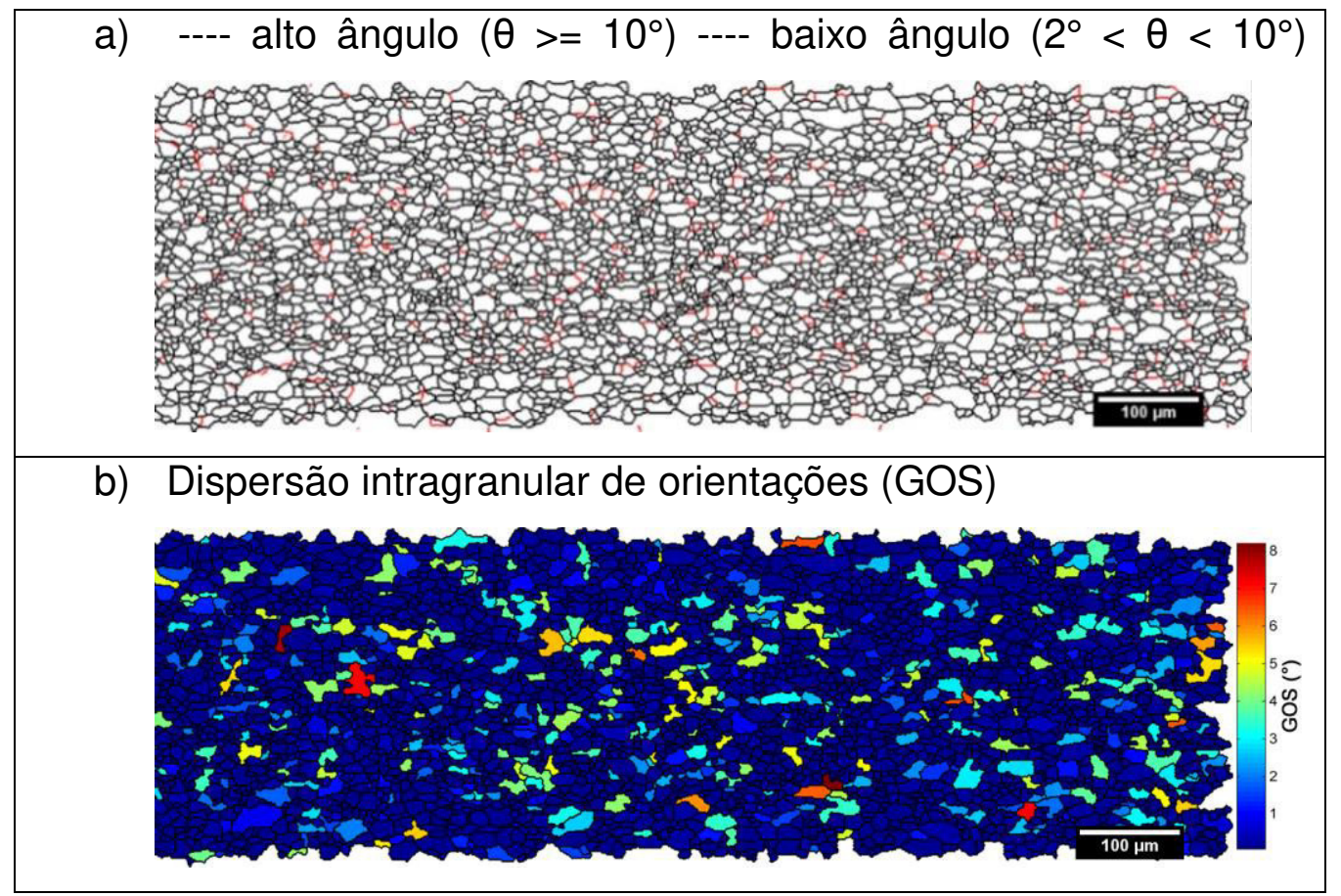

Fonte: Elaborada pelo autor.

Figura 17 - Perfis de desorientação ponto à origem e ponto a ponto, calculados dentro de um dos grãos que apresenta GOS $>2$. Fio recozido em $650^{\circ} \mathrm{C}$ por $10 \mathrm{~min}$.
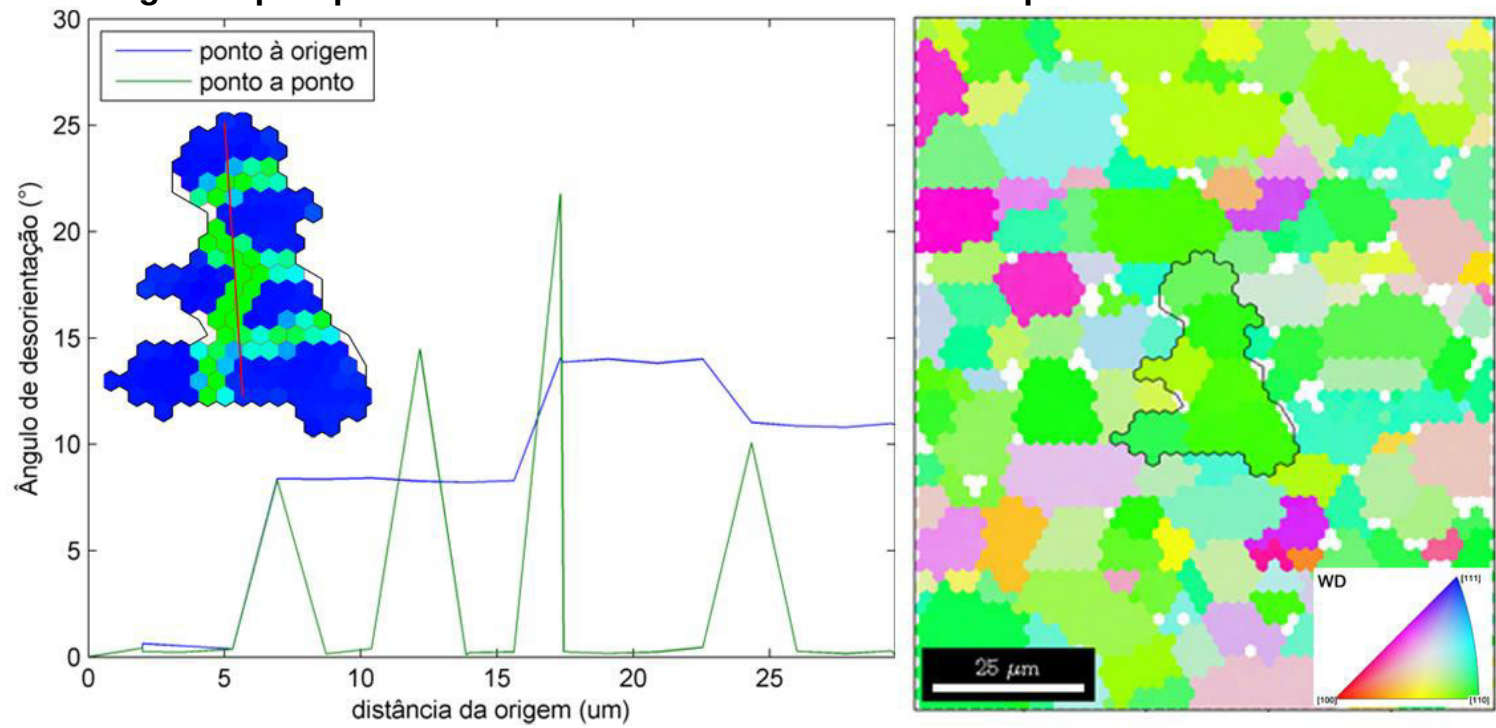

Fonte: Elaborada pelo autor. 
Figura 18 - Distribuição da desorientação entre as orientações médias dos grãos com GOS $>2^{\circ}$ e a fibra $<110>/ /$ WD, medida em um fio recozido em $650^{\circ} \mathrm{C}$ por $10 \mathrm{~min}$.

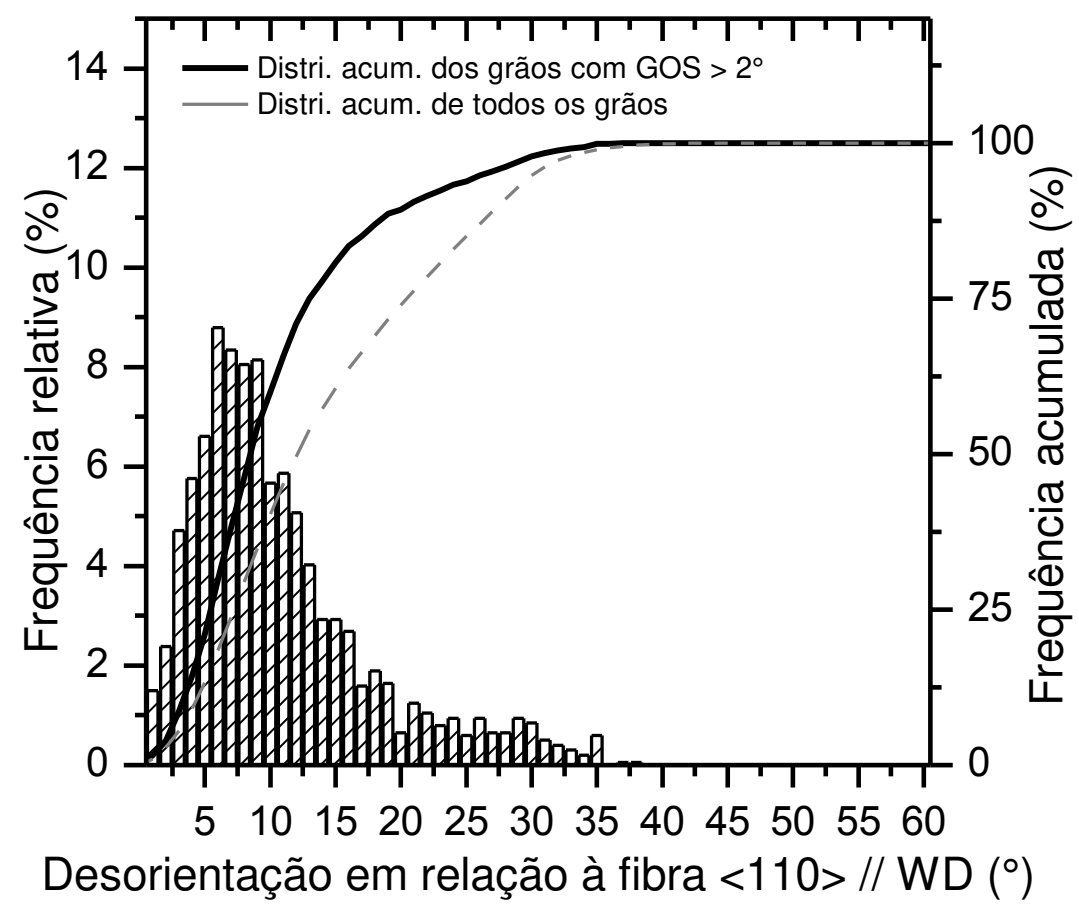

Fonte: Elaborada pelo autor.

A frequência de contornos classificados como CSL é mostrada na Figura 19. A amostra apresenta maior frequência de contornos do tipo $\Sigma 1$ (baixo ângulo) e $\sum 3$. Os contornos $\sum 3$ não são facetados como as maclas e são reportados como incoerentes (155). Também foram encontradas frações residuais de contornos dos tipos $\sum 7, \sum 9$ e $\Sigma 11$. Quando se analisa orientação dos grãos que formam estes contornos, nota-se uma concentração de grãos orientados em torno da fibra $<110>$ //WD para as relações mais frequentes $(\Sigma 1, \Sigma 3, \Sigma 11, \Sigma 9$ e $\Sigma 17 \mathrm{~b})$. Estes contornos estão mais concentrados no centro devido ao menor tamanho de grão neste local. Esta informação é comprovada pela distribuição dos diferentes pontos triplos ao longo da direção radial, onde os tipos mais frequentes se localizam no centro, logo após o início do recozimento (3 min). 
Figura 19 - Frequência de contornos que apresentam relação CSL assumindo o critério de Brandon. Fio recozido em $650^{\circ} \mathrm{C}$ por $10 \mathrm{~min}$.

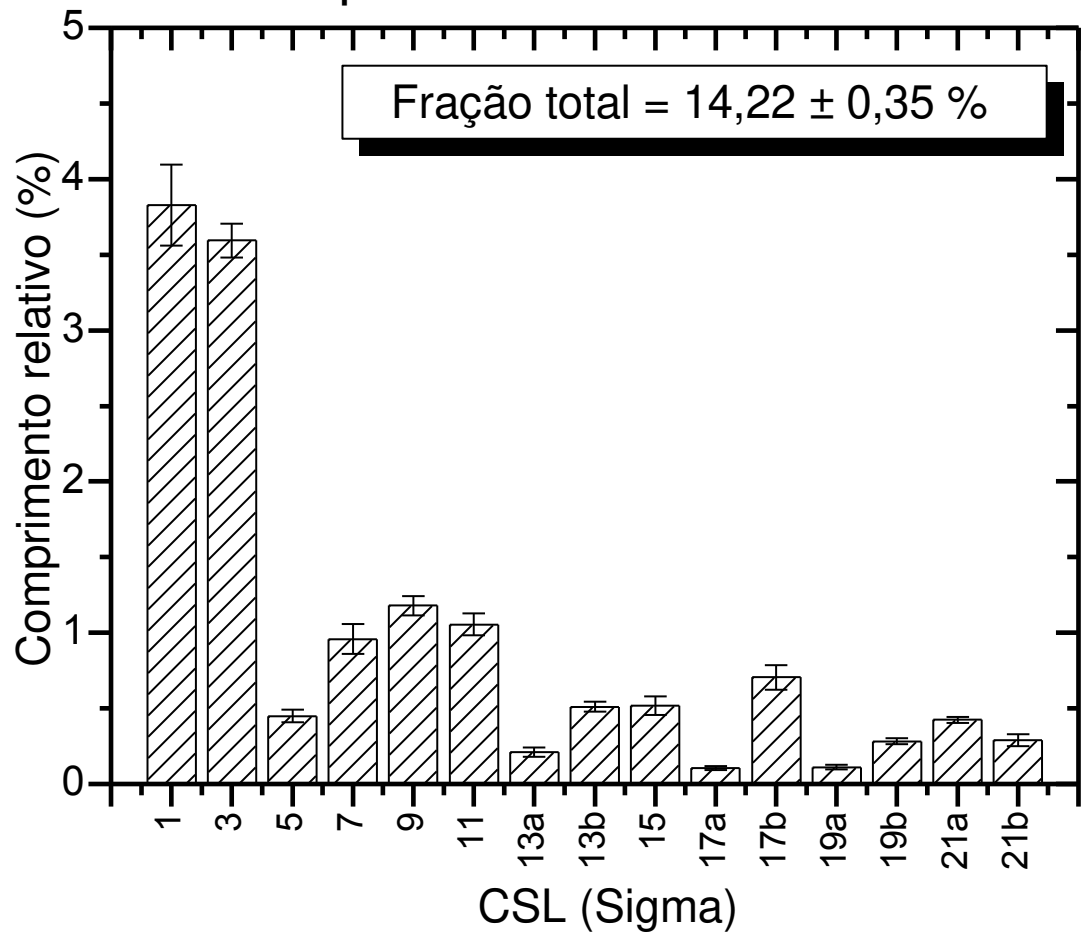

Fonte: Elaborada pelo autor.

A interpretação da microestrutura após a recristalização primária é crucial para o entendimento do posterior crescimento de grão. Uma microestrutura com distribuição ampla do tamanho de grão aumenta a probabilidade de crescimento anormal de grão $(41,154)$. A recristalização primária estreita a distribuição de tamanho de grão quanto maior é a deformação prévia imposta (50). Apenas com estas duas informações e, baseando-se nos resultados anteriores, é esperada maior probabilidade para o crescimento anormal na região próxima à superfície, pois esta apresenta maior dispersão do tamanho de grão (interpretar as barras de erros da Figura 14). Entretanto, o centro do fio apresenta maior potencial termodinâmico para o crescimento de grão, uma vez que o tamanho médio de grão no centro é significativamente menor que da superfície. Qualquer interpretação do crescimento de grão baseado na microestrutura estática após a recristalização primária pode ser equivocada, uma vez que o crescimento de grão ocorre de forma dinâmica (65) e depende fortemente da distribuição de partículas dispersas na matriz. 


\subsection{Crescimento normal de grão em $850^{\circ} \mathrm{C}$}

A Figura 20 mostra os mapas de orientação das amostras recozidas por até $4 \mathrm{~h}$. Nota-se um ligeiro crescimento normal de grão que, embora sutil, ocorre de forma heterogênea na seção radial e é suficiente para diminuir $20,4 \%$ do comprimento de contornos por unidade de área. A razão de aspecto apresentada pelos grãos mantém-se constante durante este fenômeno e é próxima àquela observada na amostra após recristalização primária ( 1,5 vezes).

A Figura 21 apresenta a área média dos grãos ao longo da direção radial para as amostras recozidas por até $4 \mathrm{~h}$. Na amostra recozida por apenas $3 \mathrm{~min}$, os grãos da superfície possuem área média significativamente maior que os do centro. A partir de $1 \mathrm{~h}$, os grãos do centro adquirem tamanho similar aos da superfície, o que indica diferenças nas velocidades de crescimento. Após 4 h, o centro possui grãos com área média maior que os da superfície. Os grãos da superfície sofrem poucas variações dimensionais durante o recozimento e possuem área média similar à encontrada após a recristalização primária. 0 tamanho de grão heterogêneo após a recristalização primária pode ser a razão para a diferença nas velocidades de crescimento observadas, pois o menor tamanho de grão no centro significa um maior potencial termodinâmico para 0 crescimento de grão nesta região (Figura 14).

Outra variável que pode influenciar o crescimento dos grãos é a presença de textura cristalográfica. Quando analisadas as orientações encontradas no fio recozido por $4 \mathrm{~h}$, observa-se que a textura é similar à encontrada após a recristalização primária, com diferença apenas nas intensidades. Após 4 h, o volume encontrado foi de 47,4 $\pm 2,2 \%$. Este aumento está relacionado ao crescimento normal de grão e, portanto, ele ocorre no centro. A fibra $<100>/ / W D$ continua presente na região periférica do fio, porém em pequena intensidade. Não houve indícios de heterogeneidades de textura após a recristalização primária. Além disso, a mudança de textura do material recozido em $850^{\circ} \mathrm{C}$ ocorre principalmente no centro, região onde o crescimento normal se mostra mais ativo.

Quando se analisa a frequência dos diferentes tipos de contornos presentes, elas são similares às verificadas no material após recristalização primária (Figura 19). Entretanto, há um significativo aumento na fração de contornos de baixo ângulo e contornos com relação CSL $\Sigma 3$ na amostra recozida por 4 h. Este aumento acompanha 0 aumento na frequência de grãos com altos valores de 
dispersão intragranular de orientações $\left(\mathrm{GOS}>2^{\circ}\right)$. Estes grãos representam 7,5 $\pm 0,8 \%$ dos grãos encontrados na amostra recozida por $4 \mathrm{~h}$. A Figura 22 mostra o maior grão encontrado nesta amostra, o qual é formado por diversos grãos com orientações similares que cresceram até se tocarem. Como apontado por diversos autores $(48,60,73,121)$, é difícil relacionar a mesotextura com o fenômeno de crescimento anormal de grão. Na presente Tese, propõe-se que o crescimento normal de grão aumenta a dispersão do tamanho de grão no centro, aumentando a probabilidade de o crescimento anormal de grão acontecer nesta região.

Foi observada também uma tendência dos grãos com orientação pertencente a fibra $<110>/ / W D$ apresentarem vantagem dimensional/topológica em relação aos grãos de outras orientações. Esta característica não foi percebida na amostra recozida em $650^{\circ} \mathrm{C}$ por $10 \mathrm{~min}$, entretanto ela é evidente nas amostras recozidas em $850^{\circ} \mathrm{C}$. Nesta temperatura, as amostras apresentam indícios de crescimento normal de grão logo no início do recozimento. A Figura 23 mostra similaridade na distribuição normalizada do tamanho dos grãos orientados na fibra $<110>$ // WD e na dos grãos de outras orientações para a amostra recozida em $650^{\circ} \mathrm{C}$ por $10 \mathrm{~min}$, sendo que ambas distribuições se encontram deslocadas para a direita. As amostras recozidas em $850^{\circ} \mathrm{C}$ por $3 \mathrm{~min}, 5 \mathrm{~min}$ e $1 \mathrm{~h}$ apresentam distribuições normalizadas menos deslocadas. A distribuição dos grãos com orientações pertencentes à fibra é mais dispersa que a dos grãos com outras orientações. Isto significa que a frequência de grãos grandes e com orientação pertencente à fibra <110>/WD é maior, em comparação com a de grãos grandes com outras orientações. Esta característica é ainda mais marcante na amostra recozida em $850^{\circ} \mathrm{C}$ por $4 \mathrm{~h}$. Como há uma relação linear entre o tamanho do grão e a sua classe topológica (156), a distribuição do número de vizinhos dos grãos pertencentes a fibra $<110>/ / W D$ também é mais dispersa após o recozimento em $850^{\circ} \mathrm{C}$ por $4 \mathrm{~h}$, como mostra a Figura 24 . As inserções trazem as ampliações nas caudas das distribuições.

A Figura 25 mostra a frequência de grãos ao longo da direção radial que apresentam mais de 12 vizinhos e que possuem tamanho normalizado maior que 1. Os valores mínimos foram escolhidos arbitrariamente, considerando os valores da amostra após a recristalização primária. Baseado na teoria topológica para o crescimento anormal de grão (17), ambas as frequências são diretamente proporcionais à probabilidade para o crescimento anormal de grão. Aqui, assume- 
se uma frequência mínima para que o crescimento anormal de grão seja possível, sendo sugerido 1,5\% para o caso do número de vizinhos e 1\% para o tamanho normalizado (valores arbitrários escolhidos via análise gráfica). Fica claro que as distribuições apresentam maiores frequências de grãos grandes e com muitos vizinhos no centro da amostra recozida em $850^{\circ} \mathrm{C}$ por $4 \mathrm{~h}$. As Figura $25 \mathrm{c}$ e d mostram a frequência de grãos grandes e com orientação pertencente à fibra $<110>$ // WD ao longo da direção radial. Já as Figura 25e e f mostram a frequência espacial de grãos grandes de outras orientações. Estes últimos gráficos mostram que estes grãos maiores apresentam orientação próxima à fibra <110> // WD. Os valores de contiguidade dos grãos da fibra <110> // WD são mostrados na Figura 26. Isso comprova que estes grãos desenvolvem vantagem dimensional/topológica pelo aumento do seu contato mútuo durante o crescimento normal e não pela maior velocidade de crescimento apresentada por alguns contornos, como muitas vezes sugerido na literatura $(80,117,157)$.

Figura 20 - Mapas de orientação para os fios recozidos em $850^{\circ} \mathrm{C}$ em diferentes tempos mostrando o crescimento normal de grão. A coloração segue a escala da figura de polo inversa em relação a WD.

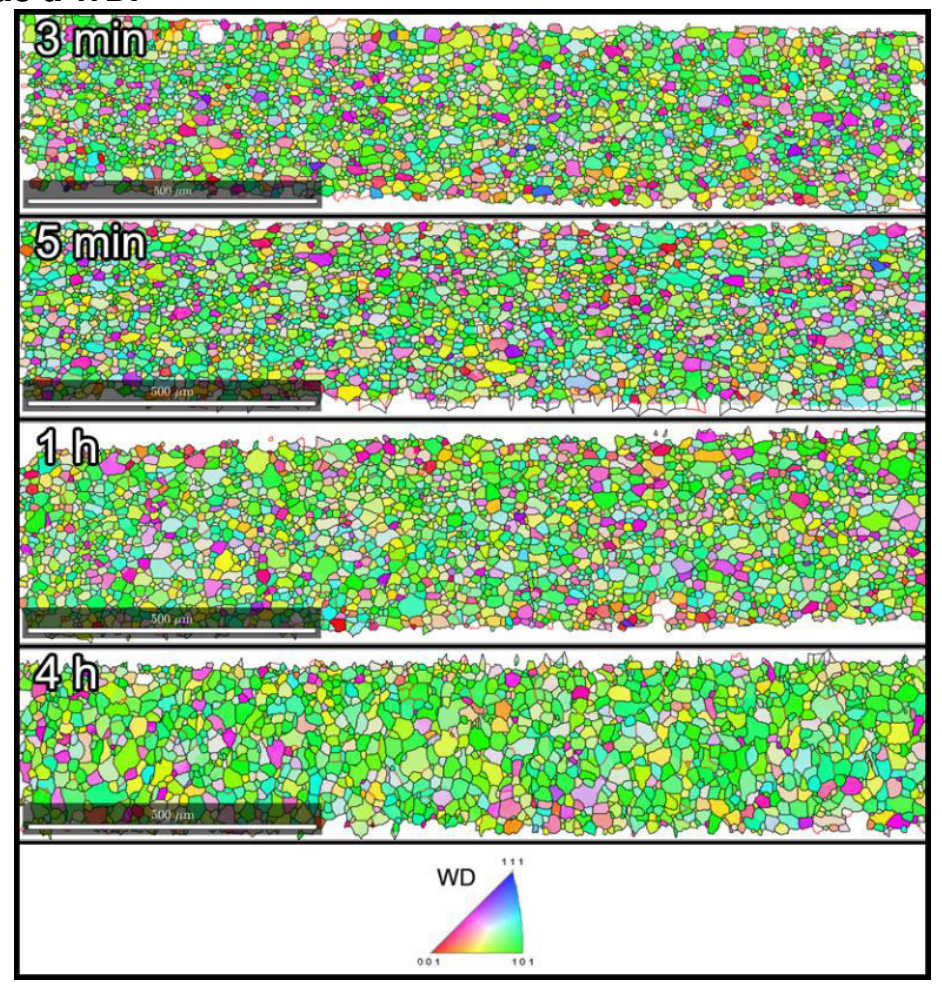

Fonte: Elaborada pelo autor. 
Figura 21 - Área média dos grãos em função da posição radial no fio recozido em $850^{\circ} \mathrm{C}$ por diferentes tempos. As barras de erro são os intervalos de confiança de $95 \%$.

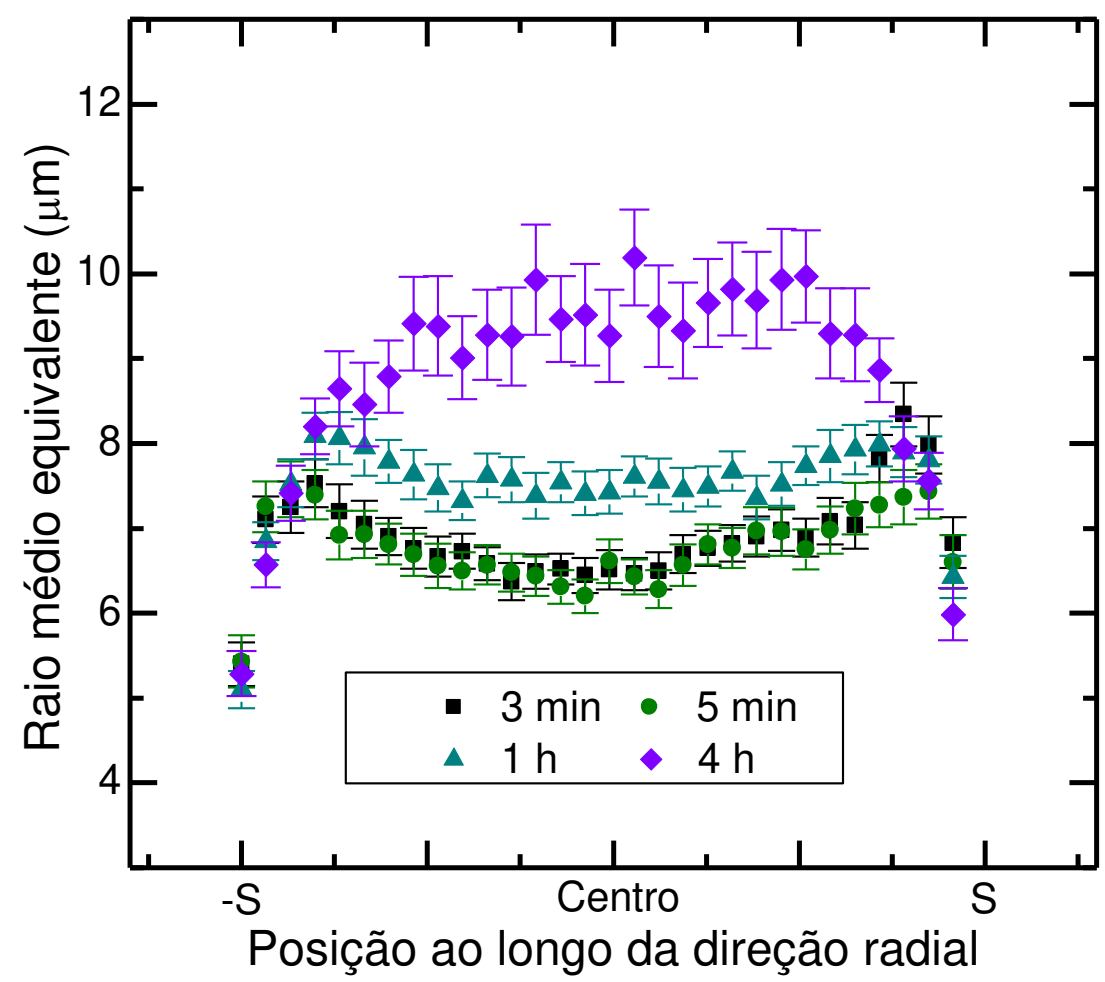

Fonte: Elaborada pelo autor.

Figura 22 - Mapas de orientação do maior grão encontrado na amostra recozida por $4 \mathrm{~h}$. 0 grão é colorido com relação a direção de trefilação (WD) e da direção radial (RD). As figuras de polo apresentam as orientações discretas dentro do grão.

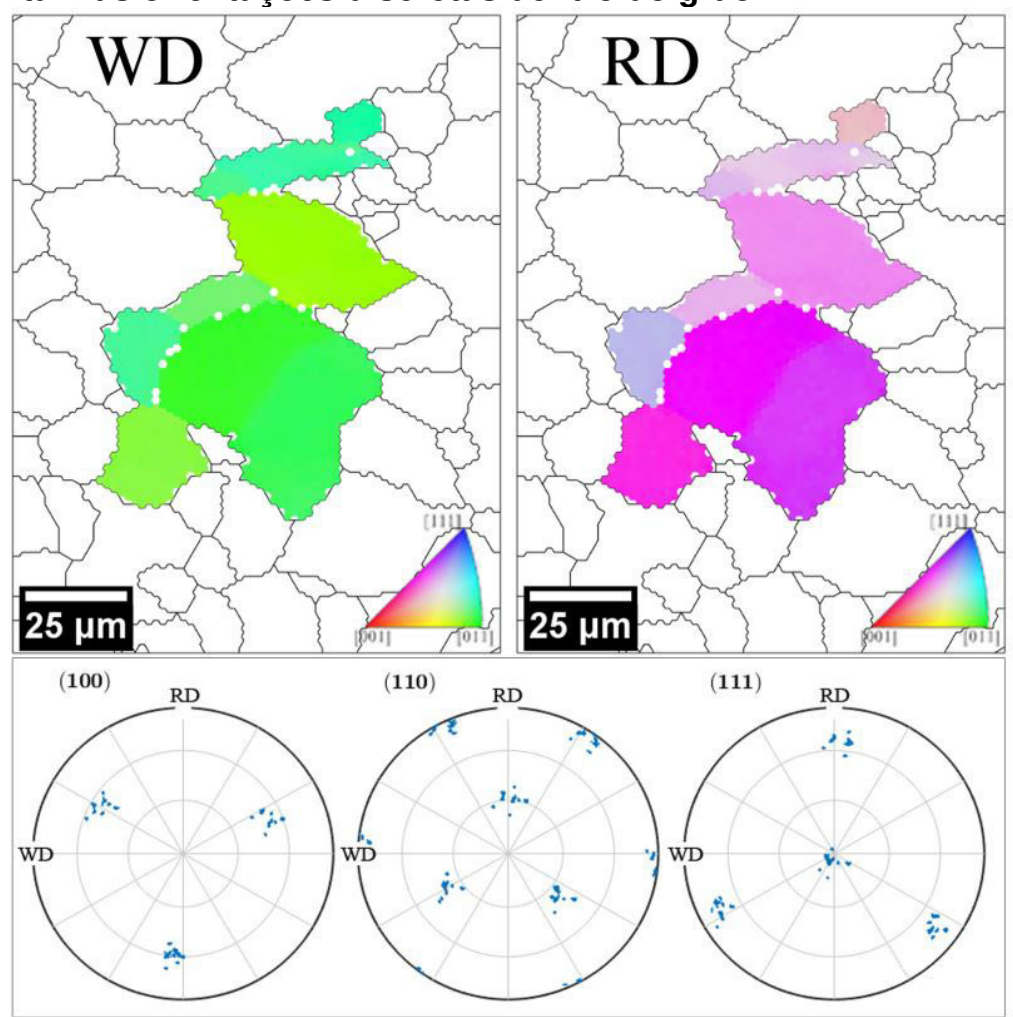

Fonte: Elaborada pelo autor. 
Figura 23 - Distribuições normalizadas para diversas amostras do fio de ferro. Os gráficos apresentam as distribuições dos grãos com orientação pertencente a fibra <110> // WD e também dos grãos com outras orientações.
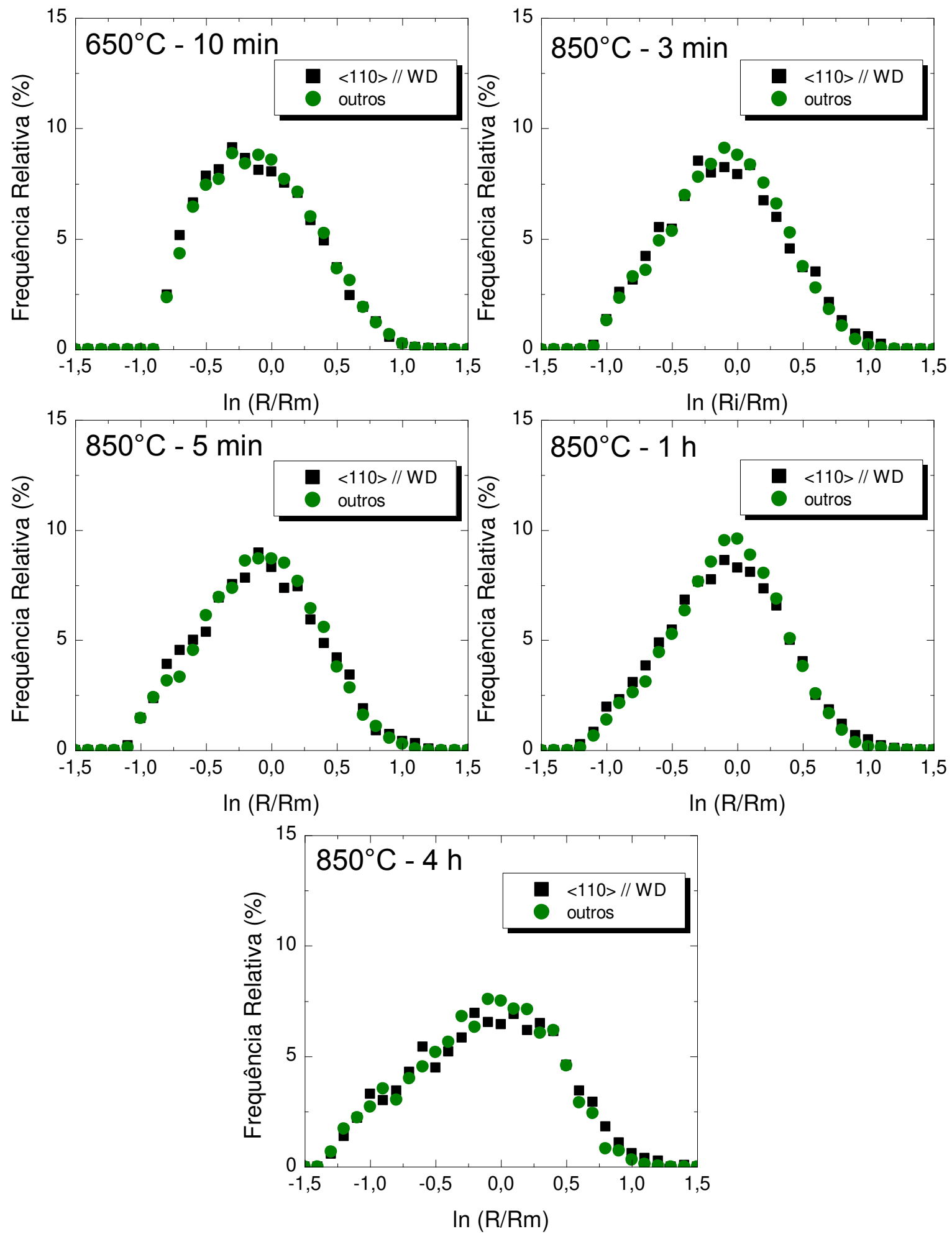

Fonte: Elaborada pelo autor. 
Figura 24 - Distribuições de número de vizinhos para diversas amostras do fio de ferro. Os gráficos apresentam as distribuições dos grãos com orientação pertencente a fibra $<110>/ /$ WD e também dos grãos com outras orientações.
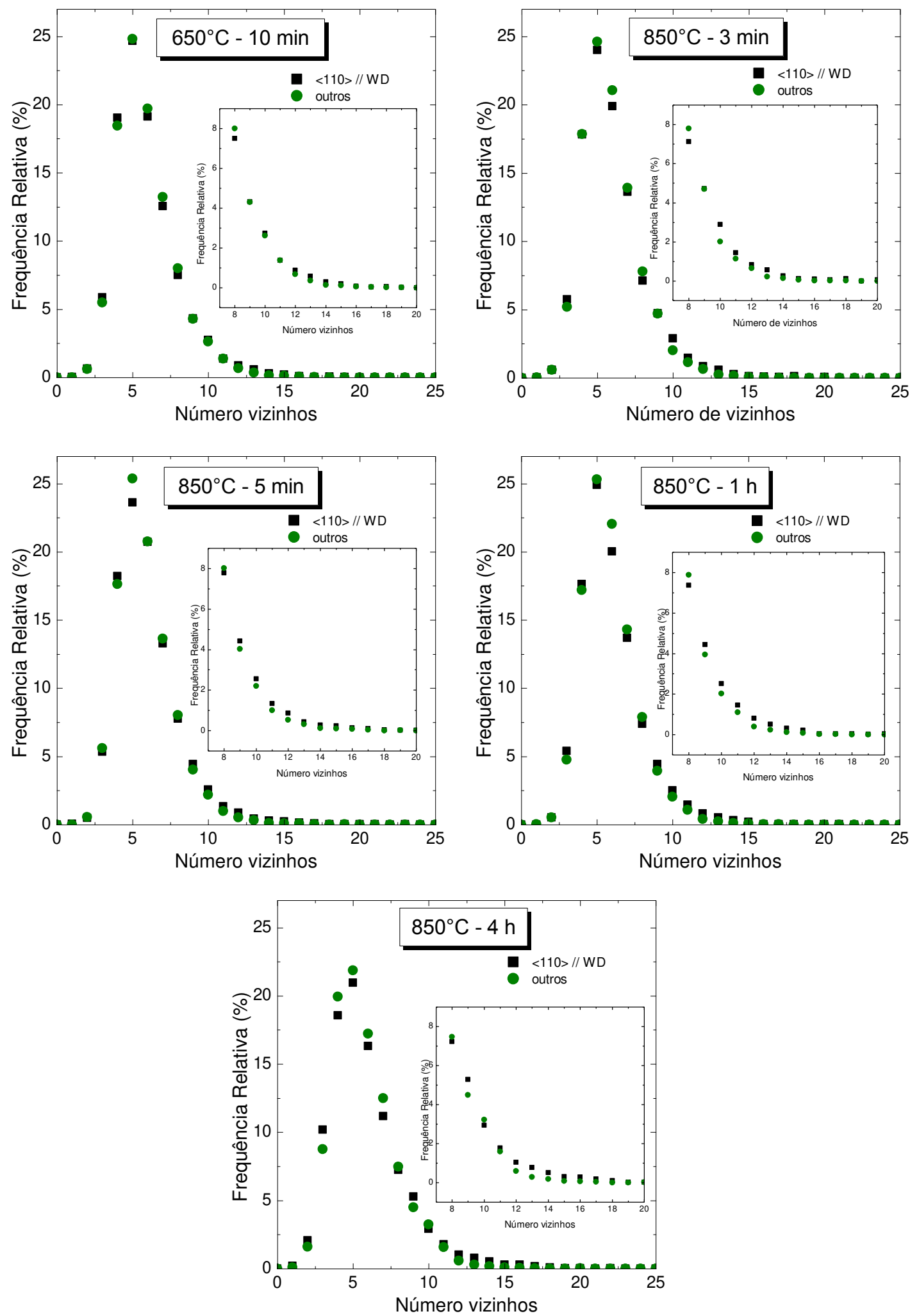

Fonte: Elaborada pelo autor. 
Figura 25 - Frequência de grãos com (a, c, e) mais de 12 vizinhos e com (b, d, f) tamanho normalizado maior que 1 para grãos ao longo da direção radial. Os dados são das amostras recozidas em $850^{\circ} \mathrm{C}$ por diversos tempos e os gráficos são referentes a $(a, b)$ todos os grãos; (c, d) grãos com orientações pertencentes a fibra <110> // WD e (e, f) grãos com outras orientações.
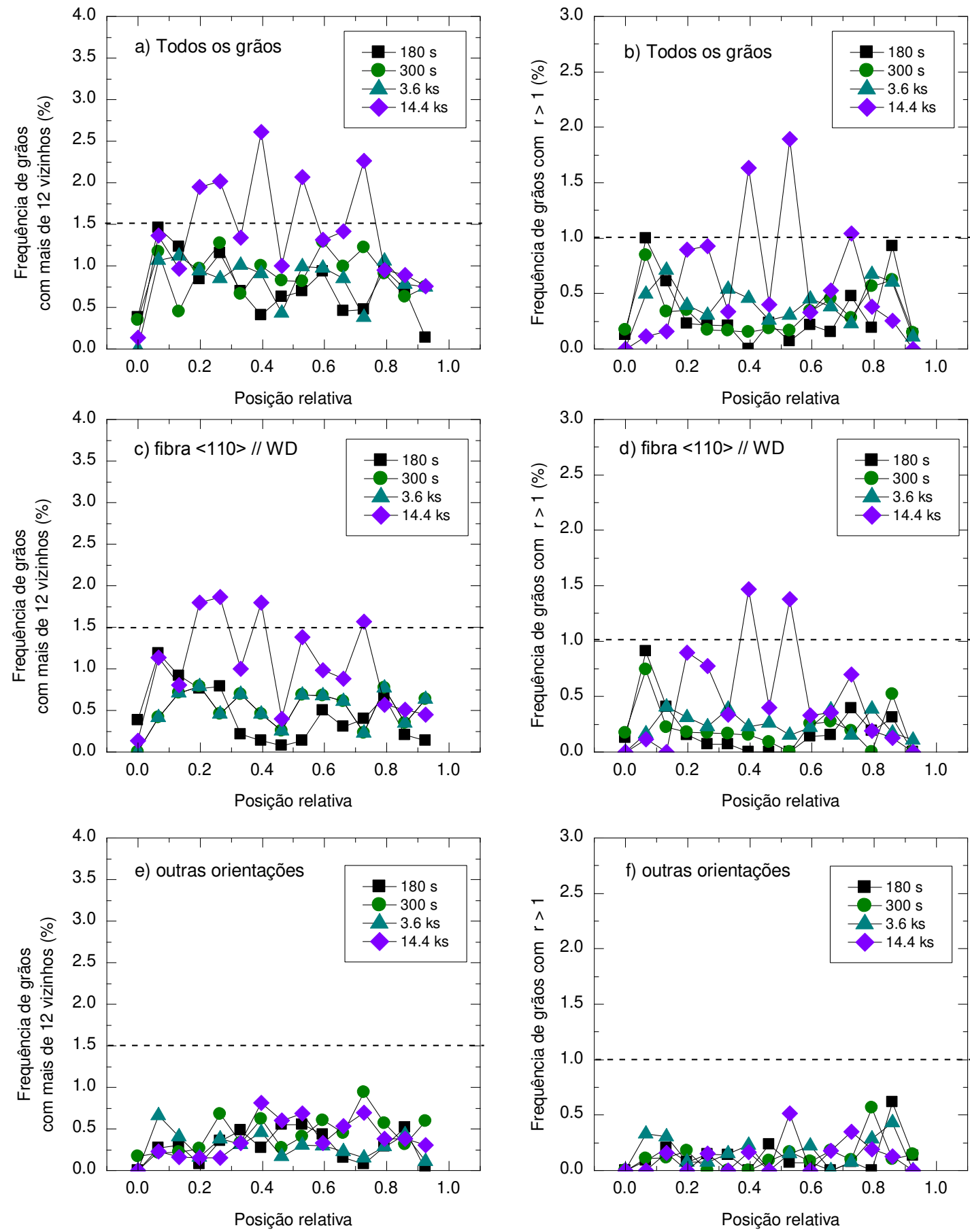

Fonte: Elaborada pelo autor. 
Figura 26 - Contiguidade dos grãos com orientação pertencente à fibra $<110>/ /$ WD para as amostras recozidas em $850^{\circ} \mathrm{C}$ por diferentes tempos.

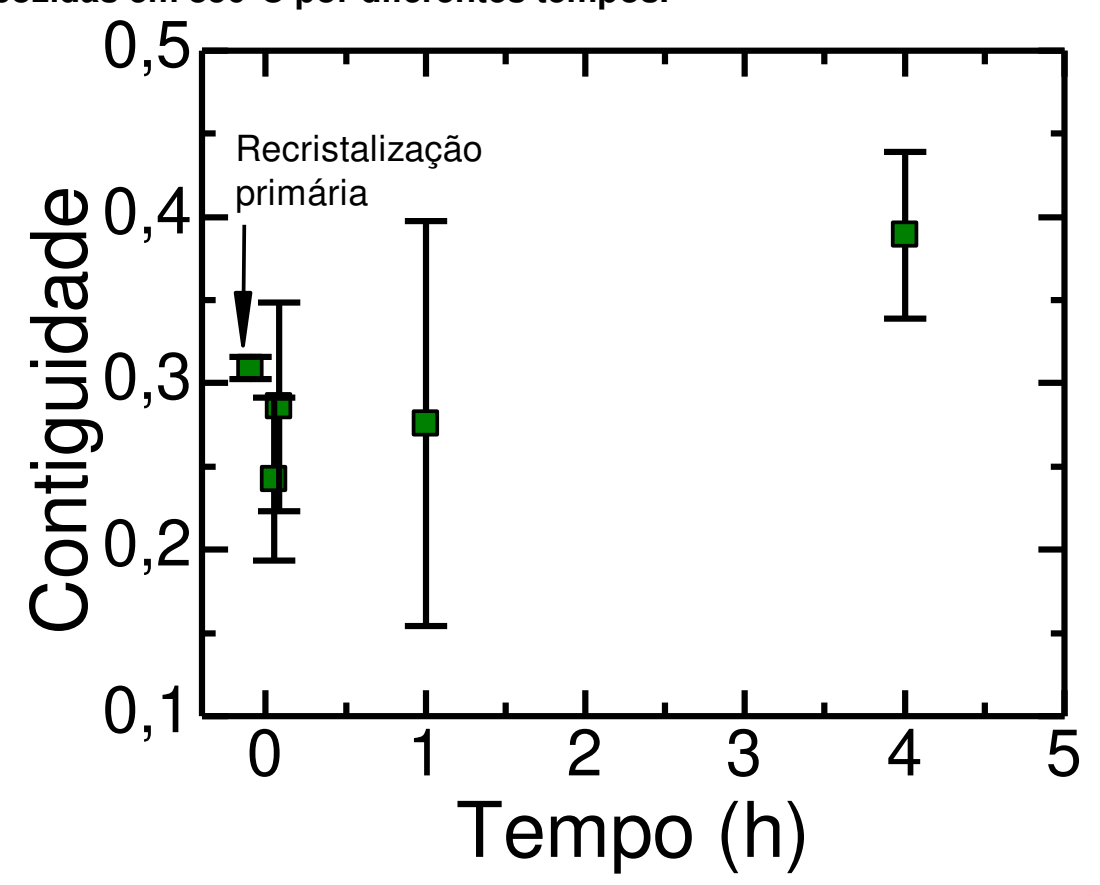

Fonte: Elaborada pelo autor.

A Figura 27 mostra a frequência de pontos triplos ao longo da direção radial para as amostras antes do crescimento anormal de grão. O menor tamanho médio no centro, encontrado na amostra recozida por $3 \mathrm{~min}$, explica a alta frequência de pontos triplos encontrados nesta região. Com o passar do recozimento, ocorre ligeiro crescimento normal dos grãos e a distribuição de pontos triplos muda. Após $4 \mathrm{~h}$, existem mais pontos triplos próximos à superfície do que no centro. Os pontos triplos com alta energia integral são os mais frequentes, sendo que os três tipos mais energéticos representam $94,5 \%$ dos pontos triplos. A Figura 28 apresenta a frequência dos tipos de pontos triplos encontrados nas amostras recozidas por 3 min e $4 \mathrm{~h}$. As distribuições representam apenas os grãos encontrados no centro dos mapeamentos. A frequência dos dez tipos de pontos triplos propostos muda pouco com o crescimento normal de grão. A frequência daqueles compostos por três contornos de alto ângulo $(\mathrm{H}-\mathrm{H}-\mathrm{H})$ diminui durante o crescimento de grão, enquanto que a dos formados por um ou dois contornos de alto ângulo aumenta. Este resultado é condizente com o modelo de contornos de alto ângulo $(73,80)$ que sugere que os contornos e pontos triplos mais móveis irão desaparecer mais rapidamente durante o crescimento de grão. Partindo do mesmo princípio, estes resultados são conflitantes com o modelo dos contornos CSL (117). 
Acredita-se que as mudanças na frequência dos tipos de pontos triplos resultam do aumento na contiguidade dos grãos da fibra <110>/WD. As mudanças, portanto, não refletem qualquer propriedade anisotrópica de pontos triplos que poderia justificar sua relação com o início do crescimento anormal. Espera-se um equilíbrio entre as mudanças topológicas durante o crescimento normal de grão $(65,66,130)$. Os resultados apresentados na Figura 28 sugerem que o crescimento normal de grão ocorre sem o devido equilíbrio nas mudanças topológicas (65). Os aglomerados de grãos com orientação pertencente à fibra são fortes candidatos a desenvolverem o crescimento anormal de grão pois, nestas estruturas, a transição de perda de vizinhos é dificultada (68), o que possibilita que estes aglomerados cresçam por troca de vizinhos e tornem-se grãos anormais (17).

Outra variável metalúrgica que atua fortemente na movimentação de contornos é a presença de partículas finas. As imagens de microscopia eletrônica de transmissão, adquiridas no modo varredura, são mostradas na Figura 29. Elas foram obtidas na (a) superfície e no (b) centro da amostra recozida em $850^{\circ} \mathrm{C}$ por 3 min. Nota-se a presença de pequenas partículas com dezenas de nanômetros de diâmetro tanto no centro quanto na superfície. A análise química com o auxílio de EDX revela que as partículas menores são constituídas principalmente de Al e $\mathrm{N}$, ao passo que as maiores apresentam $\mathrm{Mn}$ e $\mathrm{S}$ na sua composição. $\mathrm{A}$ composição química das partículas menores, adquirida por tomografia de sonda atômica (APT), confirma que estas partículas são formadas majoritariamente de Al e N, com presença minoritária de Si, Mn, C e S, como mostra a Figura 30. Os íons de Mn estão localizados fora da partícula e se concentram próximos às faces. Algumas destas faces são planas, o que sugere possível coerência destas partículas com a matriz (158).

As distribuições de tamanho de partículas são similares entre as duas regiões na amostra recozida por 3 min, porém a dispersão de tamanhos é mais estreita na superfície. As distribuições podem ser visualizadas na Figura 31. Os raios médios de partículas no centro e na superfície são 11,4 \pm 1,2 nm e 10,0 \pm 0,6 nm, respectivamente, que são dimensões similares as reportadas em um aço baixo carbono acalmado com alumínio (143). Há em média $5 \pm 1$ partículas/ $\mu m^{2}$ no centro, contra $16 \pm 4$ partículas/ $\mu \mathrm{m}^{2}$ na superfície. Este resultado sugere que as forças de ancoramento são mais intensas na última região. 
Figura 27 - Distribuição espacial de pontos triplos ao longo da direção radial para as amostras recozidas em $850^{\circ} \mathrm{C}$ antes do crescimento anormal de grão.

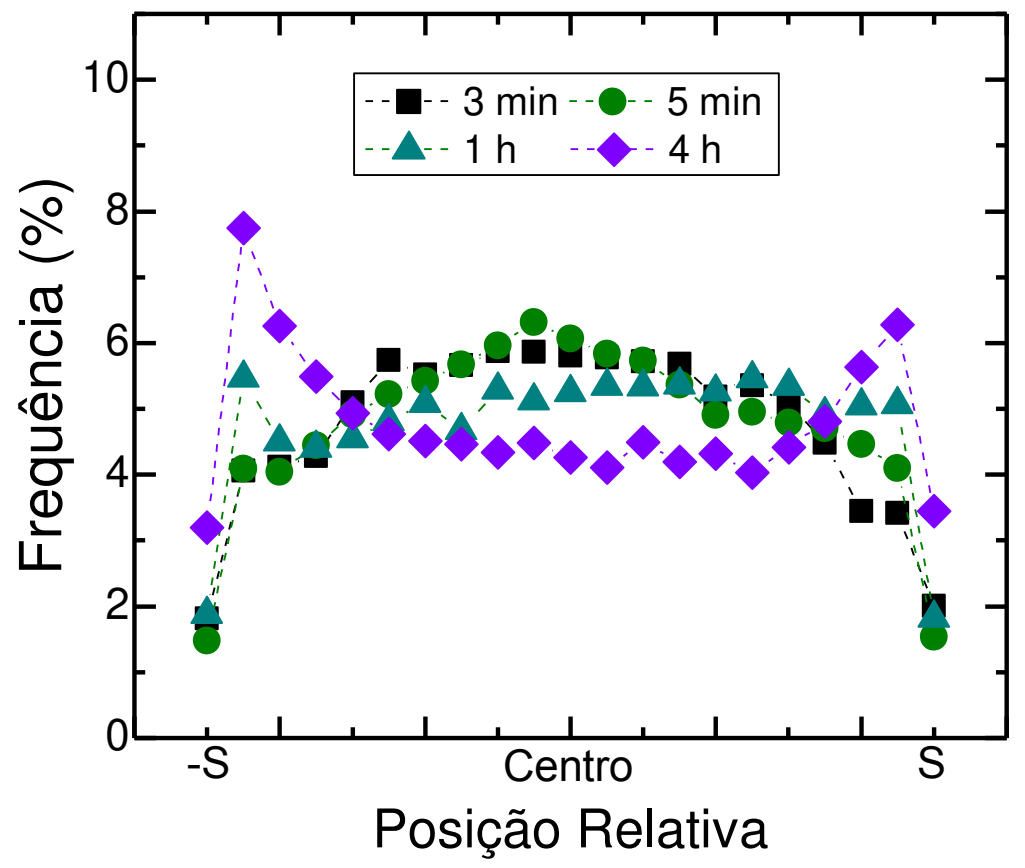

Fonte: Elaborada pelo autor.

Figura 28 - Frequência dos tipos de pontos triplos da amostra recozida em $850^{\circ} \mathrm{C}$ por $3 \mathrm{~min}$ e $4 \mathrm{~h}$. As distribuições são relativas apenas aos grãos encontrados no centro.

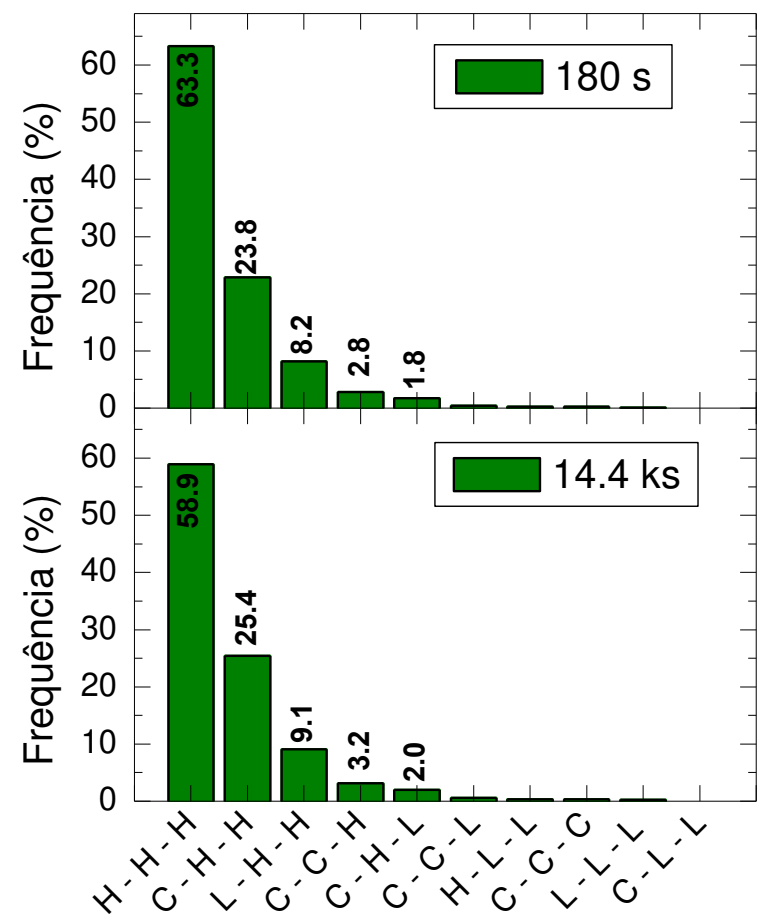

Tipos de pontos triplos

$\mathrm{H}=$ contorno de alto ângulo

$\mathrm{L}=$ contorno de baixo ângulo

$\mathrm{C}=$ contorno CSL (de $\Sigma 3$ até $\Sigma 21$ )

Fonte: Elaborada pelo autor. 
Figura 29 - Imagens das lamelas retiradas na (a) superfície e no (b) centro da amostra recozida em $850^{\circ} \mathrm{C}$ por $3 \mathrm{~min}$. MET, campo escuro.

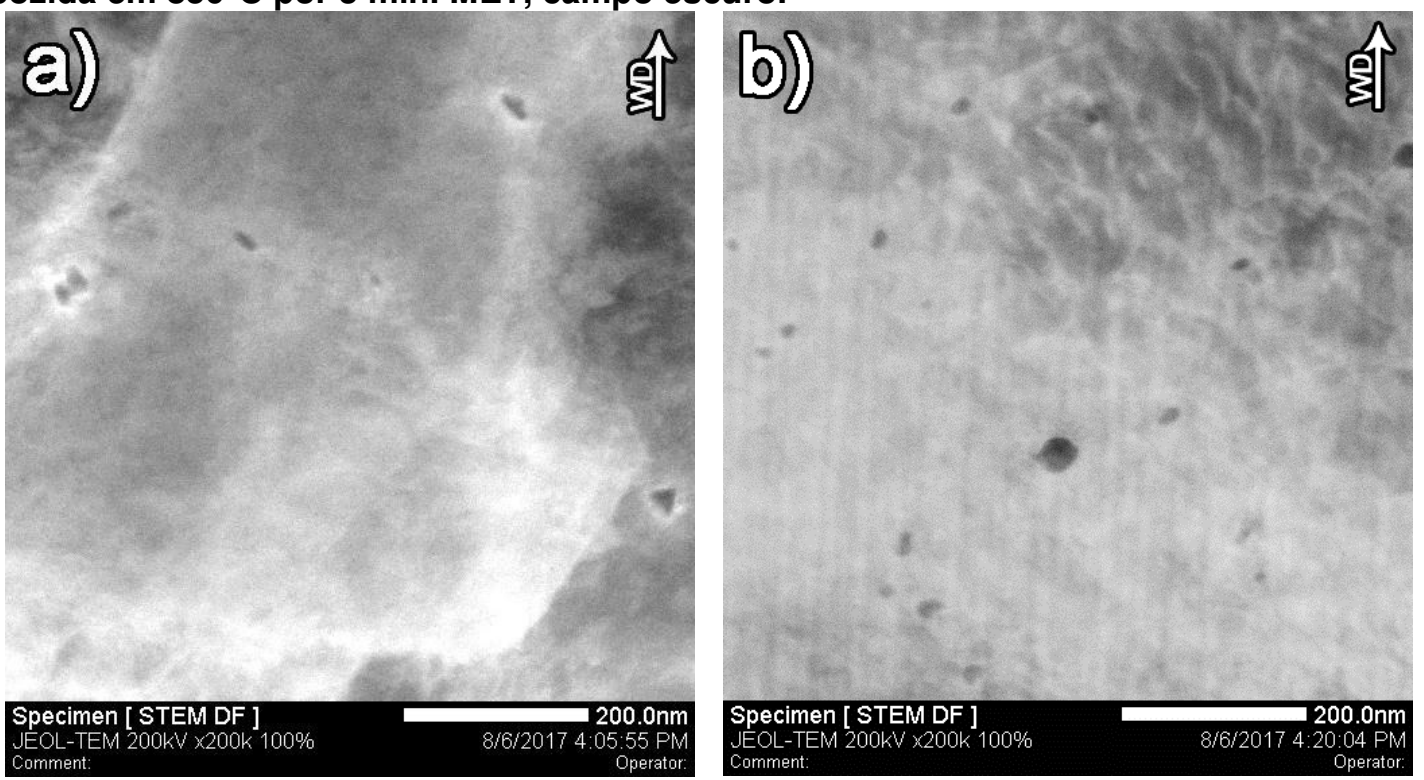

Fonte: Elaborada pelo autor.

Figura 30 - Tomografia de força atômica (APT) mostrando duas partículas de AIN encontradas na amostra recozida em $850^{\circ} \mathrm{C}$ por $3 \mathrm{~min}$. A intensidade da cor dos voxels representa a densidade local dos respectivos íons.

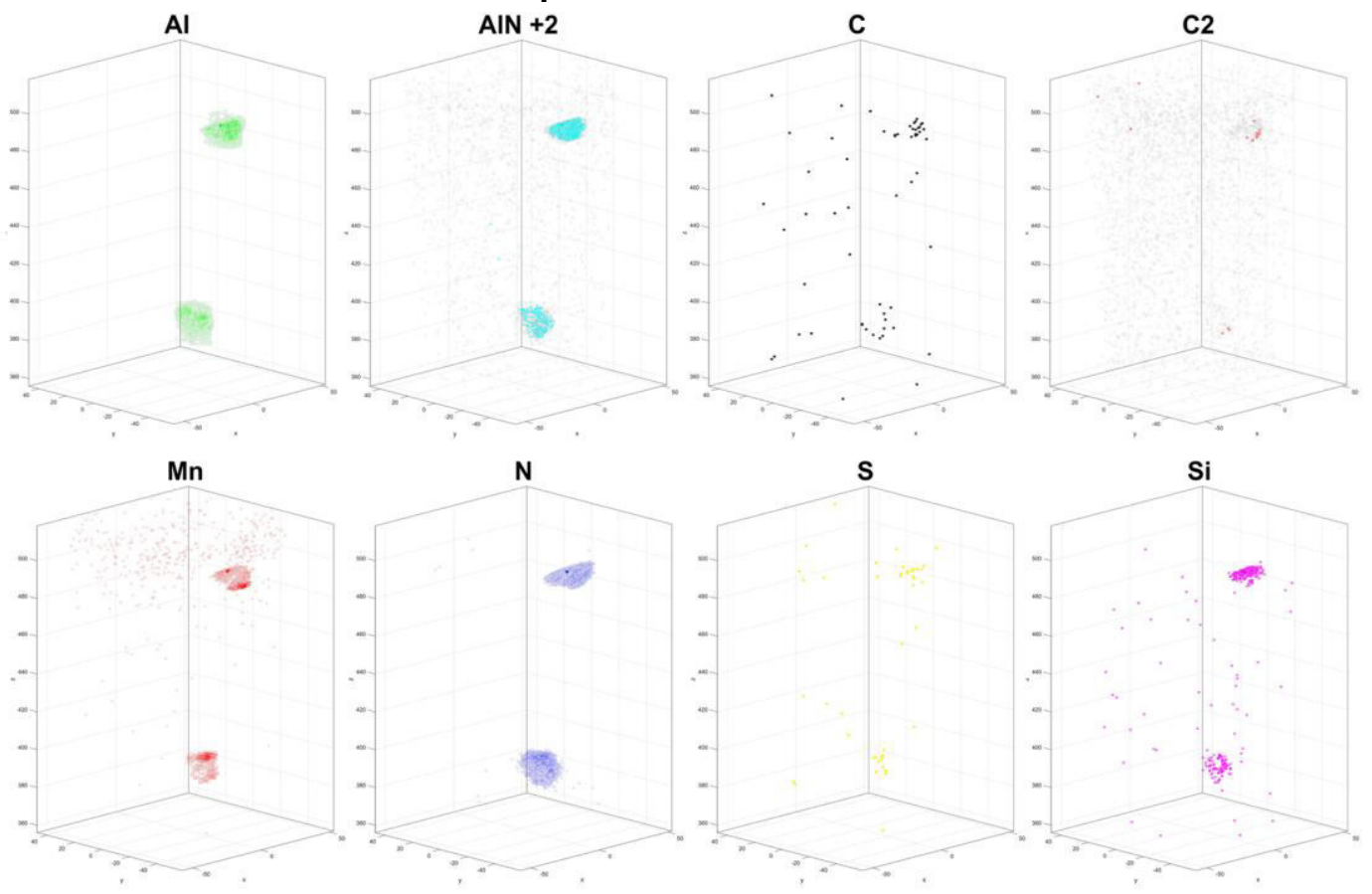

Fonte: Elaborada pelo autor. 
Figura 31 - Distribuições de tamanho de partículas, medidas no centro e na superfície. Amostra recozida em $850^{\circ} \mathrm{C}$ por $3 \mathrm{~min}$.

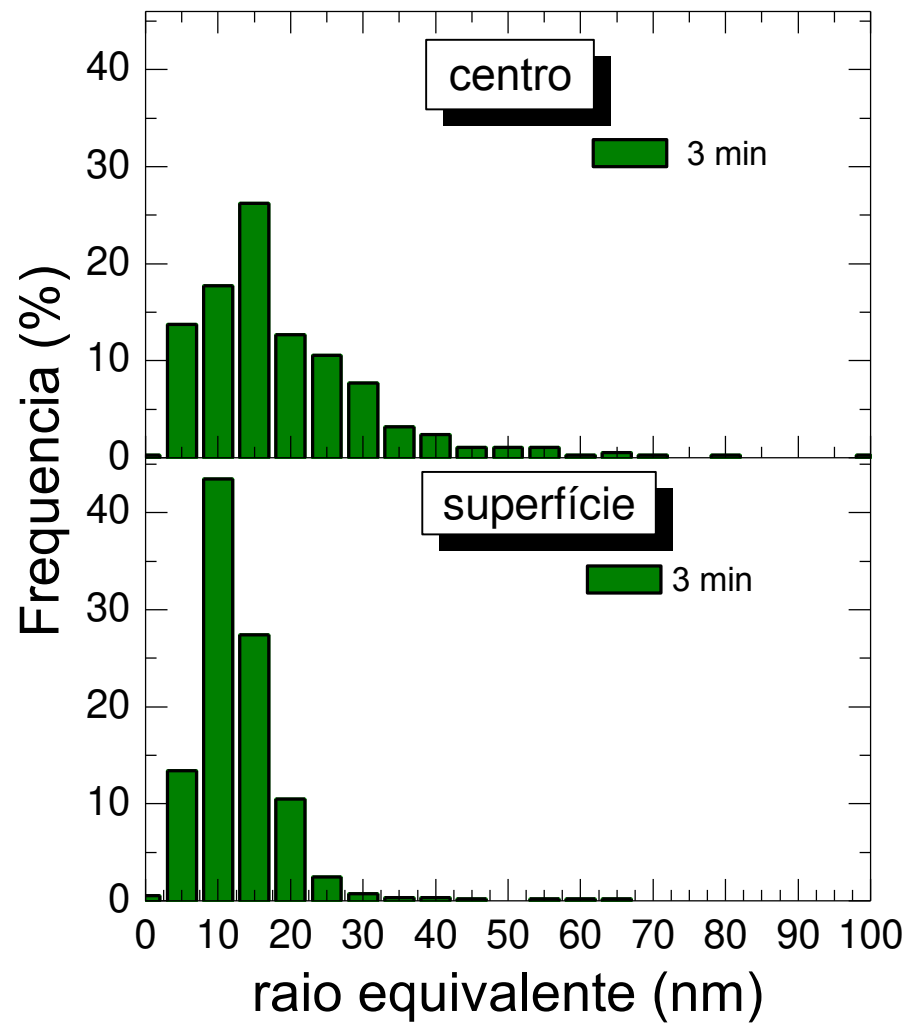

Fonte: Elaborada pelo autor.

\subsection{Crescimento anormal de grão em $850^{\circ} \mathrm{C}$}

Após $4 \mathrm{~h}$ de recozimento, evidencia-se o crescimento anormal de grão. No início, estes grãos apresentam crescimento isotrópico; porém, o crescimento torna-se mais anisotrópico quando eles adquirem dimensões próximas ao diâmetro do fio. $O$ tamanho limite dos grãos anormais tem característica atemporal, o que pode ser verificado na Figura 32. A imagem de microscopia ótica da amostra recozida por $5 \mathrm{~h}$ mostra grande dispersão no tamanho dos grãos anormais que aparecem de forma heterogênea no comprimento amostrado. Esta amostra é a primeira onde os grãos anormais são visualmente distinguíveis. Um dos grãos anormais possui seção com comprimento de $3,5 \mathrm{~mm}$, enquanto outros são menores que o diâmetro do fio. Em um mesmo recozimento, alguns fios apresentam grãos anormais enquanto que outros não. Há um aumento na quantidade de grãos anormais para os maiores tempos de recozimento.

Há sempre uma camada de grãos pequenos entre os grãos anormais e a superfície livre do fio. Esta característica é preservada durante todo o recozimento 
em $850^{\circ} \mathrm{C}$ e já havia sido reportada anteriormente $(40,43,46,57)$. Neste capítulo são apresentados alguns fatores que podem explicar esta heterogeneidade.

A análise estereológica do comprimento dos contornos por unidade de área (LA) mostra que, após 8 h, ocorre uma diminuição da superfície de contornos pela maior frequência de grãos anormais. Estes resultados são apresentados na Figura 33. Esta diminuição é seguida de um aumento proporcional no volume da fibra $<110>$ // WD, sendo medido volume de $68 \pm 5 \%$ na amostra recozida por $48 \mathrm{~h}$. As barras de erro de ambas medidas são maiores nas amostras após crescimento anormal de grão, o que representa a heterogeneidade do fenômeno ao longo do comprimento do fio.

O crescimento anormal de grão é o principal mecanismo de fortalecimento de textura após a recristalização primária. A Figura 34 apresenta a orientação média dos 363 grãos anormais analisados neste estudo. As orientações dos grãos anormais se acumulam próximas à fibra <110> // WD, com alguns deles apresentando orientações intermediárias. A distribuição de desorientações entre a orientação média dos grãos anormais e a orientação ideal da fibra <110> // WD é mostrada na Figura 35a. A distribuição acumulada mostra que $77,4 \%$ dos grãos anormais estão orientados a menos de $10^{\circ}$ da fibra. Quando analisado todos grãos de uma amostra antes do crescimento anormal de grão (Figura 35b), a porcentagem é de $45,1 \%$. Se considerados apenas os grãos do centro, a frequência acumulada é apenas 35\%.

Parece não haver consenso sobre a orientação dos grãos anormais desenvolvidos em fios de metais com estrutura ccc $(43,96,104,105)$. Os resultados apresentados nesta Tese comprovam, por meio de uma análise probabilística, que o crescimento anormal de grão é seletivo para grãos orientados próximo à fibra $<110>$ // WD. Entretanto, a baixa frequência de grãos anormais, em comparação à quantidade inicial de grãos orientados próximos à fibra, mostra que apenas uma parcela destes grãos desenvolve-se como grãos anormais. 
Figura 32 - Seção longitudinal dos fios recozidos em $850^{\circ} \mathrm{C}$ por diversos tempos. 0 tamanho dos grãos anormais é atemporal. Microscopia ótica.

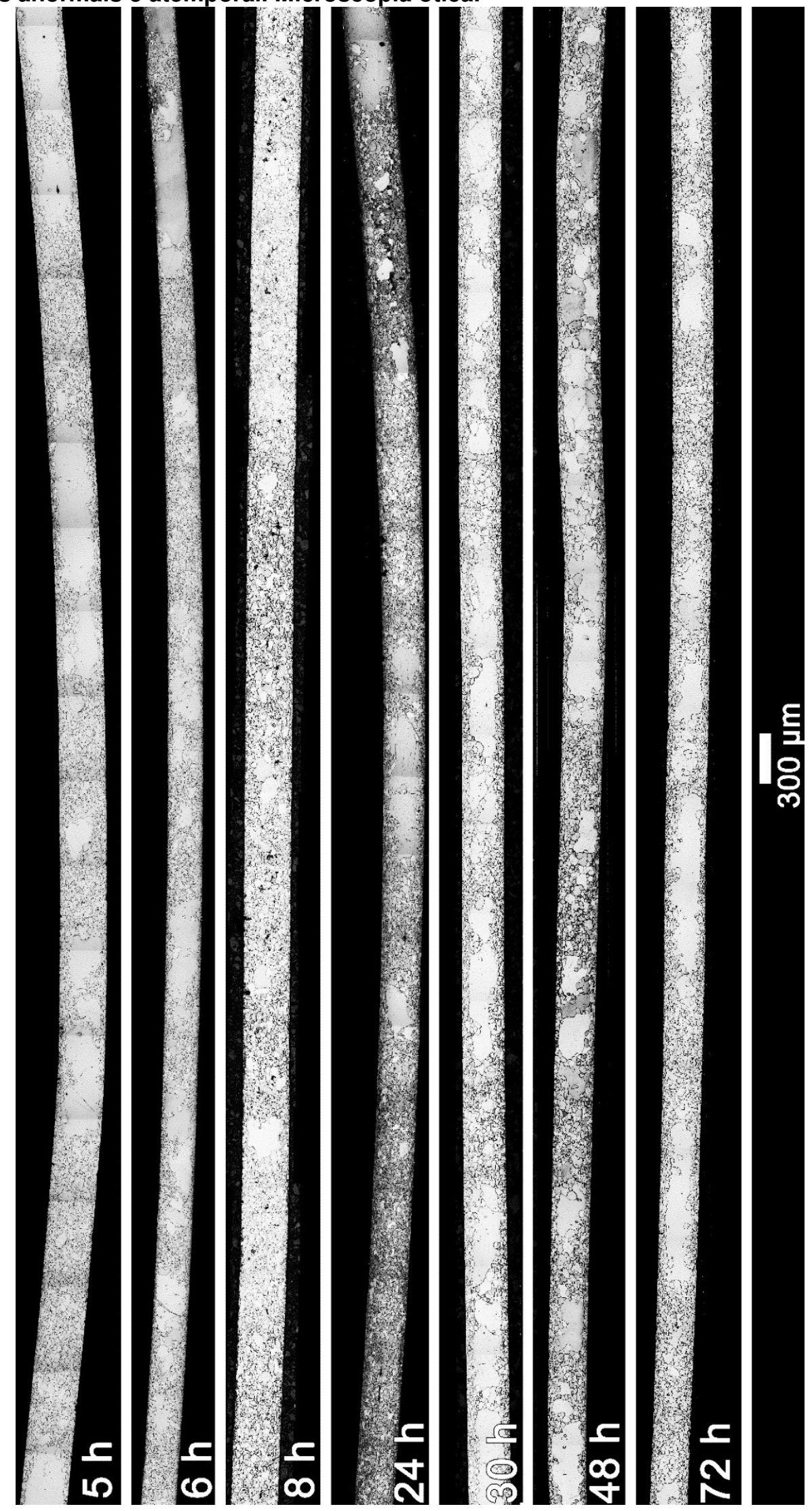

Fonte: Elaborada pelo autor. 
Figura 33 - Comprimento de contornos por unidade de área $\left(L_{A}\right)$ e volume da fibra $\langle 110\rangle / /$ WD para a amostra recozida em $850^{\circ} \mathrm{C}$. 0 primeiro ponto representa a amostra após a recristalização primária.

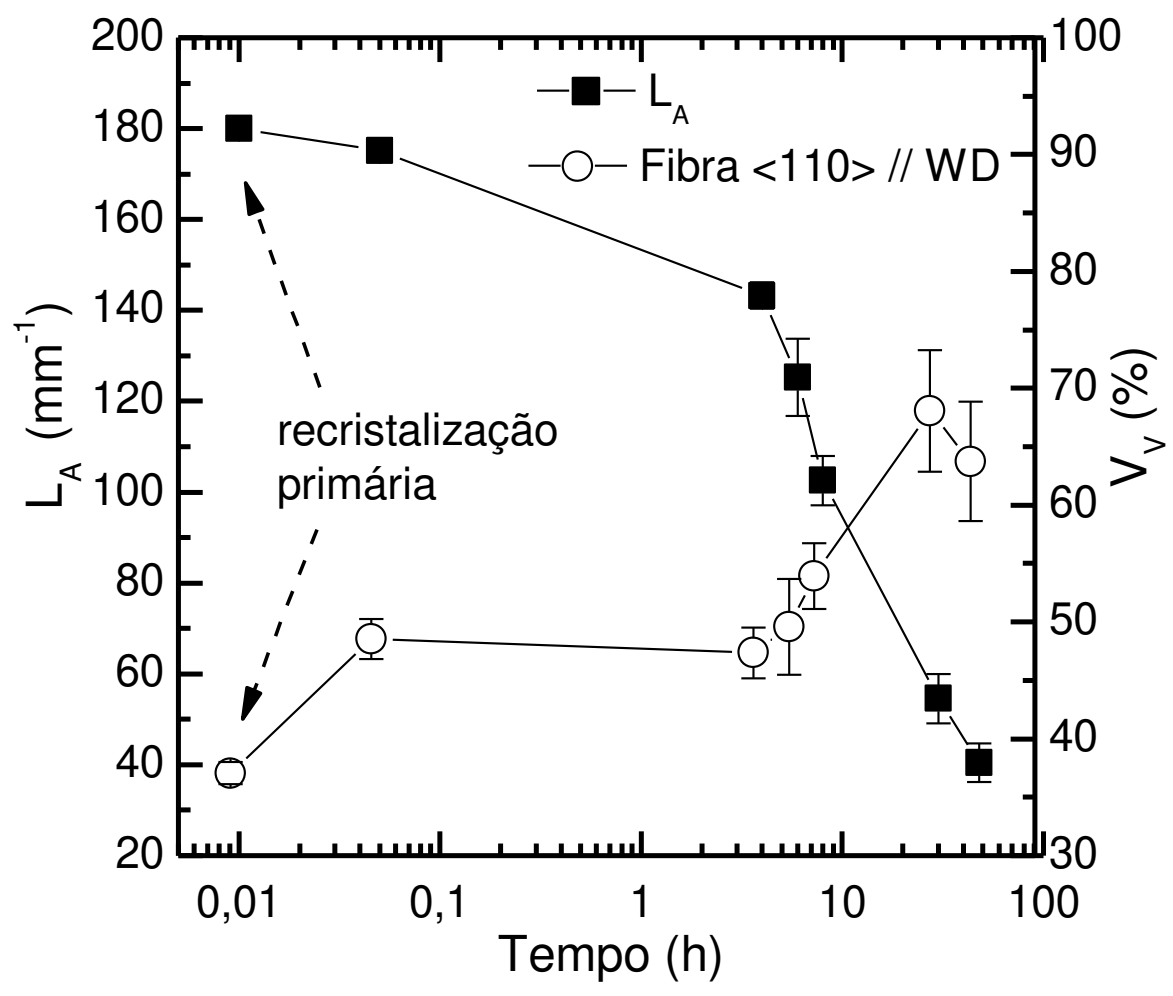

Fonte: Elaborada pelo autor.

Figura 34 - Figura de polo invertida mostrando as orientações médias dos 363 grãos anormais verificados nos fios recozidos em $850^{\circ} \mathrm{C}$ para diferentes tempos.

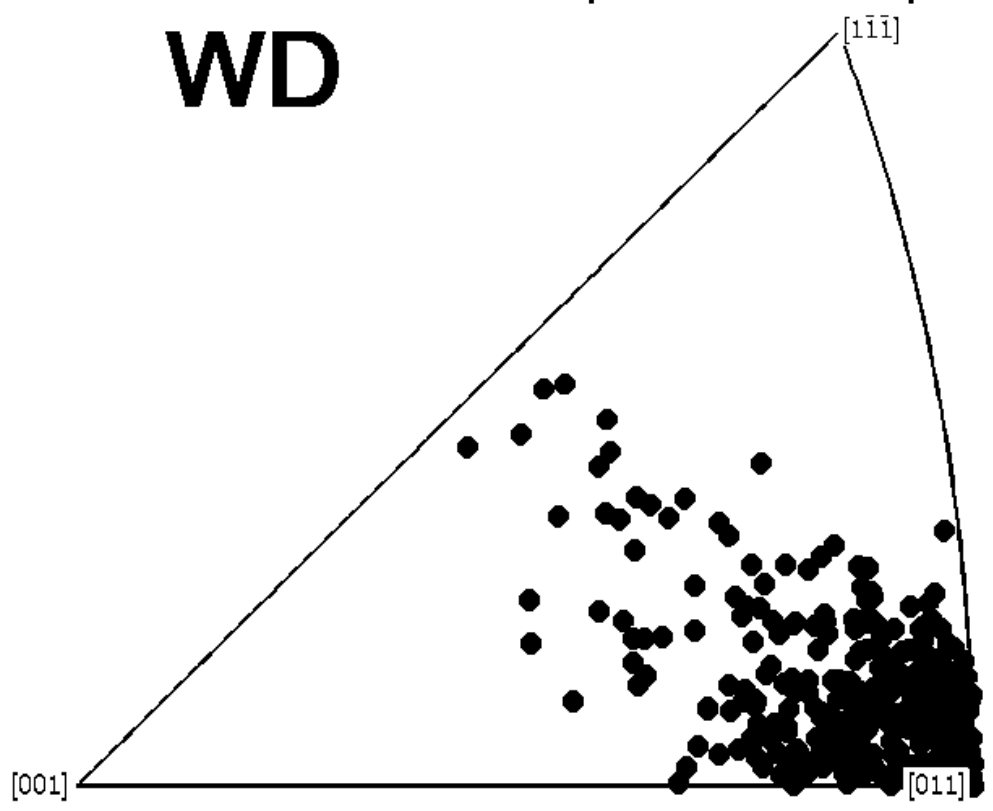

Fonte: Elaborada pelo autor. 
Figura 35 - Desorientação em relação à fibra <110> // WD para (a) os 363 grãos anormais e (b) todos os grãos encontrados no fio recozido em $850^{\circ} \mathrm{C}$ por $4 \mathrm{~h}$.

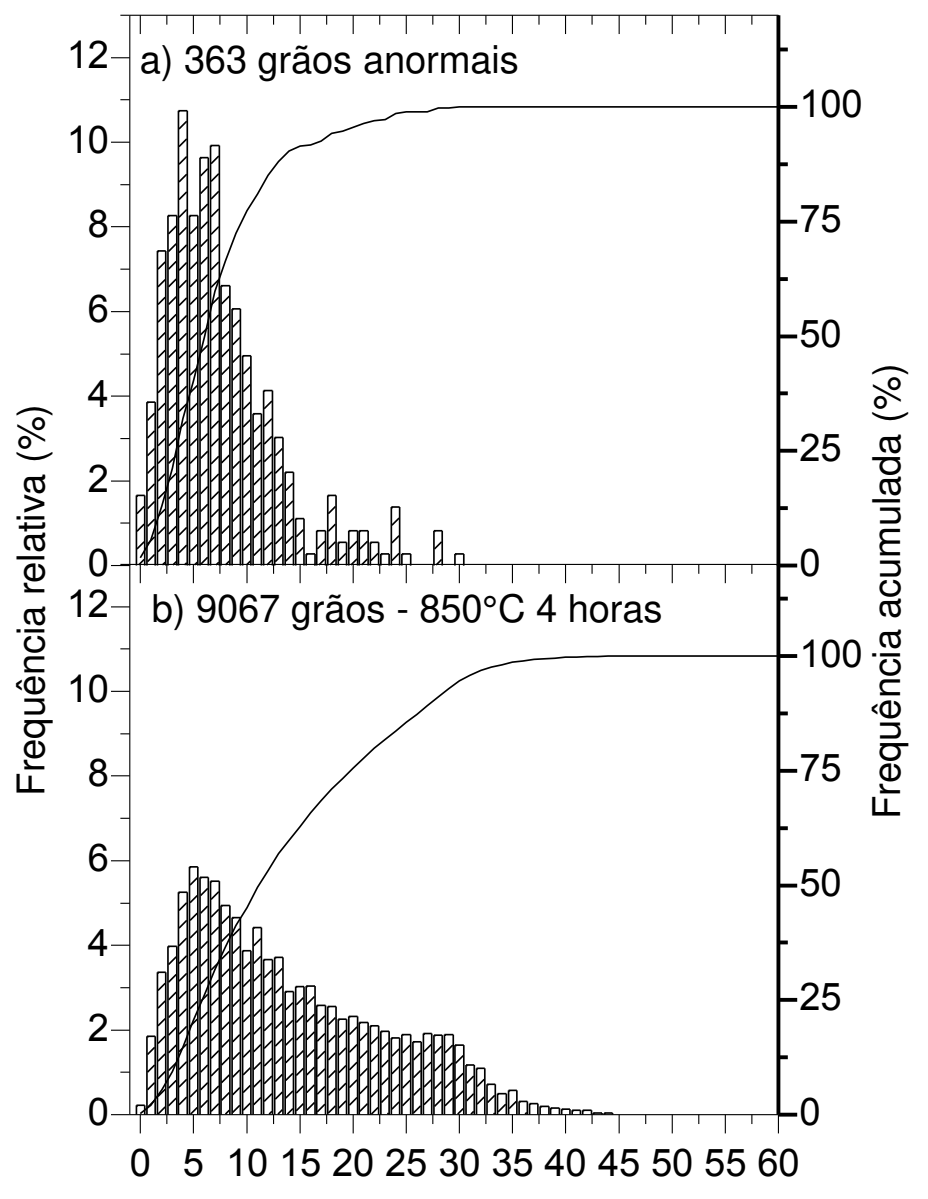

Desorientação em relação à fibra $<110>/ /$ WD $\left(^{\circ}\right)$

Fonte: Elaborada pelo autor.

Alguns grãos anormais apresentam grãos-ilha em seu interior (13,78). Estes grãos encontram-se isolados ou agrupados com outros grãos menores. Outras microestruturas peculiares são encontradas próximas aos grãos anormais, como os grãos-península, contornos planos e coincidentes, pontos triplos com ângulos diedrais fora do equilíbrio isotrópico e grãos com menos de 6 faces e concavidade contrária ao baricentro. Todas estas microestruturas desrespeitam a relação topológica de von Neumman-Mullins (159). Ao medir a desorientação entre os grãos-ilha e os grãos anormais que o circundam, é possível verificar que apenas 3 dos 124 grãos-ilha possuem baixo ângulo de desorientação com o grão anormal e outros 17 apresentam alta relação de coincidência (CSL). Os 104 contornos restantes apresentam alto ângulo de desorientação em relação ao grão anormal hospedeiro. Isso corrobora com a interpretação de que as anisotropias energética 
ou de mobilidade não justificam sozinhas a formação dos grãos-ilha (80). Não foi possível identificar diferenças significantes entre o tamanho dos grãos-ilha e 0 tamanho médio dos grãos da matriz (76). A presença destes grãos sugere 0 crescimento normal dos grãos antes do crescimento anormal (160). A Figura 36 que traz a distribuição do tamanho dos grãos anormais e também a distribuição de tamanho dos grãos anormais que apresentam grãos-ilha. Fica difícil relacionar a presença de grãos-ilha com o mecanismo de iniciação (nucleação) do crescimento anormal de grão, uma vez que os grãos-ilha são encontrados principalmente nos grãos anormais maiores.

A relação dos contornos CSL com o crescimento anormal de grão é reportada constantemente na literatura $(39,64,73,117,120)$, entretanto; há certo ceticismo sobre a validade destas evidências (121). Os dados da literatura ou possuem pouca significância $(75,121)$ ou apresentam inconsistências com os modelos sugeridos (160). Neste trabalho, não foi possível encontrar correlação entre a presença de contornos CSL com o crescimento anormal de grão.

A Figura 37 mostra a imagens das lamelas retiradas na amostra recozida por $72 \mathrm{~h}$. Elas possuem partículas maiores e mais arredondadas que as verificadas na amostra recozida por $3 \mathrm{~min}$. Isto sugere o engrossamento das partículas, entretanto, deve-se enfatizar que as partículas continuam mais frequentes na lamela retirada da superfície. Nesta região, a natureza química das partículas muda com o recozimento prolongado. Elas se tornam mais ricas em $\mathrm{Cr}, \mathrm{Mn}$ e $\mathrm{O}$ com algumas apresentando $\mathrm{Si}$ na composição. Outros autores reportam a presença destes elementos na formação de nitretos complexos durante 0 recozimento de aços baixo-carbono $(161,162)$, sendo estes formados pela adsorção de nitrogênio da atmosfera $(45,102,163)$. Nesta amostra, não foi encontrado enxofre na composição das partículas próximas à superfície, provavelmente devido à evaporação deste elemento $(58,164)$. O tamanho e formato das partículas no centro também sugerem engrossamento, entretanto, a composição química das partículas é similar à encontrada na amostra recozida por 3 min.

A distribuição de tamanho dos precipitados é mais larga na amostra recozida por $72 \mathrm{~h}$ do que na amostra recozida por $3 \mathrm{~min}$. As distribuições de tamanho de partículas medidas no centro e na superfície são mostradas na Figura 38. Esta figura também traz, para fins de comparação, a distribuição de tamanhos de 
partículas medidas na amostra recozida por $3 \mathrm{~min}$. A distribuição do tamanho dos precipitados na superfície é unimodal, enquanto que no centro ela tende à bimodal. Para avaliar a influência dos precipitados no movimento dos contornos, é mais apropriado avaliar o comprimento de interface partícula-matriz por unidade de área (LA), que é proporcional à superfície de contornos por unidade de volume (Sv). A Tabela 2 mostra que, após prolongado recozimento, o comprimento de interface por unidade de área na superfície é maior que no centro, mesmo quando comparado ao valor medido na amostra recozida por $3 \mathrm{~min}$. A força de arraste exercida pelo particulado sobre os contornos condiciona à imobilidade os contornos próximos à superfície, o que explica a persistência dos grãos pequenos na superfície mesmo após prolongado recozimento.

As imagens de microscopia eletrônica de varredura mostram a presença de perlita fina nos contornos de grãos das amostras que sofreram crescimento anormal de grão (Figura 39). A presença de perlita após o resfriamento rápido é uma evidência da formação de austenita saturada no recozimento. A simulação termodinâmica prevê 20 vol-\% de austenita em $850^{\circ} \mathrm{C}$. A formação de austenita muda localmente a distribuição de partículas, pois os principais elementos formadores das partículas são gamagênicos ( $C, N$ e $M n)$. A mudança na forma dos precipitados durante o recozimento aumenta a probabilidade do crescimento anormal de grão (45,55-58).

Tabela 2 - Comprimentos da interface partícula-matriz por unidade de área, medidos sobre imagens obtidas por microscopia eletrônica de varredura.

\begin{tabular}{ccc} 
Posição & \multicolumn{2}{c}{$\mathbf{L A}_{\mathbf{A}}\left(\mu \mathrm{m}^{-1}\right)$} \\
\hline & $3 \mathrm{~min}$ & $72 \mathrm{~h}$ \\
Centro & $0,64 \pm 0,12$ & $0,47 \pm 0,11$ \\
Superfície & $1,31 \pm 0,23$ & $1,09 \pm 0,18$
\end{tabular}

Fonte: Elaborada pelo autor. 
Figura 36 - Distribuição de tamanho de todos os grãos anormais e daqueles que apresentam grãos-ilha. A frequência de grãos anormais com grãos-ilha é calculada em relação ao total de grãos anormais dentro de cada grupo.

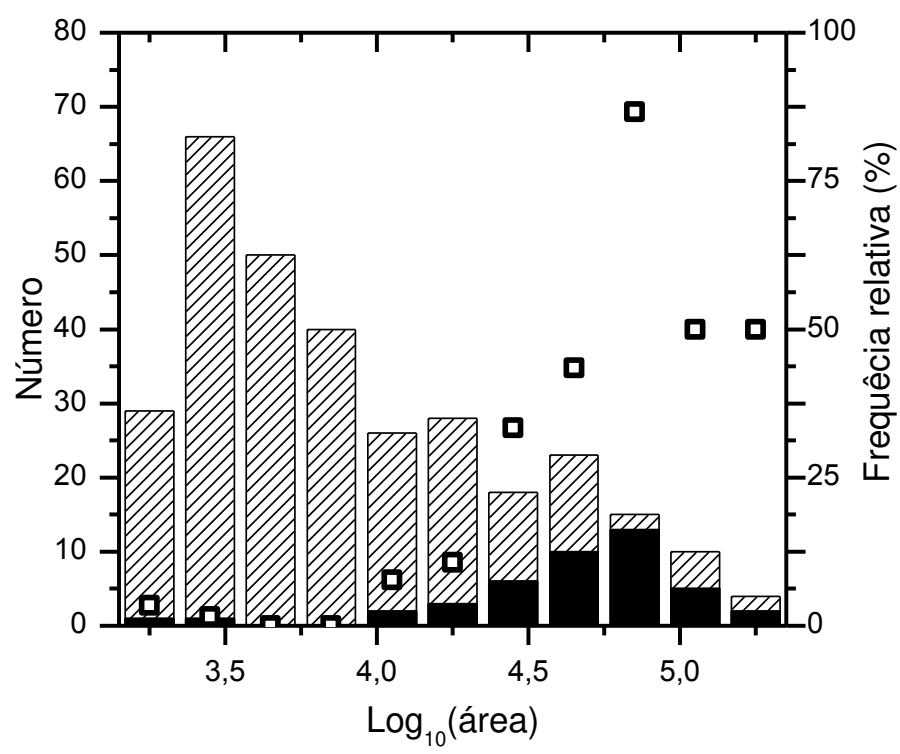

DII]Grãos anormais

Grãos anormais com grãos-ilha

- Frequência de grãos anormais com grãos-ilha

Fonte: Elaborada pelo autor.

Figura 37 - Imagens de STEM das lamelas retiradas da (a) superfície e do (b) centro na amostra recozida em $850^{\circ} \mathrm{C}$ por $72 \mathrm{~h}$. Detecção do campo escuro.

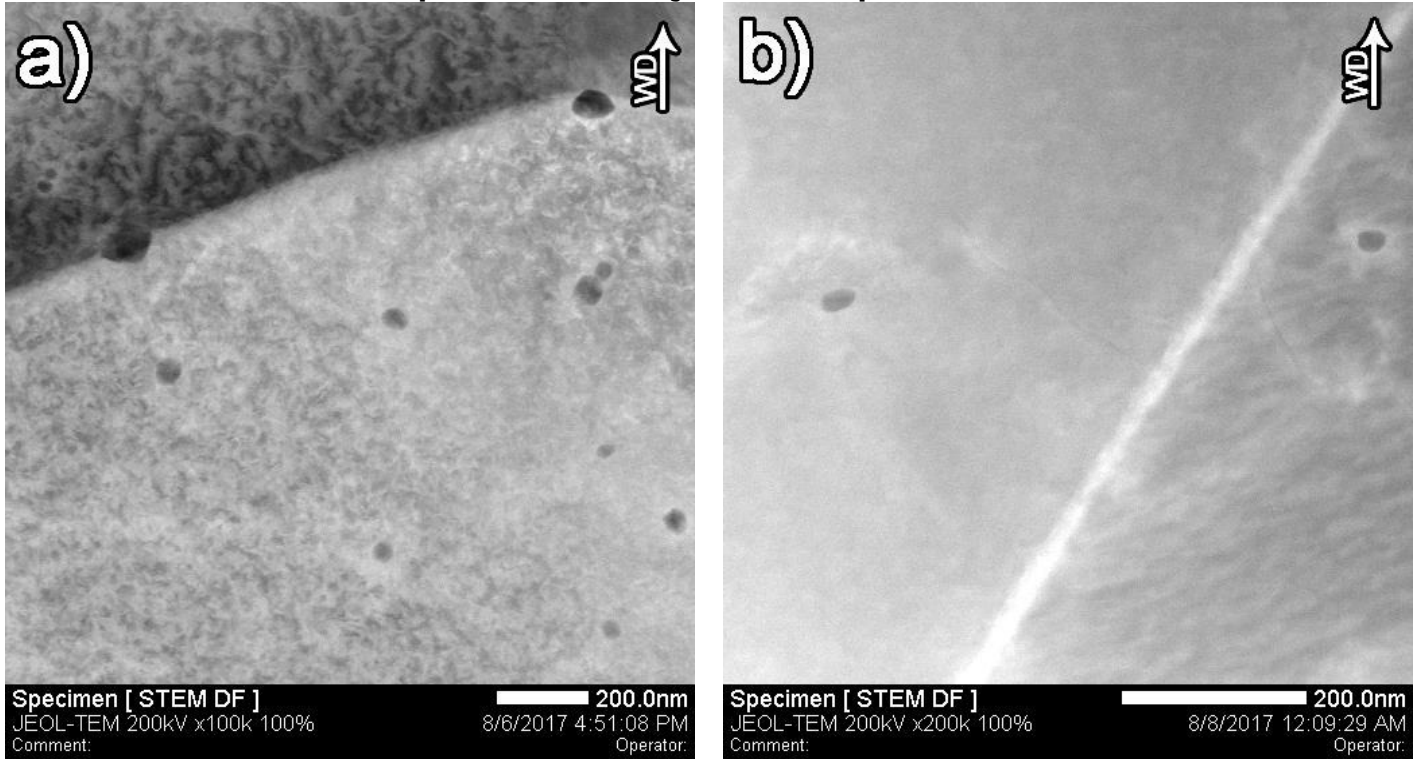

Fonte: Elaborada pelo autor. 
Figura 38 - Distribuição de tamanho de partículas medidas no centro e na superfície da amostra recozida em $850^{\circ} \mathrm{C}$ por $3 \mathrm{~min}$ e $72 \mathrm{~h}$. As distribuições do menor tempo foram adicionadas para propósitos comparativos.

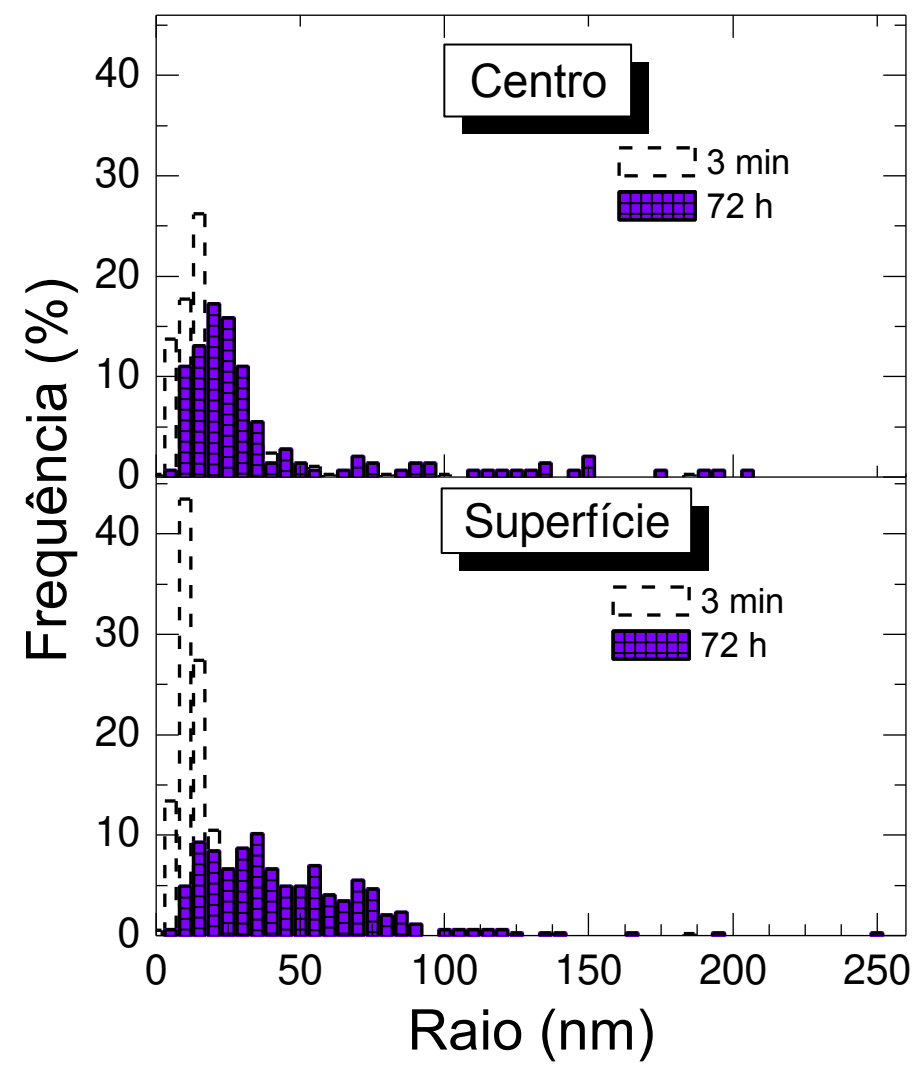

Fonte: Elaborada pelo autor.

Figura 39 - Imagem de microscopia eletrônica de varredura (FEG-SEM) mostrando uma colônia perlítica na amostra recozida em $850^{\circ} \mathrm{C}$ por $48 \mathrm{~h}$. Detecção de elétrons retroespalhados.

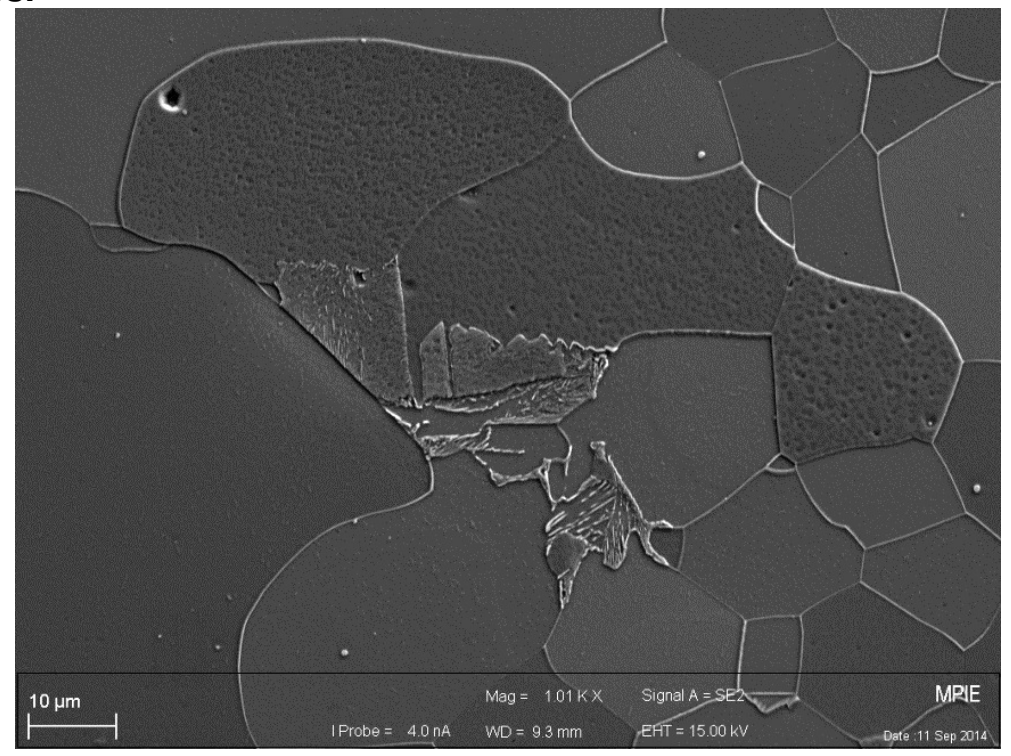

Fonte: Elaborada pelo autor. 


\subsection{Efeito da dimensão da amostra no crescimento anormal de grão}

A mudança na composição química das partículas levanta a discussão sobre as possíveis interações entre a amostra e a atmosfera $(45,47)$. O excesso de partículas na superfície pode ter origem nestas interações ou ele já existia na amostra na condição "como recebido". Para esclarecer esta dúvida, procedeu-se o polimento eletrolítico em alguns fios com a intenção de reduzir o diâmetro de modo uniforme, seguido de recozimento em $850^{\circ} \mathrm{C}$ por $24 \mathrm{~h}$.

A microestrutura das amostras afinadas é similar à observada nos fios com o diâmetro inicial, como mostrado na Figura 40. Até um diâmetro limite, ocorre a presença de alguns grãos anormais que sempre são circundados por grãos menores. Nos fios com menos de $150 \mu \mathrm{m}$ de diâmetro, não há indícios de crescimento normal ou anormal de grão. Este resultado demonstra que a alta frequência de partículas na superfície provém das interações entre a amostra e a atmosfera durante o recozimento.

Cheng et al. (143) e Brahmi \& Borrelly (165) mediram a cinética de precipitação de AIN em aços baixo-carbono. Se os resultados do último trabalho (163) forem extrapolados, é prevista a precipitação de modo praticamente instantâneo de AIN em $850^{\circ} \mathrm{C}$. O trabalho desenvolvido por Nakashima et al. (45) mostra que a microestrutura após crescimento anormal de grão relaciona-se intimamente com o número e distribuição de partículas. Estas propriedades variam com a espessura da amostra e com a atmosfera de recozimento.

Em fios finos, espera-se que estas interações sejam mais intensas pela maior restrição dimensional desta geometria. Isto demonstra que os grãos pequenos persistem na superfície devido à precipitação contínua nesta região, que mantém as elevadas forças de arraste sobre o movimento dos contornos durante todo o recozimento. 
Figura 40 - Imagens de microscopia ótica de fios com diferentes diâmetros após recozimento em $850^{\circ} \mathrm{C}$ por $24 \mathrm{~h}$.

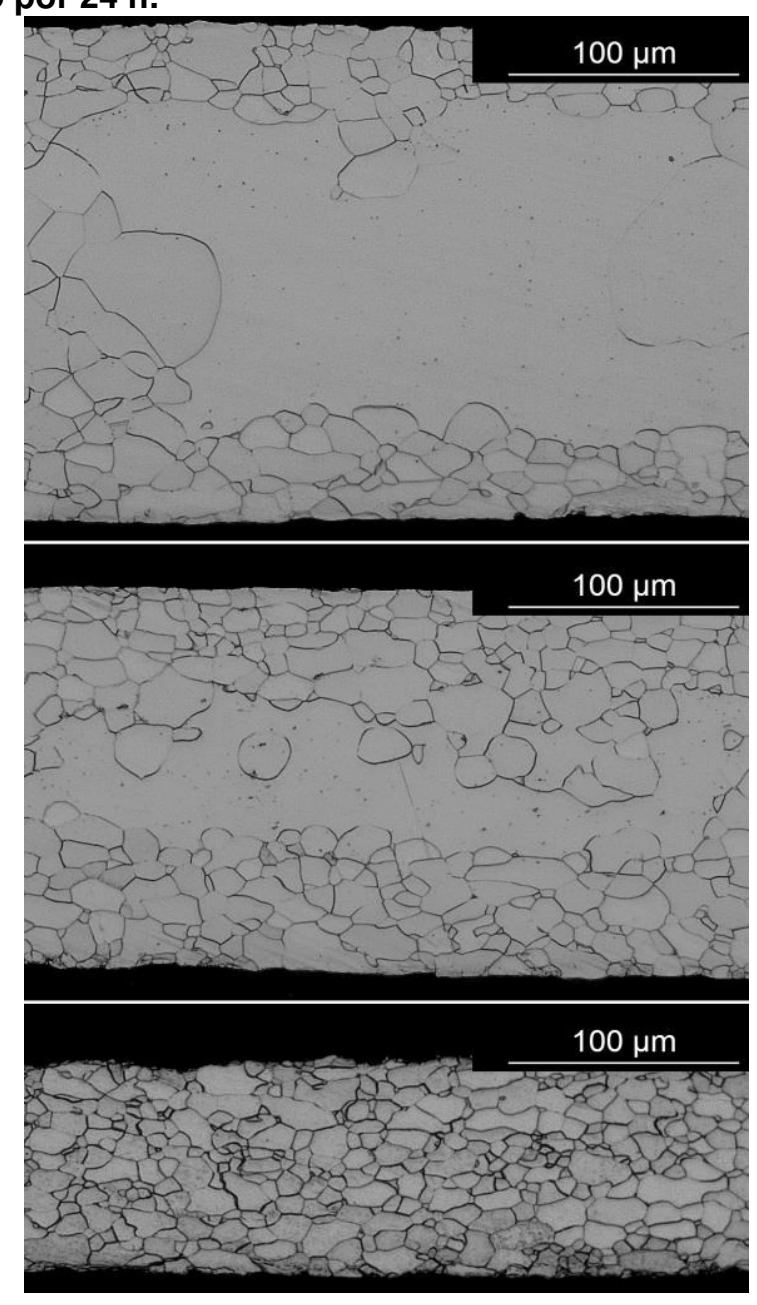

Fonte: Elaborada pelo autor.

\subsection{Efeito da atmosfera de recozimento no crescimento anormal de grão}

Foram realizados experimentos controlados para avaliar o eventual efeito da atmosfera de recozimento no comportamento do material frente ao crescimento anormal de grão. Algumas amostras foram recozidas em $850^{\circ} \mathrm{C}$ por $6 \mathrm{~h}$ em um sistema de vácuo dinâmico acoplado à uma bomba turbomolecular. Os resultados mostram baixa frequência de grãos visualmente distinguíveis como grãos anormais. Entretanto, alguns deles são encontrados e, em muitos casos, eles cresceram até a interface com a superfície livre, como é possível ver nas imagens da Figura 41. Os comprimentos médios de interceptos, medidos na direção de trefilação, foram 19,3 \pm 3,7 $\mu \mathrm{m}$ na superfície e 19,4 $\pm 2,2 \mu \mathrm{m}$ no centro. Em um comparativo, a amostra recozida em $850^{\circ} \mathrm{C}$ por 3 min em vácuo mecânico apresenta comprimento médio de intercepto de 12,6 \pm 0,9 $\mu \mathrm{m}$ na superfície e 10,6 
$\pm 0.7 \mu \mathrm{m}$ no centro, o que comprova o crescimento normal de grão na amostra recozida em alto vácuo. É possível identificar uma quantidade considerável de partículas coalescidas dentro dos grãos anormais. Quando o tempo de recozimento é aumentado para $24 \mathrm{~h}$, pôde-se observar um grão anormal cobrindo toda a seção do fio, como mostra a Figura 42. Este resultado sugere que sem a precipitação contínua de partículas, a movimentação dos contornos é aparentemente mais livre.

A amostra recozida a pressão atmosférica apresenta microestrutura similar à verificada na amostra recozida sob vácuo mecânico, com grãos pequenos presentes entre os grãos anormais e a superfície livre. Esta microestrutura pode ser vista na Figura 43. O comprimento médio de interceptos, medidos na direção de trefilação, é de $12,2 \pm 1,1 \mu \mathrm{m}$ na superfície e $15.6 \pm 1,7$ no centro. Este resultado mostra que houve crescimento normal de grão no centro, mas que ele foi inibido na superfície. Nesta amostra, a espessura da camada de grãos pequenos próximos à superfície é aparentemente maior.

O fio recozido em atmosfera rica em gás nitrogênio apresentou acentuada escamação nas regiões próximas à superfície, como mostra a Figura 44. As amostras apresentam grande quantidade de precipitados mais finos que decoram os contornos. O comprimento médio de interceptos é similar ao da amostra recozida em atmosfera de vácuo mecânico por 3 min, sendo 13,9 \pm 1,2 $\mu \mathrm{m}$ na superfície e 16,2 \pm 2,0 $\mu \mathrm{m}$ no centro. Alguns grãos anormais também foram identificados. Os grãos anormais são menos frequentes e possuem tamanho menor que os da amostra recozida nas mesmas condições, porém em vácuo mecânico. Independente da natureza das partículas, é possível prever que a intensa precipitação influencia a dinâmica de crescimento de grão, inibindo a movimentação de contornos e o crescimento normal de grão. O crescimento anormal de grão não é tão aparente nesta amostra, pois ele é menos provável de ocorrer sobre condições tão restritas de movimentação. 
Figura 41 - Imagens da seção longitudinal de um fio recozido em $850^{\circ} \mathrm{C}$ por $6 \mathrm{~h}$ em alto vácuo dinâmico.
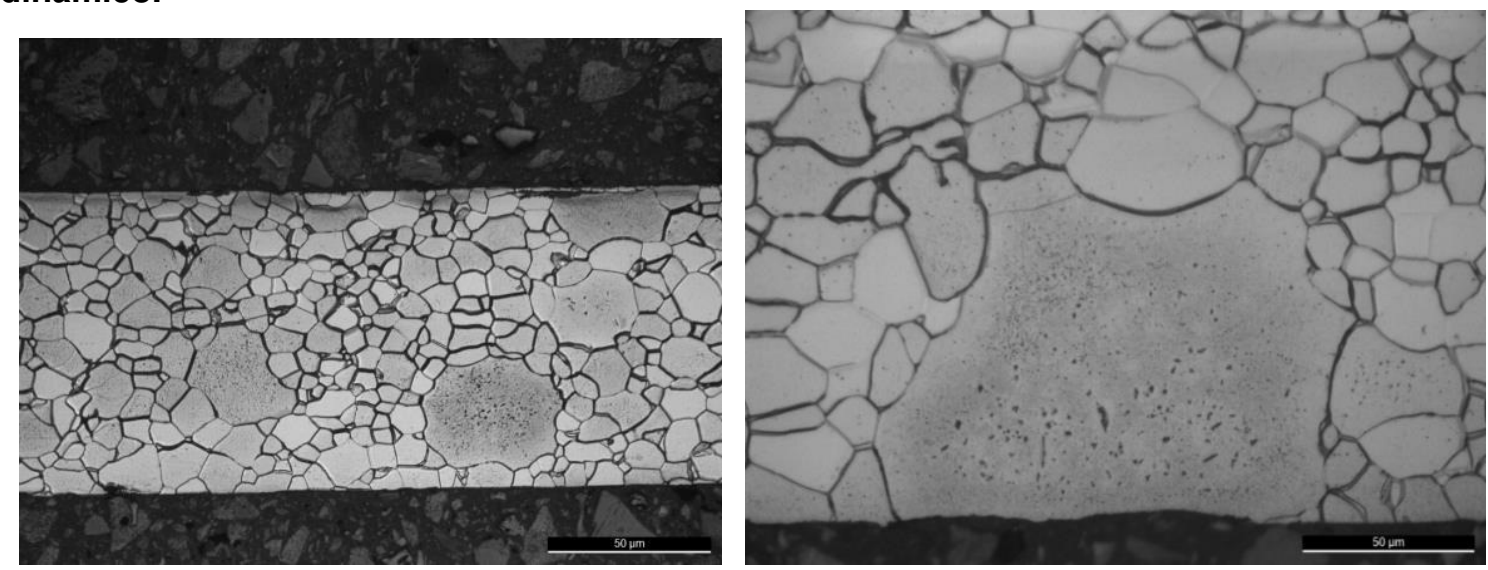

Fonte: Elaborada pelo autor.

Figura 42 - Imagem de SEM de um fio recozido em $850^{\circ} \mathrm{C}$ por $24 \mathrm{~h}$ apresentando um grão anormal que cresceu em toda a seção radial.

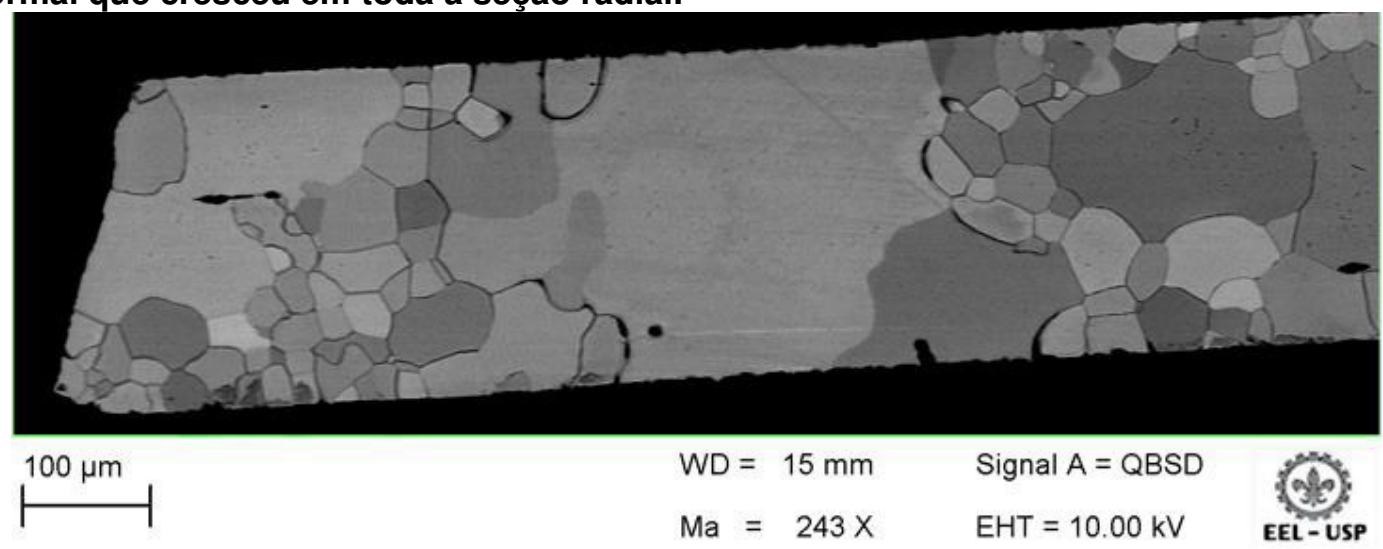

Fonte: Elaborada pelo autor.

Figura 43 - Microscopia ótica da seção longitudinal de um fio recozido em $850^{\circ} \mathrm{C}$ por $24 \mathrm{~h}$ ao ar e sob pressão atmosférica.

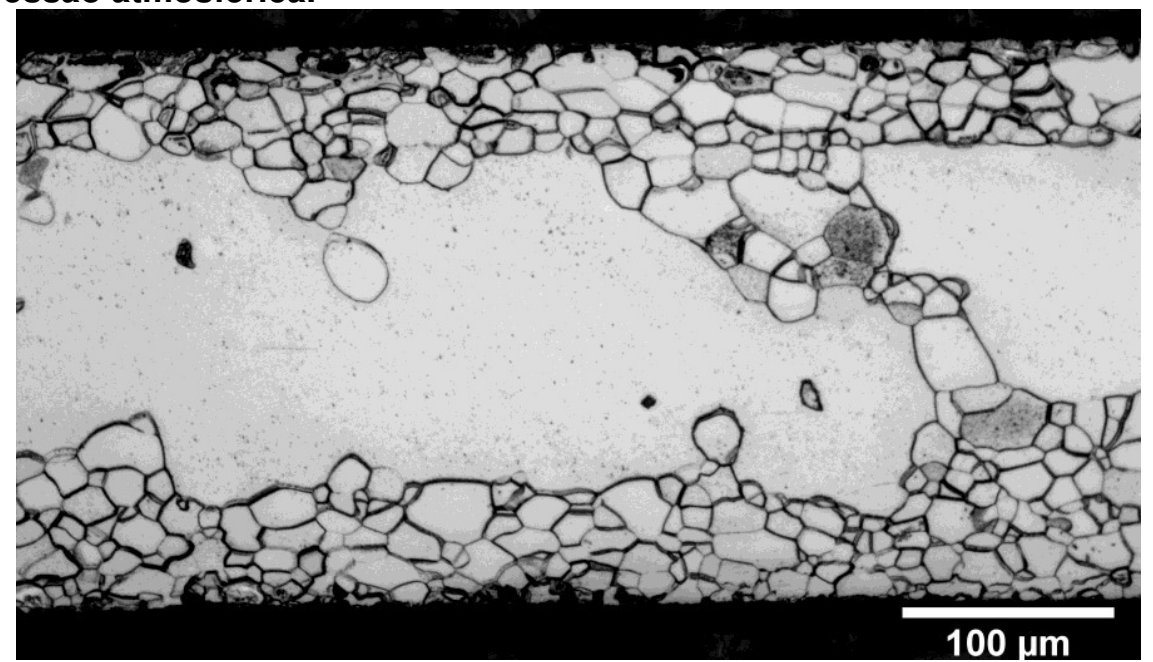

Fonte: Elaborada pelo autor. 
Figura 44 - Imagens de microscopia ótica da seção longitudinal de um fio recozido em $850^{\circ} \mathrm{C}$ por $24 \mathrm{~h} \mathrm{em}$ atmosfera rica em gás nitrogênio.
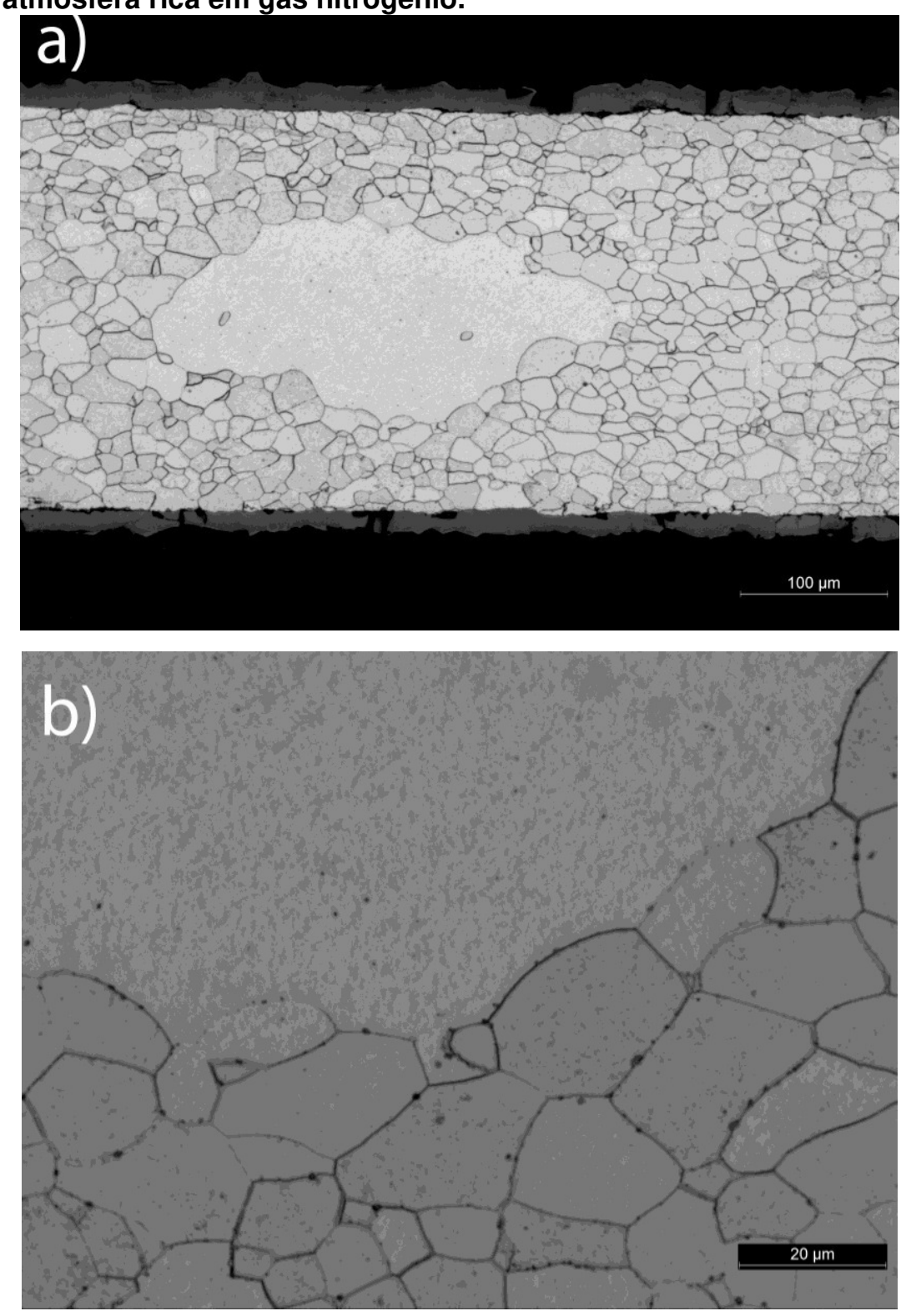

Fonte: Elaborada pelo autor.

Quanto ao fio atacado com a solução Klemm I, ele apresentou uma fase característica que molha os contornos de grão, decorando-os intensamente, como revela a Figura 45. O comprimento médio de interceptos é 12,3 $\pm 1,1 \mu \mathrm{m}$ na superfície e 11,6 \pm 1,2 $\mu \mathrm{m}$ no centro. Estas dimensões são parecidas com as encontradas na amostra recozida em $850^{\circ} \mathrm{C}$ por $3 \mathrm{~min}$. Não há presença de grãos anormais em toda a seção da amostra. Acredita-se que não há condições para o crescimento anormal de grão nesta amostra, uma vez que o crescimento de normal grão é restringido pela presença dos precipitados. 
Estes resultados mostram, de forma irrefutável, que há influência da atmosfera de recozimento no comportamento deste material frente ao crescimento anormal de grão. Dependendo do tipo de atmosfera, precipitados se formam junto à superfície, resultantes da interação atmosfera-amostra, aumentando o potencial retardador de Zener e inibindo o crescimento de grão.

Figura 45 - Microscopia ótica na seção longitudinal de um fio recozido em $850^{\circ} \mathrm{C}$ por $24 \mathrm{~h}$ após ser tingido com solução rica em enxofre.
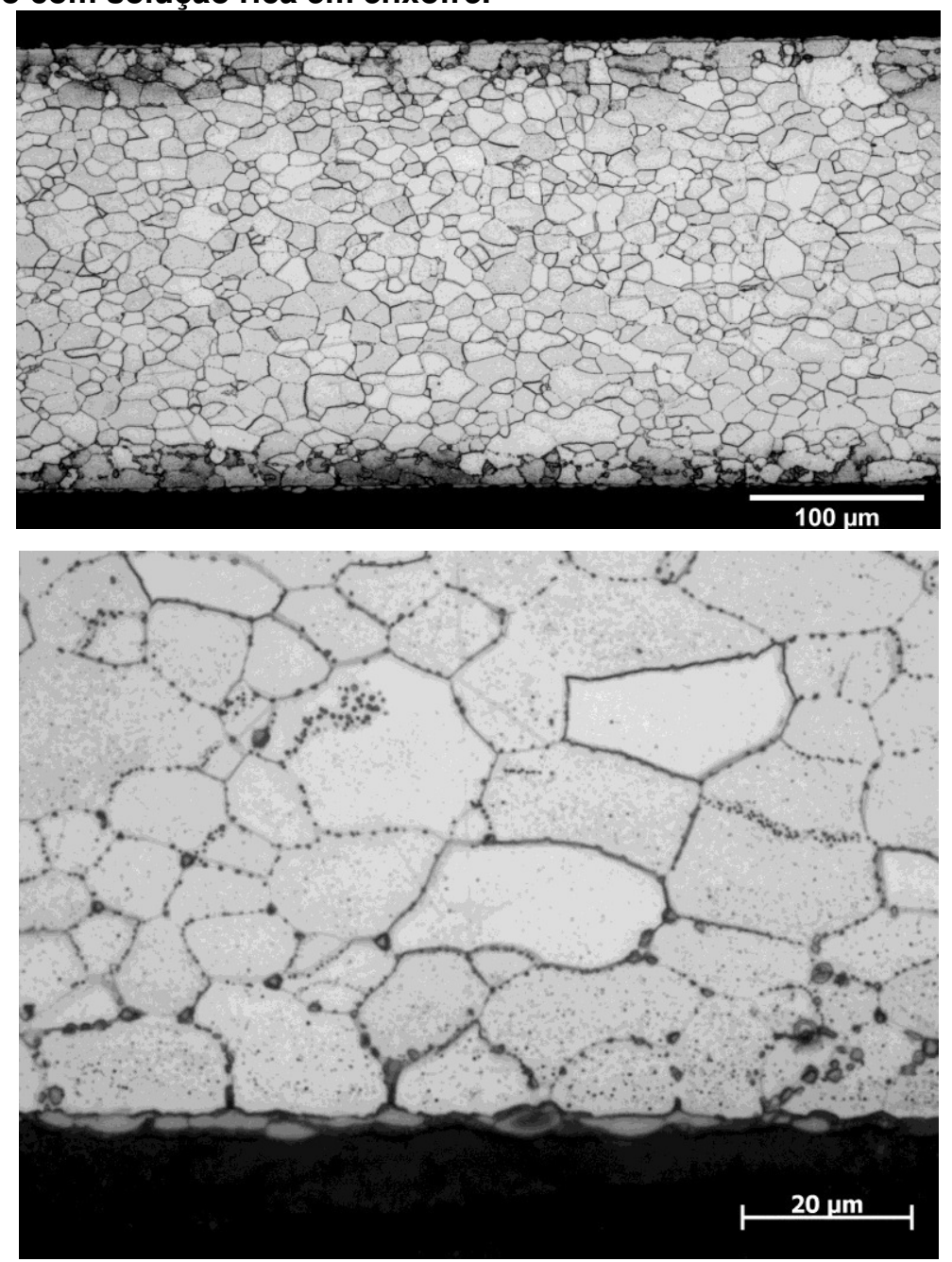

Fonte: Elaborada pelo autor 


\subsection{Equilíbrio de pressões no crescimento normal de grão}

A Eq. (8) propõe um parâmetro geométrico que relaciona a área de interface por unidade de volume com medidas realizadas na seção longitudinal. A Figura 46 mostra o parâmetro estimador (Sv) em função da razão de aspecto. O parâmetro estimador é igual a 4/ா quando a razão de aspecto dos grãos é igual a 1 (grãos isomórficos). A figura também mostra que o parâmetro estimador aumenta quando a esfera é alongada em um esferóide prolato. O parâmetro estimador é limitado à uma assíntota próxima de 1.6 para grãos com razão de aspecto maior ou igual a 6. Neste caso, a área de contornos por unidade de volume será $25 \%$ maior do que seria se os grãos fossem isomórficos. É importante notar que a equação utilizada para descrever o perímetro da elipse é uma das aproximações derivadas por Ramanujan (137). Uma fórmula exata que descreva o perímetro da elipse prossegue como uma busca na sociedade científica, sendo que as melhores aproximações atualmente apresentadas envolvem cálculos complexos com funções hipergeométricas (166).

Os valores de $S_{v}$ para contornos e interfaces de precipitados foram calculados e são mostrados na Tabela 3. A área de contorno por unidade de volume é a mesma na superfície e no centro. Entretanto, a área de interface por unidade de volume na superfície é maior que no centro. O parâmetro $B$ também foi calculado. Rios $(154,167)$ sugere que o crescimento normal dos grãos da matriz cessará quando o termo dentro dos colchetes da Eq. (4) for igual a zero. Pelas considerações do autor, isto ocorrerá quando ß for igual ou menor que 3. Esta é o valor encontrado no centro, o que sugere que o tamanho de grãos nesta região está em equilíbrio com a área de interface por unidade de volume e que o tamanho de grão é controlado pela dissolução e/ou engrossamento dos precipitados. Fica também evidente que as pressões de ancoramento geradas pelas partículas na superfície são tão elevadas que os contornos desta região não apresentam qualquer mobilidade após a recristalização primária. Isso explica o motivo pelo qual os contornos na superfície são mais ondulados, comparados aos contornos planos encontrados nos grãos poligonais do centro.

Após 4 h de recozimento, o crescimento anormal de grão começa no centro pelo desequilíbrio nas transições topológica (66), ocasionado pelo prévio crescimento normal de grão. Mesmo após prolongado recozimento, os grãos 
próximos a superfície permanecem com tamanho similar aos encontrados no início do recozimento. A área de interface na região da superfície aumenta para 0,83 \pm $0,14 \mu \mathrm{m}^{-1}$ na amostra recozida por $72 \mathrm{~h}$. Este número pode estar superestimado devido à distribuição ainda mais heterogênea de precipitados; entretanto, ele sugere que os níveis de pressão de arraste se mantêm elevados na superfície pela contínua precipitação de nitretos.

Os contornos próximos à superfície permanecem imóveis e os grãos pequenos não podem ser englobados pelos grãos anormais. $O$ valor de área de interface por unidade de volume não pôde ser calculado para o centro na amostra recozida por $72 \mathrm{~h}$, uma vez que a distribuição espacial das partículas é ainda mais heterogênea nesta região. Além disso, as partículas mais grosseiras apresentam morfologia poligonal, que aumenta a incerteza dos resultados obtidos pelo presente método.

Figura 46 - Parâmetro estimador em função da razão de aspecto. 0 eixo da direita traz a variação percentual na superfície de um esferóide prolato, em comparação a superfície de uma esfera com o mesmo volume.

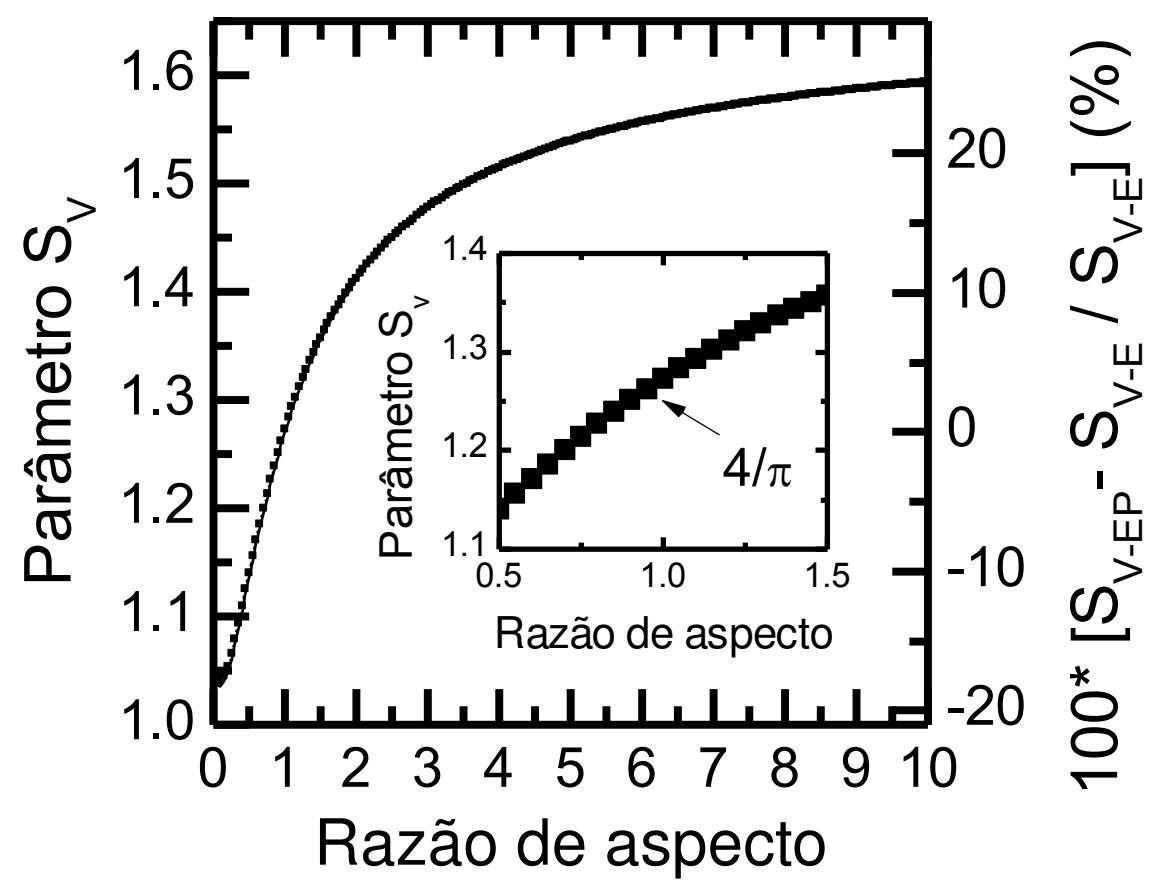

$S_{V \text {-EP }}$ - Razão área/volume de um esferóide prolato

$S_{V-E}-$ Razão área/volume de uma esfera

Fonte: Elaborada pelo autor. 
Tabela 3 - Área de contornos por unidade de volume $\left(\mathrm{S}_{\mathrm{v}}{ }^{\mathrm{GB}}\right)$; área de interface matriz/partícula por unidade de volume $\left(S_{\mathrm{v}}{ }^{\mathrm{Z}}\right)$ e parâmetro de correlação $(B)$ dado pela razão entre os dois últimos parâmetros.

Superfície

$$
\begin{array}{cc}
\operatorname{Sv} v^{G B}\left(\mu m^{-1}\right) & 0,19752 \pm 0,030802 \\
S v^{Z}\left(\mu m^{-1}\right) & 0,204239 \pm 0,037124 \\
B & 0,9671 \pm 0,2395
\end{array}
$$

Centro

$$
\begin{gathered}
0,2255908+0,025934 \\
0,072850448 \pm 0,012667 \\
3,0966 \pm 0,2085
\end{gathered}
$$

Fonte: Elaborada pelo autor.

\subsection{Molhamento no estado sólido}

Outras microestruturas peculiares são encontradas próximas aos grãos anormais, como os grãos-península. Também são encontrados contornos planos e coincidentes (CSL), presença de grãos de menos de 6 faces e com concavidade contrária ao baricentro, desrespeitando a lei de von Neumman-Mullins, e pontos triplos com ângulos diedrais fora do equilíbrio isotrópico (72). Estes indícios sugerem que o crescimento anormal pode estar relacionado à anisotropia energética do sistema, onde o molhamento no estado sólido seria o mecanismo preponderante.

Para checar esta possibilidade, estas microestruturas foram identificadas visualmente após preparação por seccionamento seriado. Este método possibilita inferir, por características tridimensionais, se há ou não frentes de molhamento nas regiões adjacentes aos grãos anormais (75). Foram encontradas características de molhamento em diversos grãos anormais quando da inspeção em 2D, enquanto que outras frentes de molhamento foram identificadas após seccionamento seriado. A Figura 47 mostra um destes indícios. As setas na Figura 47a indicam grãos pequenos que possuem menos de 6 lados e com contornos curvados contrários ao baricentro. Uma pequena protrusão do grão anormal também é identificada. Após o primeiro seccionamento (Figura 47b), é possível verificar que estes grãos pequenos são, na verdade, frentes do grão anormal crescendo pelos contornos dos grãos vizinhos na direção perpendicular à imagem. O mapa de orientações de EBSD sugere que os contornos envolvidos nesta microestrutura ou são de baixo ângulo ou apresentam alta coincidência. A Figura 
47c comprova que o grão anormal está molhando os contornos dos grãos vizinhos na direção citada.

A literatura reporta indícios de molhamento no estado sólido a partir de inspeção visual $(74,75,126,146)$ por microscopia ótica ou eletrônica. Como uma significativa quantidade de grãos anormais foi mapeada por EBSD, foi possível desenvolver um algoritmo computacional que buscar possíveis indícios de molhamento no entorno do grão anormal baseado na similaridade de orientação entre o grão anormal e os grãos menores adjacentes. Foram consideradas as áreas de 309 grãos anormais, excluindo-se aqueles que cruzam os limites do mapeamento. De todos os grãos anormais, 38 apresentaram grãos na proximidade que possuíam a mesma orientação e que possuem características de molhamento no estado sólido. Isso representa $12,3 \%$ dos grãos anormais analisados.

Quando se analisa a distribuição destes grãos com relação ao logaritmo da área da seção (Figura 48), é possível inferir que os indícios de molhamento são encontrados em todos os grupos de tamanho de grão, porém, com maior frequência nos grãos anormais maiores. Estes dados sugerem que o mecanismo de molhamento no estado sólido é possível; entretanto, como estes indícios são mais frequêntes nos grãos anormais maiores, o mecanismo de molhamento no estado sólido dificilmente tem relação com a etapa de nucleação do crescimento anormal, como sugerem as explicações dadas pela literatura $(75,122)$. 
Figura 47 - Seccionamento seriado de uma região que apresentou indícios de molhamento no estado sólido. (a) e (c) são imagens de microscopia ótica e (b) é um mapa de orientações. A sequência de profundidade vai de "a" até "c".
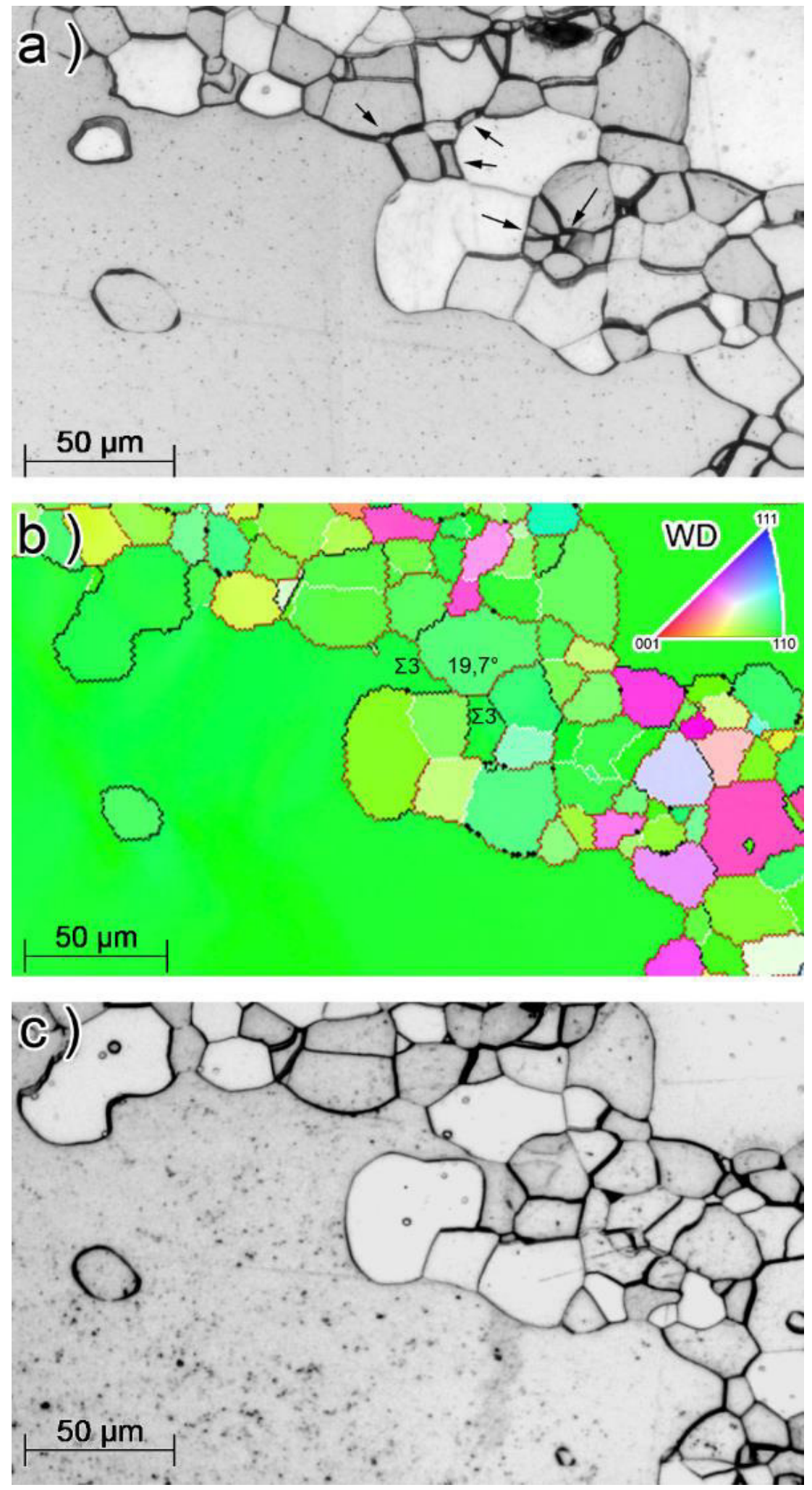

Fonte: Elaborada pelo autor. 
Figura 48 - Distribuição de tamanho dos grãos anormais, juntamente com a distribuição daqueles que apresentam vizinhos com orientação similar. A frequência de grãos anormais com vizinhos de orientação similar é calculada em relação ao total de grãos de cada grupo.

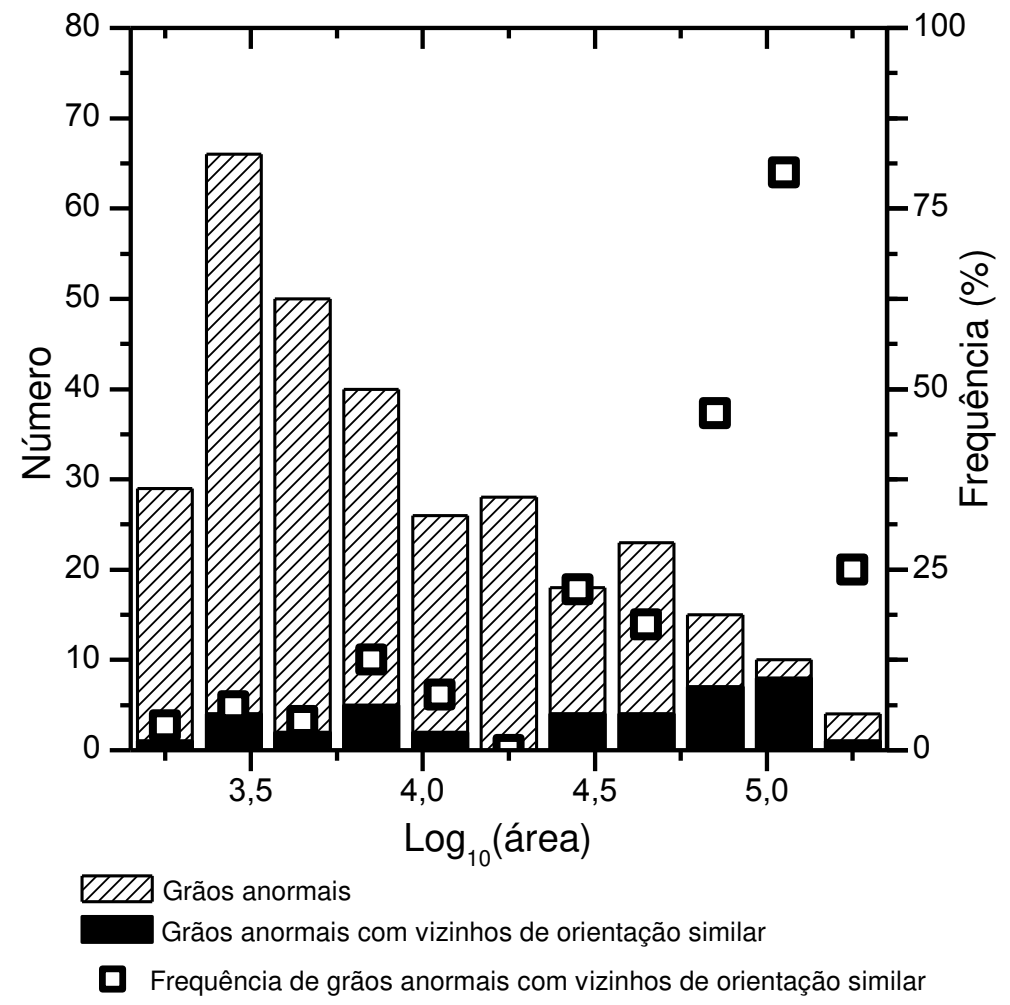

Fonte: Elaborada pelo autor. 


\section{CONCLUSÕES}

A partir dos resultados apresentados nesta Tese de Doutorado, é possível chegar às seguintes conclusões principais:

- O fio de ferro na condição "como recebido" apresenta microestrutura típica de trefilação à frio em deformação elevadas e com heterogeneidade de deformação da superfície para 0 centro. A deformação acumula-se principalmente na região central, onde também se observam maiores gradientes de orientação. Há uma distribuição heterogênea na textura ao longo da seção radial do fio, com maior presença de cristais pertencentes à fibra $<110>$ // WD no centro.

- Após recozimento em $650^{\circ} \mathrm{C}$ por $10 \mathrm{~min}$, o material sofre completa recristalização, com grãos ligeiramente alongados na direção de trefilação. $O$ tamanho médio de grão na superfície é maior que na região central. A textura de recristalização é similar à da condição "como recebido", com forte presença da fibra $<110>$ // WD.

- Os grãos com orientação <110> // WD apresentam moderada contiguidade após a recristalização. Aglomerados formam grãos maiores que apresentam vantagem dimensional/topológica para o crescimento anormal de grão. $O$ mútuo contato entre estes grãos força o desequilíbrio nas transições topológicas ocorrentes durante o crescimento normal de grão.

- Observa-se discreto crescimento normal de grão em $850^{\circ} \mathrm{C}$ até 4 h. Este crescimento é mais apreciável na região central. $O$ crescimento normal de grão é responsável pelo fortalecimento da textura e por reduzir $20 \%$ da densidade de contornos de alto ângulo. Após $4 \mathrm{~h}$, o tamanho médio de grão no centro é maior que na superfície, contrário ao observado na amostra após recristalização. A distribuição de tamanho de grão é mais larga nesta amostra devido ao aumento na contiguidade dos grãos da fibra $<110>/$ WD. A frequência de pontos triplos ao longo da direção radial muda com 0 crescimento normal de grão e as alterações na frequência dos diferentes tipos de pontos triplos ocorre pelo aumento da contiguidade dos grãos orientados na fibra $<110>$ // WD com o crescimento normal. Este fenômeno também promove um desequilíbrio nas transições topológicas durante o crescimento normal dos grãos. 
- A amostra recozida em $850^{\circ} \mathrm{C}$ por 3 min apresenta precipitados nanométricos ricos em Al e N, sendo que os maiores contêm Mn e S. A composição química e o tamanho médio das partículas são similares nas duas regiões do fio, com uma distribuição mais estreita de tamanho na superfície. As forças de ancoramento para migração de contornos são mais intensas junto à superfície do fio.

- Após $5 \mathrm{~h}$ de recozimento em $850^{\circ} \mathrm{C}$, o crescimento anormal de grão passa a ser notado. Os grãos anormais estão distribuídos de forma heterogênea no comprimento do fio e se localizam na região central. A dimensão dos grãos tem características atemporais, ocorrendo um aumento na frequência de grãos anormais com o tempo. Após $8 \mathrm{~h}$, ocorre diminuição no comprimento de contornos por unidade de área, acompanhada de um aumento considerável na fração da fibra <110> // WD. O crescimento anormal de grão é o fenômeno responsável por estas mudanças.

- O crescimento anormal é seletivo para alguns grãos com orientação $<110>/ /$ WD. Os resultados sugerem que alguns grãos orientados na fibra têm maiores chances de crescer de forma anormal, pois eles têm mais chances de aumentar sua contiguidade durante o crescimento normal dos grãos e de crescerem fora do equilíbrio topológico esperado no crescimento normal de grão.

- A análise da desorientação entre grãos-ilha e os grãos anormais revela que a maioria destas estruturas são circundadas por contornos de alto ângulo, o que enfraquece a hipótese de que estas estruturas são causadas pela menor mobilidade dos contornos de baixo ângulo. A presença de grãos-ilha no interior dos grãos anormais sugere o prévio crescimento normal de grão e não está relacionado aos mecanismos de "nucleação" dos grãos anormais.

- Os precipitados encontrados na amostra recozida em $850^{\circ} \mathrm{C}$ por 72 h são maiores e mais arredondados que os encontrados na amostra recozida na mesma temperatura por 3 min. A composição química das partículas da superfície muda com o recozimento, sendo que nesta região também há grande frequência de precipitados muito finos que surgem pela interação entre a amostra e a atmosfera. A elevada fração de partículas na superfície garante 
que os contornos de grão desta região permaneçam imóveis, mesmo após prolongado recozimento.

- O recozimento dos fios afinados por polimento eletrolítico comprova que a persistência dos grãos pequenos entre a superfície livre do fio e os grãos anormais ocorre pela precipitação de partículas finas próximo à superfície. Os fios mais finos que $150 \mu \mathrm{m}$ não apresentam indícios de crescimento normal ou anormal de grão. A atmosfera de recozimento altera sensivelmente as microestruturas formadas, uma vez a fração de precipitados varia com a atmosfera empregada.

- Os resultados mostram a importância da ocorrência do crescimento normal antes do crescimento anormal de grão. A razão entre a área de contorno por unidade de volume e a área de interface por unidade de volume sugere que o tamanho de grão no centro está em equilíbrio com os precipitados na amostra recozida em $850^{\circ} \mathrm{C}$ por $3 \mathrm{~min}$. Assim, o tamanho de grão no centro é controlado pela dissolução e/ou engrossamento dos precipitados. Já a região próxima à superfície apresenta excesso de precipitados que inibem a movimentação dos contornos. Esta característica explica a microestrutura heterogênea desenvolvida após o crescimento anormal.

- Foram observados indícios de molhamento no estado sólido. Os grãos anormais de todos os tamanhos apresentam estes indícios, sendo que os maiores apresentam com maior frequência as características de molhamento no estado sólido. Esses indícios não permitem, entretanto, afirmar que o crescimento anormal de grão tem o molhamento de contornos no estado sólido como mecanismo preponderante.

- O modelo topológico de crescimento anormal de grão é o mais adequado para descrever as mudanças microestruturais neste fio. $O$ aumento na contiguidade dos grãos orientados na fibra <110> // WD, juntamente com a dissolução e/ou engrossamento das partículas cria condições ideais para o crescimento anormal de grão. 


\section{REFERÊNCIAS}

1 SHERRY, R.H. Coarse crystallization in cold-worked steel parts. SAE Technical Papers, 1916.

2 GOSS, N.P. Electrical sheet and method and apparatus for its manufacture and test. US Patent 1.965.559, 1934.

3 MAY, J.E.; TURNBULL, D. Secondary recrystallization in silicon iron. Transactions of the Metallurgical Society of AIME, v. 212, p. 769-781, 1957.

4 FUJII, T. et al. Preparation of a large-scale molybdenum single-crystal sheet by means of secondary recrystallization. Journal of The Less-Common Metals, v. 96, p. 297-304, 1984.

5 CIULIK, J.; TALEFF, E.M. Dynamic abnormal grain growth: a new method to produce single crystals. Scripta Materialia, v. 61, n. 9, p. 895-898, 2009.

6 WORTHINGTON, D L. et al. Dynamic abnormal grain growth in molybdenum. Metallurgical and Materials Transactions A, v. 44, n. 11, p. 5025-5038, 2013.

7 YAMAMOTO, T.; SAKUMA, T. Fabrication of barium titanate single crystals by solid-state grain growth. Journal of the American Ceramic Society, v. 77, n. 4, p. 1107-1109, 1994.

8 FISHER, J.G. et al. Growth of potassium sodium niobate single crystals by solid state crystal growth. Journal of Crystal Growth, v. 303, n. 2, p. 487492, 2007.

9 KUSAMA, T. et al. Ultra-large single crystals by abnormal grain growth. Nature Communications, v. 8, n. 1, p. 354, 2017.

10 SNOW, D.B. The recrystallization of heavily-drawn doped tungsten wire. Metallurgical Transactions A, v. 7, n. 6, p. 783-794, 1976.

11 WALTER, J.L.; BRIANT, C.L. Tungsten wire for incandescent lamps. Journal of Materials Research, v. 5, n. 9, p. 2004-2022, 1990.

12 LI, J.; BAKER, I. An EBSP study of directionally recrystallized cold-rolled nickel. Materials Science and Engineering: A, v. 392, p. 8-22, 2005.

13 MESSINA, R. et al. Observations of and model for insular grains and grain clusters formed during anomalous grain growth in N18 superalloy. Journal of Applied Physics, v. 84, n. 11, p. 6366, 1998. 
14 NA, S.M.; FLATAU, A.B. Global Goss grain growth and grain boundary characteristics in magnetostrictive Galfenol sheets. Smart Materials and Structures, v. 22, n. 12, p. 125026, 2013.

15 YUAN, C. et al. Secondary recrystallization behavior in the rolled columnargrained $\mathrm{Fe}-\mathrm{Ga}$ alloys. Journal of Magnetism and Magnetic Materials, $\mathrm{v}$. 391, p. 145-150, 2015.

16 RALPH, B. Grain growth. Materials Science and Technology, v. 6, n. 11, p. 1136-1144, 1990.

17 RIOS, P.R.; GLICKSMAN, M.E. Topological theory of abnormal grain growth. Acta Materialia, v. 54, n. 19, p. 5313-5321, 2006.

18 HUNDERI, O.; RYUM, N. The kinetics of normal grain growth. Journal of Materials Science, v. 15, n. 5, p. 1104-1108, 1980.

19 MARTHINSEN, K; HUNDERI, O.; RYUM, N. The influence of spatial grain size correlation and topology on normal grain growth in two dimensions. Acta Materialia, v. 44, n. 4, p. 1681-1689, 1996.

20 GLICKSMAN, M.E.; RIOS, P.R.; LEWIS D.J. Regular N-hedra: A topological approach for analyzing three-dimensional textured polycrystals. Acta Materialia, v. 55, n. 12, p. 4167-4180, 2007.

21 GLADMAN, T. On the theory of the effect of precipitate particles on grain growth in metals. Proceedings of the Royal Society A: Mathematical, Physical and Engineering Sciences, v. 294, p. 298-309, 1966.

22 FANG, F. et al. Inhibitor induced secondary recrystallization in thin-gauge grain-oriented silicon steel with high permeability. Materials and Design, v. 105, p. 398-403, 2016.

$23 \mathrm{KIM}, \mathrm{H}$.-C. et al. Effect of primary recrystallization texture on abnormal grain growth in an aluminum alloy. Scripta Materialia, v. 57, n. 4, p. 325-327, 2007.

24 PALMER, J.E.; THOMPSON, C. V.; SMITH, H.I. Grain growth and grain size distributions in thin germanium films. Journal of Applied Physics, v. 62, n. 6, p. 2492, 1987.

25 FROST, H.J.; THOMPSON, C.V.; WALTON, D.T. Abnormal grain growth in thin films due to anisotropy of free-surface energies. Materials Science Forum, v. 94-96, p. 543-550, 1992. 
26 ANTONIONE, C. et al. Effect of slight deformations on grain growth in iron. Journal of Materials Science, v. 12, p. 747-750, 1977.

27 ASHBROOK, R.W.; MARDER, A.R. The effect of initial carbide morphology on abnormal grain growth in decarburized low carbon steel. Metallurgical Transactions A, v. 16, n. 5, p. 897-906, 1985.

28 MILLER, V.M. et al. Recrystallization and the development of abnormally large grains after small strain deformation in a polycrystalline nickel-based superalloy. Metallurgical and Materials Transactions A, v. 47, n. 4, p. 1566-1574, 2016.

29 ZILNYK, K.D. et al. Grain growth inhibition by connected porosity in sintered niobium. Acta Materialia, v. 61, n. 15, p. 5821-5828, 2013.

30 CZUBAYKO, U. et al. Influence of triple junctions on grain boundary motion. Acta Materialia, v. 46, n. 16, p. 5863-5871, 1998.

31 GOTTSTEIN, G.; KING, A.H.; SHVINDLERMAN, L.S. The effect of triplejunction drag on grain growth. Acta Materialia, v. 48, n. 2, p. 397-403, 2000.

32 PROTASOVA, S.G. et al. Triple junction motion in aluminum tricrystals. Acta Materialia, v. 49, n. 13, p. 2519-2525, 2001.

33 LÜCKE, K.; HECKELMANN, I.; ABBRUZZESE, G. Statistical theory of twodimensional grain growth-II. Kinetics of grain growth. Acta Metallurgica et Materialia, v. 40, n. 3, p. 533-542, 1992.

34 HAU-RIEGE, S.P.; THOMPSON, C. V. In situ transmission electron microscope studies of the kinetics of abnormal grain growth in electroplated copper films. Applied Physics Letters, v. 76, n. 3, p. 309-311, 2000.

35 CHOOKAJORN, T.; MURDOCH, H.A.; SCHUH, C. Design of Stable Nanocrystalline Alloys. Science, v. 337, n. 6097, p. 951-954, 2012.

36 KIM, S.G.; PARK, Y.B. Grain boundary segregation, solute drag and abnormal grain growth. Acta Materialia, v. 56, n. 15, p. 3739-3753, 2008.

37 KRILL, C. et al. Size-dependent grain-growth kinetics observed in nanocrystalline Fe. Physical Review Letters, v. 86, n. 5, p. 842-845, 2001.

38 PAUL, H.; KRILL, C.E. Anomalously linear grain growth in nanocrystalline Fe. Scripta Materialia, v. 65, n. 1, p. 5-8, 2011.

39 RIOS, P.R.; ZÖLLNER, D. Grain growth - unresolved issues. Materials Science and Technology, v. 34, p. 629-638, 2018. 
40 PEASE, N.C. et al. SEM study of origin of Goss texture in Fe-3.25Si. Metal Science, v. 15, n. 5, p. 203-209, 1981.

41 TWEED, C.J.; HANSEN, N.; RALPH, B. Grain growth in samples of aluminum containing alumina particles. Metallurgical Transactions A, v. 14, n. 11, p. 2235-2243, 1983.

42 OCHIAI, I. et al. Mechanism of the formation of columnar structure in lowcarbon steel wires during annealing. Tetsu-to-Hagane, v. 70, n. 15, p. 20092016, 1984.

43 OHBA, Y. Secondary recrystallization of pure molybdenum wires. Acta Metallurgica, v. 34, n. 7, p. 1329-1334, 1986.

44 BRIANT, C.L.; HORACSEK, O.; HORACSEK K. The effect of wire history on the coarsened substructure and secondary recrystallization of doped tungsten. Metallurgical Transactions A, v. 24, n. 4, p. 843-851, 1993.

45 NAKASHIMA, S.; TAKASHIMA, K.; HARASE, J. Effect of thickness on secondary recrystallization of Fe-3\%Si. Acta Metallurgica et Materialia, v. 42 , n. 2, p. 539-547, 1994.

46 NOELL, P.J.; TALEFF, E.M. The effects of grain size and texture on dynamic abnormal grain growth in Mo. Metallurgical and Materials Transactions A, v. 47, n. 10, p. 5023-5036, 2016.

$47 \mathrm{HE}, \mathrm{C}$. et al. Effect of annealing atmospheres on secondary recrystallization in thin-gauge grain-oriented silicon steel: Microstructures and textures. Journal of Magnetism and Magnetic Materials, v. 439, p. 403-410, 2017.

48 OLIVEIRA, V.B.; SANDIM, H.R.Z.; RAABE, D. Abnormal grain growth in Eurofer-97 steel in the ferrite phase field. Journal of Nuclear Materials, v. 485, p. 23-38, 2017.

49 HILLERT, M. On the theory of normal and abnormal grain growth. Acta Metallurgica, v. 13, n. 3, p. 227-238, 1965.

50 RHINES, F.N.; PATTERSON, B.R. Effect of the degree of prior cold work on the grain volume distribution and the rate of grain growth of recrystallized aluminum. Metallurgical Transactions A, v. 13, n. 6, p. 985-993, 1982.

51 CONRAD, H.; SWINTOWSKI, M.; MANNAN S.L. Effect of cold work on recrystallization behavior and grain size distribution in titanium. Metallurgical Transactions A, v. 16, n. 5, p. 703-708, 1985. 
52 HARASE, J. Coincidence boundary and secondary recrystallization in fcc and bcc metals. Canadian Metallurgical Quarterly, v. 34, n. 3, p. 185-193, 1995.

53 YOSHITOMI, Y. et al. Role of inhibitor for secondary recrystallization texture evolution in Fe-3\% Si alloy. Materials Science Forum, v. 113-115, p. 281286, 1993.

54 KOUL, A.K.; PICKERING, F.B. Grain coarsening in Fe-Ni-Cr alloys and the influence of second phase particles. Acta Metallurgica, v. 30, n. 7, p. 13031308, 1982.

55 FRIEDMAN, S.; BRETT, J. Porosity and anomalous recrystallization behavior in doped tungsten wire. Metallurgical Transactions B., v. 1, n. 11, p. 32253231, 1970.

56 YOO, M.K.; HIRAOKA, Y.; CHOI J. Recrystallization of molybdenum wire doped with lanthanum oxide. International Journal of Refractory Metals and Hard Materials, v. 13, n. 4, p. 221-227, 1995.

57 YOO, M.K.; HIRAOKA, Y.; CHOI, J. Recrystallization of molybdenum wire doped with potassium-silicate. Metallurgical and Materials Transactions A, v. 26, n. 4, p. 801-816, 1995.

58 GRENOBLE, $\mathrm{H}$. The role of solutes in the secondary recrystallization of silicon iron. IEEE Transactions on Magnetics, v. 13, n. 5, p. 1427-1432, 1977.

59 MUSIOL, C. Elephant grain growth in 12\% chromium steels. Metals Technology, v. 3, n. 1, p. 173-182, 1976.

60 SAMAJDAR, I.; VERLINDEN, B.; VAN HOUTTE, P. Textural changes through grain growth in Ti-bearing IF-steel investigated by orientation imaging microscopy and X-ray diffraction. ISIJ International, v. 37, n. 10, p. 10101015, 1997.

61 HOLM, E.A.; HASSOLD, G.N.; MIODOWNIK, M.A. On misorientation distribution evolution during anisotropic grain growth. Acta Materialia, v. 49, n. 15, p. 2981-2991, 2001.

62 NAKASHIMA, S.; TAKASHIMA, K.; HARASE, J. Effect of cold rolling reduction on secondary recrystallization in grain-oriented electrical steel produced by single-stage rolling process. ISIJ International, v. 31, n. 9, p. 1013-1019, 1991. 
63 ARAI, S.; USHIGAMI, Y.; TAKAHASHI, N. Effect of cold rolling reduction on secondary recrystallization of 3\% Si-Fe. Materials Science Forum, v. 204, p. 617-622, 1996.

64 RIOS, P.R.; GOTTSTEIN, G. Texture evolution during normal and abnormal grain growth in an Al-1 wt\% Mn alloy. Acta Materialia, v. 49, n. 13, p. 25112518, 2001.

65 ZÖLLNER, D.; RIOS, P.R. On the topology and size advantage of potentially abnormal grains. Computational Materials Science, v. 153, p. 382-391, 2018.

66 ZÖLLNER, D.; RIOS, P.R. Topological changes in coarsening networks. Acta Materialia, v. 130, p. 147-154, 2017.

67 DORNER, D.; ZAEFFERER, S.; RAABE, D. Retention of the Goss orientation between microbands during cold rolling of an Fe3\%Si single crystal. Acta Materialia, v. 55, n. 7, p. 2519-2530, 2007.

68 SPRAGUE, A.P.; PATTERSON, B.R.; GRANDHI, S. Topological characteristics of two-dimensional grain growth-simulation and analysis. Metallurgical and Materials Transactions A, v. 41, n. 3, p. 592-602, 2010.

69 PARK, H.; LEE, D.N. The evolution of annealing textures in 90 Pct drawn copper wire. Metallurgical and Materials Transactions A, v. 34, n. 3, p. 531-541, 2003.

70 WRIGHT, R.N. Secondary recrystallization in heavily drawn ETP copper wire. Metallurgical Transactions A, v. 7, n. 12, p. 1891-1896, 1976.

71 BRIANT, C.L.; ZAVERL, F.; CARTER, T. The effect of deformation on abnormal grain growth in tungsten ingots. Acta Metallurgica et Materialia, v. 42, n. 8, p. 2811-2821, 1994.

72 SMITH, C.S. Some elementary principles of polycrystalline microstructure. Metallurgical Reviews, v. 9, n. 33, p. 1-62, 1964.

73 RAJMOHAN, N.; SZPUNAR, J.A. An analytical method for characterizing grain boundaries around growing Goss grains during secondary recrystallization. Scripta Materialia, v. 44, n. 10, p. 2387-2392, 2001.

74 ALMEIDA JUNIOR, D.R. Crescimento de grão num fio de ferro comercialmente puro trefilado a frio. Dissertação (Mestrado em Ciências). Escola de Engenharia de Lorena - Universidade de São Paulo. Lorena, 2015. 
75 NA, T. et al. Misorientation angle analysis near the growth front of abnormally growing grains in 5052 aluminum alloy. Acta Materialia, v. 115, p. 224-229, 2016.

76 BENNETT, T.A.; KALU, P.N.; ROLLETT, A.D. On the character of hostisland grain interfaces in Fe-1\%Si alloy. Scripta Materialia, v. 57, n. 1, p. 41-44, 2007.

77 ZHANG, Z.W.; CHEN, G.; CHEN, G.L. Dynamics and mechanism of columnar grain growth of pure iron under directional annealing. Acta Materialia, v. 55, n. 17, p. 5988-5998, 2007.

78 KOO, J.B.; YOON, D.Y.; HENRY, M.F. Island grains of low misorientation angles formed during abnormal grain growth in $\mathrm{Cu}$. Metallurgical and Materials Transactions A, v. 31, n. 5, p. 1489-1491, 2000.

79 SHIN, S.-M.; CHANG, S.-K.; DE COOMAN, B.C. Evolution of texture and related magnetic properties in Fe-3\%Si steel during single-step annealing. ISIJ International, v. 48, n. 12, p. 1788-1794, 2008.

80 HAYAKAWA, Y.; MURAKI, M.; SZPUNAR, J.A. The changes of grain boundary character distribution during the secondary recrystallization of electrical steel. Acta Materialia, v. 46, n. 3, p. 1063-1073, 1998.

81 DENNIS, J.; BATE, P.S.; HUMPHREYS, F.J. Abnormal grain growth in Al3.5Cu. Acta Materialia, v. 57, n. 15, p. 4539-4547, 2009.

82 ETTER, A.L.; BAUDIN, T.; PENELLE, R. Influence of the Goss grain environment during secondary recrystallisation of conventional grain-oriented Fe-3\%Si steels. Scripta Materialia, v. 47, n. 11, p. 725-730, 2002.

83 DIETER, G.E. Mechanical Metallurgy. New York: Mcgraw-Hill Press, 1986.

84 GIL SEVILLANO, J.; GONZÁLEZ, D. Heterogeneous deformation and internal stresses developed in bcc wires by axisymmetric elongation. Materials Science Forum, v. 550, p. 75-84, 2007.

85 SPITZIG, W.A.; TRYBUS, C.L.; LAABS, F.C. Structure properties of heavily cold-drawn niobium. Materials Science and Engineering A, v. 145, n. 2, p. 179-187, 1991.

86 LANGFORD, G.; COHEN, M. Microstructural analysis by high-voltage electron diffraction of severely drawn iron wires. Metallurgical Transactions A, v. 6, n. 3, p. 901-910, 1975. 
87 NAKA, S. et al. Variation in the degree of order and its influence on mechanical behavior in complex B2 aluminides of refractory metals. Materials Science and Engineering A, v. 193, p. 69-76, 1995.

88 CHIN, R.K.; STEIF, P.S. A computational study of strain inhomogeneity in wire drawing. International Journal of Machine Tools and Manufacture, v. 35, n. 8, p. 1087-1098, 1995.

89 TAHERI, A.K.; MACCAGNO, T.M.; JONAS, J.J. Dynamic strain aging and the wire drawing of low carbon steel rods. ISIJ International, v. 35, n. 12, p. 1532-1540, 1995.

90 KEMP, I.P.; POLLARD, G.; BRAMLEY, A.N. Temperature distributions in the high speed drawing of high strength steel wire. International Journal of Mechanical Sciences, v. 27, p. 803-811, 1985.

91 RANDLE, V.; ENGLER, O. Introduction to texture analysis: macrotexture, microtexture and orientation mapping. London: CRC Press, 2000.

92 HU, H. Texture of Metals. Texture, v. 1, n. 4, p. 233-258, 1974.

93 SUGONDO; SZPUNAR, J.A.; GANGLI, P. Development of texture in lowcarbon steels for cold heading. Journal of Materials Processing Technology, v. 26, n. 3, p. 305-321, 1991.

94 SASAKI, T.T. et al. Microstructural evolution of copper clad steel bimetallic wire. Materials Science and Engineering A, v. 528, n. 6, p. 2974-2981, 2011.

95 JANICKI, M. et al. Anisotropy of grain growth in polycrystals of $\alpha$-Fe. Materials Science and Engineering A, v. 298, p. 187-192, 2001.

96 RIECK, G.D. Growth and preferred orientations of crystals in tungsten wires. Acta Metallurgica, v. 6, n. 5, p. 360-366, 1958.

97 KURZYDŁOWSKI, K.J. et al. A quantitative description of recrystallization and grain growth in single phase B.C.C. iron. Acta Materialia, v. 44, n. 7, p. 3005-3013, 1996.

98 ANTONIONE, C. et al. Grain growth and secondary recrystallization in iron. Journal of Materials Science, v. 8, n. 1, p. 1-10, 1973.

99 SWIFT, W.M. Breakdown of primary grain boundary inhibition in 3 pct Si-Fe sheet. Metallurgical Transactions, v. 4, p. 841-845, 1973. 
100 SONG, H. et al. Secondary recrystallization behavior in a twin-roll cast grainoriented electrical steel. Journal of Magnetism and Magnetic Materials, v. 428, p. 325-332, 2017.

101 SUZUKI, S. et al. Microstructures in secondary recrystallized $\{100\}<001>$ grains of 3\%Si-Fe. Materials Science Forum, v. 204-206, p. 575-580, 1996.

102 NAKASHIMA, S.; TAKASHIMA, K.; HARASE, J. Effect of silicon content on secondary recrystallization in grain-oriented electrical steel produced by single-stage cold rolling process. ISIJ International, v. 31, n. 9, p. 1007$1012,1991$.

103 KOO, R.C. Grain-size effects on the deformation of tantalum at low temperatures. Journal of the Less Common Metals, v. 4, n. 2, p. 138-144, 1962.

104 SNOW, D.B. The recrystallization of commercially-pure and doped tungsten wire drawn to high strain. Metallurgical Transactions A, v. 10, n. 7, p. 815$821,1979$.

105 SAMAJDAR, I. et al. Secondary recrystallization in non-sag W filament wires - on the possible role of relative grain boundary character distribution. Scripta Materialia, v. 40, n. 11, p. 1263-1268, 1999.

$106 \mathrm{KATOH}$, M.; IIDA, S.; SUGITA, Y. X-ray characterization of tungsten single crystals grown by secondary recrystallization method. Journal of Crystal Growth, v. 112, n. 2-3, p. 368-372, 1991.

107 OCHIAI, I. et al. Effect of precipitation behavior of AIN on abnormal growth of ferrite grains in low-carbon steel wires. Tetsu-to-Hagané, v. 70, p. 20012008, 1984.

108 PARK, H.-K. et al. Deformation feature of Goss grains in Fe-3\%Si steel focused on stored energy after cold rolling. Material Transactions, v. 51, n. 9, p. 1547-1552, 2010.

109 HUMPHREYS, F.J.; HATHERLY, M. Recrystallization and related annealing phenomena. Oxford: Pergamon Press, 2004.

110 CHEN, N. et al. Effects of topology on abnormal grain growth in silicon steel. Acta Materialia, v. 51, n. 6, p. 1755-1765, 2003.

111 RIOS, P.R. Abnormal grain growth in materials containing particles. Acta Metallurgica et Materialia, v. 42, n. 3, p. 839-843, 1994. 
112 RIOS, P.R. Abnormal grain growth development from uniform grain size distributions in presence of stable particles. Acta Materialia, v. 39, n. 12, p. 1725-1730, 1998.

113 USHIGAMI, Y. et al. Dynamic study of secondary recrystallization of 3\% Si$\mathrm{Fe}$ by synchrotron $\mathrm{x}$-radiation topography. Journal of Materials Engineering, v. 13, n. 2, p. 113-118, 1991.

114 ROLLETT, A.D.; SROLOVITZ, D.J.; ANDERSON, P. Simulation and theory of abnormal grain growth - anisotropic grain boundary energies and mobilities. Acta Metallurgica, v. 37, n. 4, p. 1227-1240, 1989.

115 LEE, D.-K. et al. Comparison of the advantages conferred by mobility and energy of the grain boundary in inducing abnormal grain growth using Monte Carlo simulations. Materials Transactions, v. 50, n. 11, p. 2521-2525, 2009.

116 RIOS, P.R. Abnormal grain growth development from uniform grain size distributions due to a mobility advantage. Scripta Materialia, v. 38, n. 9, p. 1359-1364, 1998.

117 LIN, P. et al. Coincidence site lattice (CSL) grain boundaries and Goss texture development in Fe-3\% Si alloy. Acta Materialia, v. 44, n. 12, p. 4677-4683, 1996.

118 BRANDON, D.G. et al. A field ion microscope study of atomic configuration at grain boundaries. Acta Metallurgica, v. 12, p. 813-821, 1964.

119 KHORASHADIZADEH, A. et al. Five-parameter grain boundary analysis by 3D EBSD of an ultra-fine grained CuZr alloy processed by equal channel angular pressing. Advanced Engineering Materials, v. 13, n. 4, p. 237-244, 2011.

120 CHANG, S.K. Texture change from primary to secondary recrystallization by hot-band normalizing in grain-oriented silicon steels. Materials Science and Engineering A., v. 452, p. 93-98, 2007.

121 MORAWIEC, A. Grain misorientations in theories of abnormal grain growth in silicon steel. Scripta Materialia, v. 43, p. 275-278, 2000.

122 HWANG, N.M.; LEE, S.B.; KIM D.-Y. Abnormal grain growth by solid-state wetting along grain boundary or triple junction. Scripta Materialia, v. 44, n. 7, p. 1153-1160, 2001. 
123 HOLM, E.A.; MIODOWNIK, M.A.; ROLLETT, A.D. On abnormal subgrain growth and the origin of recrystallization nuclei. Acta Materialia, v. 51, n. 9 , p. 2701-2716, 2003.

124 LEE, C.H.; KIM, C.H. Pressureless sintering and related reaction phenomena of Al2O3-doped B4C. Journal of Materials Science, v. 27, n. 23, p. 63356340, 1992.

125 STRAUMAL, B. et al. Grain growth and grain boundary wetting phase transitions in the Al-Ga and Al-Sn-Ga alloys of high purity. Le Journal de Physique IV, v. 5, n. C7, p. 233-241, 1995.

126 PARK, H. et al. Microstructural evidence of abnormal grain growth by solidstate wetting in Fe-3\% Si steel. Journal of Applied Physics, v. 95, n. 10, p. 5515-5521, 2004.

127 PARK, C.-S. et al. Misorientation characteristics of penetrating morphologies at the growth front of abnormally growing grains in aluminum alloy. Philosophical Magazine Letters, v. 92, n. 7, p. 344-351, 2012.

128 DUNN, C.; KOGH, E. Comparison of dislocation densities of primary and secondary recrystallization grains of Si-Fe. Acta Metallurgica, v. 5, n. 10, p. 548-554, 1957.

129 PEDRAZAS, N.A. et al. Dynamic abnormal grain growth in tantalum. Materials Science and Engineering A, v. 610, p. 76-84, 2014.

130 DEHOFF, R.T. Metric and topological contributions to the rate of change of boundary length in two-dimensional grain growth. Acta Materialia, v. 46, $\mathrm{n}$. 14, p. 5175-5185, 1998.

131 ØRSUND, R.; HJELEN, J.; NES, E. Local lattice curvature and deformation heterogeneities in heavily deformed aluminium. Scripta Metallurgica, v. 23, n. 6, p. 1193-1198, 1989.

132 KAMAYA, M. Assessment of local deformation using EBSD: Quantification of accuracy of measurement and definition of local gradient. Ultramicroscopy, v. 111, n. 8, p. 1189-1199, 2011.

133 SCHWARTZ, A.J. et al. Electron backscatter diffraction in materials science. New York: Springer Press, 2009.

134 VAN BOXEL, S. et al. Visualization of grain subdivision by analysing the misorientations within a grain using electron backscatter. Journal of Microscopy, v. 218, n. 2, p. 104-114, 2005. 
135 HORNBOGEN, E. Overview no. 37. On the microstructure of alloys. Acta Metallurgica, v. 32, n. 5, p. 615-627, 1984.

136 ADAMS, B.L. Description of the intercrystalline structure distribution in polycrstaline materials. Metallurgical Transactions A, v. 17A, n. 12, p. 2199-2207, 1986.

137 OHSER, J.; MÜCKLICH, F. Statistical analysis of microstructures in materials science. Chichester: Wiley Press, 2000.

138 MORAWIEC, A. Method to calculate the grain boundary energy distribution over the space of macroscopic boundary parameters from the geometry of triple junctions. Acta Materialia, v. 48, n. 13, p. 3525-3532, 2000.

139 KARPEL, A. et al. TEM microstructural analysis of as-bonded Al-Au wirebonds. Journal of Materials Science, v. 42, n. 7, p. 2334-2346, 2007.

140 GAULT, B.; LARSON, D.J. Atom probe tomography: looking forward. Scripta Materialia, v. 148, p. 73-74, 2018.

141 LARSON, D.J. et al. Atom probe tomography spatial reconstruction: status and directions. Current Opinion in Solid State and Materials Science, v. 17, n. 5, p. 236-247, 2013.

142 GAULT, B. et al. Atom probe microscopy. New York: Springer-Verlag, 2012.

143 CHENG, L.M.; HAWBOLT, E.B.; MEADOWCROFT, T.R. Dissolution and coarsening of aluminum nitride precipitates in low carbon steel - distribution, size and morphology. Canadian Metallurgical Quarterly, v. 39, n. 1, p. 7386, 2000.

144 WOJNAR, L. Image analysis: applications in materials engineering. London: CRC Press, 1999.

145 RIOS, P.R.; FONSECA, G.S. Grain boundary pinning by Al6Mn precipitates in an Al-1wt\%Mn alloy. Scripta Materialia, v. 50, n. 1, p. 71-75, 2004.

$146 \mathrm{KO}, \mathrm{K}$.-J. et al. Morphological evidence that Goss abnormally growing grains grow by triple junction wetting during secondary recrystallization of $\mathrm{Fe}-3 \% \mathrm{Si}$ steel. Scripta Materialia, v. 59, n. 7, p. 764-767, 2008.

147 RIENDEAU, M.P.; MATAYA, M.C.; MATLOCK, D.K. Controlled drawing to produce desirable hardness and microstructural gradients in alloy 302 wire. Metallurgical and Materials Transactions A, v. 28, n. 2, p. 363-375, 1997. 
148 NAAMANE, S.; MONNET, G.; DEVINCRE, B. Low temperature deformation in iron studied with dislocation dynamics simulations. International Journal of Plasticity, v. 26, n. 1, p. 84-92, 2010.

149 WRIGHT, S.I.; NOWELL, M.M.; FIELD, D.P. A review of strain analysis using electron backscatter diffraction. Microscopy and Microanalysis, v. 17, n. 3 , p. 316-329, 2011.

150 YERRA, S.K.; VERLINDEN, B.; VAN HOUTTE, P. On crystallographic texture of as-drawn doped-W wires. Materials Science Forum, v. 495-497, p. 913918, 2005.

151 VOGT, J.B. et al. Fatigue damage assessment of alternator fans by EBSD. Procedia Engineering, v. 66, p. 608-614, 2013.

152 ZAEFFERER, S.; ROMANO, P.; FRIEDEL, F. EBSD as a tool to identify and quantify bainite and ferrite in low-alloyed Al-TRIP steels. Journal of Microscopy, v. 230, n. 3, p. 499-508, 2008.

153 RADHAKRISHNAN, B.; SARMA, G.B.; ZACHARIA, T. Modeling the kinetics and microstructural evolution during static recrystallization - Monte Carlo simulation of recrystallization. Acta Materialia, v. 46, n. 12, p. 4415-4433, 1998.

154 RIOS, P.R. Overview no. 62: A theory for grain boundary pinning by particles. Acta Metallurgica, v. 35, n. 12, p. 2805-2814, 1987.

155 GOTTSTEIN, G.; SHVINDLERMAN, L.S. Grain boundary migration in metals: thermodynamics, kinetics, applications. Boca Raton: CRC Press, 2009.

156 ABBRUZZESE, G.; HECKELMANN, I.; LÜCKE, K. Statistical theory of twodimensional grain growth $-\mathrm{I}$. The topological foundation. Acta Metallurgica et Materialia, v. 40, n. 3, p. 519-532, 1992.

157 HAYAKAWA, Y. Mechanism of secondary recrystallization of Goss grains in grain-oriented electrical steel. Science and Technology of Advanced Materials, v. 18, n. 1, p. 480-497, 2017.

158 TAKAHASHI, J.; KAWAKAMI, K.; TARUI, T. Direct observation of hydrogentrapping sites in vanadium carbide precipitation steel by atom probe tomography. Scripta Materialia, v. 67, n. 2, p. 213-216, 2012. 
159 WAKAI, F.; ENOMOTO, N.; OGAWA, H. Three-dimensional microestrutural evolution in ideal grain growth - general statistics. Acta Metallurgica, v. 48, p. 1297-1311, 2000.

160 MAAZI, N. et al. Influence of neighbourhood on abnormal Goss grain growth in $\mathrm{Fe}-3 \% \mathrm{Si}$ steels: formation of island grains in the large growing grain. Scripta materialia, v. 55, p. 641-644, 2006.

161 CLAUSS, A.R. et al. Crystal structure and morphology of mixed Cr1-xAlxN nitride precipitates: gaseous nitriding of a $\mathrm{Fe}-1.5 \mathrm{wt}-\% \mathrm{Cr}-1.5 \mathrm{wt}-\% \mathrm{Al}$ alloy. Metallurgical and Materials Transactions A, v. 40, n. 8, p. 1923-1934, 2009.

162 BERNIER, N. et al. Structure analysis of aluminium silicon manganese nitride precipitates formed in grain-oriented electrical steels. Materials Characterization, v. 86, p. 116-126, 2013.

163 YANG, F.-Y et al. Effect of annealing atmosphere on secondary recrystallization in thin-gauge grain-oriented silicon steel: evolution of inhibitors. Journal of Magnetism and Magnetic Materials, v. 439, p. 403410, 2017.

164 HEO, N.H. Surface segregation kinetics of sulfur influenced by various conditions in thin-gauged 3\% Si-Fe alloy strips. Scripta Materialia, v. 52, p. 409-413, 2005.

165 BRAHMI, A.; BORRELLY, R. Study of aluminium nitride precipitation in pure Fe-Al-N alloy by thermoelectric power measurements. Acta Materialia, v. 45, n. 5, p. 1889-1897, 1997.

166 CHANDRUPATLA, T.R.; OSLER, T.J. The perimeter of an ellipse. Math. Scientist, v. 35, n. 3, p. 122-131, 2010.

167 RIOS, P.R. Irreversible thermodynamics, parabolic law and self-similar state in grain growth. Acta Materialia, v. 52, n. 1, p. 249-256, 2004. 